\title{
FIGHTER AGILITY METRICS, RESEARCH, AND TEST
}

\author{
PHASE I REPORT
}

KU-FRL-831-2

by: Randall K. Liefer, John Valasek and David P. Eggold

Supervised by: Dr. David R. Downing

$$
\text { NCC2 }-588
$$

THE UNIVERSITY OF KANSAS CENTER FOR RESEARCH, INC.

Flight Research Laboratory

$$
\text { Lawrence, Kansas }
$$




\begin{abstract}
Proposed new metrics to assess fighter aircraft agility are collected and analyzed. A framework for classification of these new agility metrics is developed and applied. A complete set of transient agility metrics is evaluated with a high fidelity, nonlinear F-18 simulation provided by the NASA Dryden Flight Research Center. Test techniques and data reduction methods are proposed.
\end{abstract}

A method of providing cuing information to the pilot during flight test is discussed. The sensitivity of longitudinal and lateral agility metrics to deviations from the pilot cues is studied in detail. The metrics are shown to be largely insensitive to reasonable deviations from the nominal test pilot commands.

Instrumentation required to quantify agility via flight test is also considered. With one exception, each of the proposed new metrics may be measured with instrumentation currently available.

Simulation documentation and user instructions are provided in an appendix. 


\section{Table of Contents}

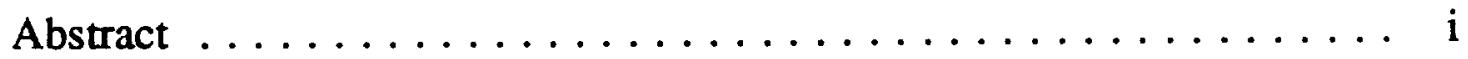

Table of Contents $\ldots \ldots \ldots \ldots \ldots \ldots \ldots \ldots$ ii

List of Figures $\ldots \ldots \ldots \ldots \ldots \ldots \ldots \ldots \ldots \ldots$ vi

List of Tables $\ldots \ldots \ldots \ldots \ldots \ldots \ldots \ldots \ldots \ldots \ldots$

List of Abbreviations $\ldots \ldots \ldots \ldots \ldots \ldots \ldots \ldots \ldots \ldots \ldots$

1. Introduction $\ldots \ldots \ldots \ldots \ldots \ldots \ldots \ldots \ldots \ldots \ldots$

1.1 Background of Agility $\ldots \ldots \ldots \ldots \ldots \ldots \ldots \ldots$

1.2 Current State of Agility $\ldots \ldots \ldots \ldots \ldots \ldots \ldots$

1.3 Objectives of this Project $\ldots \ldots \ldots \ldots \ldots \ldots \ldots \ldots$

2. Problem Definition $\ldots \ldots \ldots \ldots \ldots \ldots \ldots$

2.1 Summary of Traditional Metrics $\ldots \ldots \ldots \ldots \ldots \ldots$

2.2 Published Agility Metrics $\ldots \ldots \ldots \ldots \ldots \ldots \ldots$

2.2.1 Transient, Functional, Potential $\ldots \ldots \ldots \ldots \ldots 20$

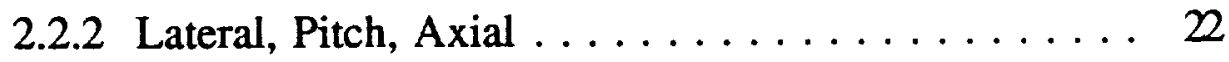


2.3 Vehicle Description (F-18 HARV) and

Simulation Overview $\ldots \ldots \ldots \ldots \ldots \ldots \ldots$

2.4 Simulation Plan $\ldots \ldots \ldots \ldots \ldots \ldots \ldots \ldots \ldots \ldots$

3. Simulation Study $\ldots \ldots \ldots \ldots \ldots \ldots \ldots \ldots \ldots \ldots \ldots$

3.1 Axial Agility $\ldots \ldots \ldots \ldots \ldots \ldots \ldots \ldots \ldots \ldots \ldots$

3.1 .1 Introduction $\ldots \ldots \ldots \ldots \ldots \ldots \ldots \ldots \ldots$

3.1.2 Axial Agility Metrics $\ldots \ldots \ldots \ldots \ldots \ldots \ldots$

3.1.3 Power Onset and Power Loss Parameters . . . . . . 34

3.1.4 Axial Agility Test Case Description ........ 36

3.1.5 Axial Agility Data Reduction Methods ........ 41

3.2 Pitch Agility $\ldots \ldots \ldots \ldots \ldots \ldots \ldots \ldots \ldots$

3.2.1 Introduction $\ldots \ldots \ldots \ldots \ldots \ldots \ldots \ldots$

3.2.2 Published Pitch Agility Metrics . . . . . . . 47

3.2.3 Pitch Rate versus Angle of Attack Metric ....... 58

3.3 Lateral Agility $\ldots \ldots \ldots \ldots \ldots \ldots \ldots \ldots \ldots \ldots \ldots$

3.3.1 Introduction $\ldots \ldots \ldots \ldots \ldots \ldots \ldots \ldots \ldots \ldots$

3.3.2 Time-to-90 Metric . . . . . . . . . . . 66

3.3.3 Test Method ................. 69

3.3.4 Data Reduction and Analysis $\ldots \ldots \ldots \ldots \ldots 71$ 


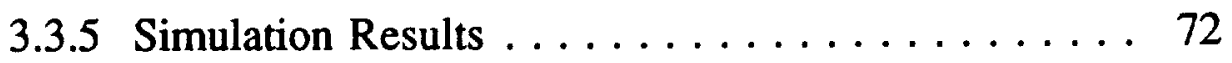

4. Flight Test Issues $\ldots \ldots \ldots \ldots \ldots \ldots \ldots \ldots \ldots$

4.1 Background $\ldots \ldots \ldots \ldots \ldots \ldots \ldots \ldots \ldots \ldots$

4.2 Analysis of Cuing Method $\ldots \ldots \ldots \ldots \ldots \ldots$

4.3 Sensitivity to Cue Following Errors $\ldots \ldots \ldots \ldots \ldots 81$

4.3.1 Sensitivity of Pitch Agility Metrics ........ 81

4.3.2 Sensitivity of Lateral Agility Metrics . . . . . . 92

4.4 Instrumentation for Agility Flight Testing $\ldots \ldots \ldots \ldots$

5. Summary ..................... 104

5.1 Conclusions $\ldots \ldots \ldots \ldots \ldots \ldots \ldots \ldots \ldots$

5.2 Recommendations for Further Research $\ldots \ldots \ldots \ldots$

6. References $\ldots \ldots \ldots \ldots \ldots \ldots \ldots \ldots \ldots \ldots \ldots \ldots$ Appendices

A. Specific Excess Power $(\mathbf{P}) \ldots \ldots \ldots \ldots \ldots \ldots$

B. Published Agility Metrics $\ldots \ldots \ldots \ldots \ldots \ldots$

C. Simulation Documentation $\ldots \ldots \ldots \ldots \ldots \ldots \ldots$

C.1 Introduction $\ldots \ldots \ldots \ldots \ldots \ldots \ldots \ldots$

C.2 Capabilities and Models . . . . . . . . . 144

C.2.1 Aerodynamics . . . . . . . . . . . 144

C.2.2 Flight Control System $\ldots \ldots \ldots \ldots \ldots \ldots$ 
C.2.3 Actuators . . . . . . . . . . . . 145

C.2.4 Equations of Motion $\ldots \ldots \ldots \ldots \ldots \ldots$

C.2.5 Integration Method $\ldots \ldots \ldots \ldots \ldots$

C.2.6 Multi-Rate Calculations . . . . . . . 146

C.2.7 Autopilot Modes . . . . . . . . . . 147

C.3 Program Organization . . . . . . . . . . . 147

C.4 User Instructions $\ldots \ldots \ldots \ldots \ldots \ldots \ldots \ldots$

C. 5 Check Case Comparisons $\ldots \ldots \ldots \ldots \ldots \ldots \ldots$ 


\section{List of Figures}

2.1 T-38 V-n Diagram $\ldots \ldots \ldots \ldots \ldots \ldots \ldots \ldots \ldots \ldots \ldots \ldots$

2.2 Typical $P_{\mathbf{s}}$ Diagram for a Single Aircraft $\ldots \ldots \ldots \ldots \ldots$

2.3 Differential $\mathbf{P}_{\mathrm{s}} \mathrm{Plot} \ldots \ldots \ldots \ldots \ldots \ldots \ldots \ldots$

2.4 Turn Rate, Turn Radius Relationships $\ldots \ldots \ldots \ldots \ldots \ldots \ldots$

2.5 F-5E Turn Performance $\ldots \ldots \ldots \ldots \ldots \ldots \ldots \ldots$

2.6 Proposed Classification Framework . . . . . . . . . . . 24

2.7 F-18 Physical Characteristics $\ldots \ldots \ldots \ldots \ldots \ldots \ldots \ldots$

2.8 Simulation Flow Diagram $\ldots \ldots \ldots \ldots \ldots \ldots \ldots \ldots \ldots$

3.1 Axial Acceleration Example, Mach .6, Sea level . . . . . . . . 37

3.2 Axial Acceleration, Mach $.4-.9$, Sea level $\ldots \ldots \ldots \ldots \ldots$

3.3 Axial Deceleration Example, Mach .6, Sea Level . . . . . . . . 39

3.4 Axial Deceleration, Mach $.4-.9$, Sea Level . . . . . . . . 40

3.5 Power Onset Parameter $\ldots \ldots \ldots \ldots \ldots \ldots \ldots \ldots \ldots$

3.6 Power Loss Parameter . . . . . . . . . . . . . . . . . . . . . . 44

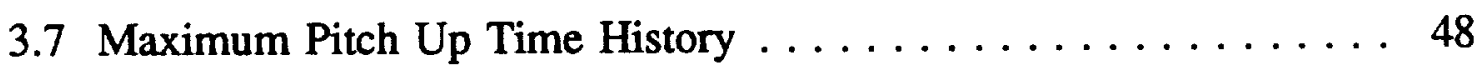

3.8 Time to Pitch to Maximum Load Factor $\ldots \ldots \ldots \ldots \ldots$

3.9 Time to Pitch From Maximum to Zero Load Factor $\ldots \ldots \ldots$. . 51

3.10 Maximum Load Factor Rate $\ldots \ldots \ldots \ldots \ldots \ldots \ldots \ldots$

3.11 Minimum Load Factor Rate $\ldots \ldots \ldots \ldots \ldots \ldots$ 
3.12 Maximum Pitch Rate from Steady Level Flight $\ldots \ldots \ldots \ldots \ldots 5$

3.13 Max Neg. Pitch Rate During Unload ............. 56

3.14 Maximum Pitch Rate Capability at $15,000 \mathrm{ft} \ldots \ldots \ldots \ldots 9$

3.15 Minimum Pitch Rate Capability at $15,000 \mathrm{ft} \ldots \ldots \ldots 60$

3.16 Kinematics of a Loaded Roll ... . . . . . . . . . . 63

3.17 Body Axis Rates for Stability Axis Rolls . . . . . . . . . 67

3.18 Control Time History for a Typical $\mathrm{T}_{90}$ Maneuver $\ldots \ldots \ldots 70$

3.19 Time to Capture $\Phi=90^{\circ}$ at $15,000 \mathrm{ft} \ldots \ldots \ldots \ldots 73$

3.20 Time to Capture $\Phi=90^{\circ}$ at $30,000 \mathrm{ft} \ldots \ldots \ldots \ldots \ldots$

4.1 Time to Max Load Factor Error Sensitivity, $15,000 \mathrm{ft} \ldots \ldots$. . . 84

4.2 Pitch Up Load Factor Rate Error Sensitivity, 15,000 ft . . . . . . 86

4.3 Nose Up Pitch Rate Error Sensitivity, $15,000 \mathrm{ft} \ldots \ldots$. . . . . 87

4.4 Time to Zero Load Factor Error Sensitivity, 15,000 ft . . . . . . 89

4.5 Pitch Down Load Factor Rate Sensitivity, $15,000 \mathrm{ft} \ldots \ldots . \ldots 90$

4.6 Nose Down Pitch Rate Error Sensitivity, $15,000 \mathrm{ft} \ldots \ldots . \ldots 91$

4.7 Stick Deflections for Typical $\mathrm{T}_{90}$ Maneuver $\ldots \ldots \ldots . \ldots 2$

$4.8 \mathrm{~T}_{90}$ Error Sensitivity, Mach $.4,15,000 \mathrm{ft} \ldots \ldots \ldots \ldots 5$

$4.9 \mathrm{~T}_{90}$ Error Sensitivity, Mach $.5,15,000 \mathrm{ft} \ldots \ldots \ldots \ldots 6$

$4.10 \mathrm{~T}_{90}$ Error Sensitivity, Mach $.6,15,000 \mathrm{ft} \ldots \ldots \ldots 7$

$4.11 \mathrm{~T}_{90}$ Error Sensitivity, Mach $.7,15,000 \mathrm{ft} \ldots \ldots \ldots \ldots$ 
$4.12 \mathrm{~T}_{90}$ Error Sensitivity, Mach $.8,15,000 \mathrm{ft} \ldots \ldots \ldots \ldots 9$

A.1 Flight Path Geometry for Accelerated Climb . . . . . . . 118

B.1 Relative Energy State $\ldots \ldots \ldots \ldots \ldots \ldots \ldots \ldots$

B.2 Concept of Combat Cycle Time $\ldots \ldots \ldots \ldots \ldots \ldots \ldots$

B.3 Definition of Pointing Margin $\ldots \ldots \ldots \ldots \ldots \ldots$

B.4 Dynamic Speed Turn Plots $\ldots \ldots \ldots \ldots \ldots \ldots \ldots$

C.1 Generalized Simulation Flow Diagram $\ldots \ldots \ldots \ldots \ldots \ldots$

C.2 Detailed Simulation Wiring Diagram $\ldots \ldots \ldots \ldots \ldots$

C.3 Sample Input File for $\operatorname{SIM} 2 \ldots \ldots \ldots \ldots \ldots \ldots$

C.4 Longitudinal Check Case, Mach $.6,10,000 \mathrm{ft} \ldots \ldots \ldots \ldots 173$

C.5 Longitudinal Check Case, Mach $8,35,000 \mathrm{ft} \ldots \ldots \ldots \ldots$

C.6 Longitudinal Check Case, Mach .9 , Sea Level . . . . . . . . 17

C.7 Lateral Check Case, Mach $.4,20,000 \mathrm{ft} \ldots \ldots \ldots \ldots$

C.8 Lateral Check Case, Mach $.6,10,000 \mathrm{ft} \ldots \ldots \ldots \ldots \ldots$

C.9 Lateral Check Case, Mach $8,35,000 \mathrm{ft} \ldots \ldots \ldots \ldots$

C.10 Lateral Check Case, Mach .9, Sea Level . . . . . . . . . 185 


\section{List of Tables}

2.1 Typical Wing Loading and Thrust to Weight Ratios ........ 10

4.1 Deviations for Pitch Sensitivity Tests $\ldots \ldots \ldots \ldots \ldots \ldots$

4.2 Deviations for Lateral Sensitivity Tests $\ldots \ldots \ldots \ldots \ldots . \ldots 94$

C.1 SIM 2 Initialization Sequence $\ldots \ldots \ldots \ldots \ldots \ldots \ldots$

C.2 Dynamic Loop Sequence for One Frame . . . . . . . . . . 164

C.3 Common Simulation Variables $\ldots \ldots \ldots \ldots \ldots \ldots \ldots$ 


\section{List of Abbreviations}

$\mathrm{C}_{\mathrm{l}_{\delta}} \quad$ Nondimensional variation of rolling moment with control surface deflection

$\mathrm{C}_{\mathrm{m}_{\delta}} \quad$ Nondimensional variation of pitching moment with control surface deflection

CAS Control Augmentation System

E Total mechanical energy

$E_{s} \quad$ Specific mechanical energy

D Drag

FCS Flight Control System

HARV High Angle of Attack Research Vehicle

HQDT Handling Qualities During Tracking

$I_{X}, I_{Y}, I_{Z} \quad$ Moment of inertias about $X, Y$ and $Z$ axes

$\mathrm{I}_{\mathrm{XZ}} \quad \mathrm{XZ}$ product of inertia

$\mathrm{L}_{\delta} \quad$ Dimensional variation of rolling moment with control surface deflection

MBB Messershcmitt-Bölkow-Blohm

$\mathrm{M}_{\delta} \quad$ Dimensional variation of pitching moment with control surface deflection

$\mathrm{P}_{\mathrm{S}} \quad$ Specific Excess Power

R Turn Radius 


\begin{tabular}{|c|c|}
\hline $\mathbf{S}$ & Reference wing area \\
\hline $\mathrm{T}_{90}$ & Time to capture $90^{\circ}$ bank angle change \\
\hline $\mathrm{T} / \mathrm{W}$ & Thrust to weight ratio \\
\hline TR & Turn rate \\
\hline V & Velocity \\
\hline $\mathrm{V} / \mathrm{V}_{\mathrm{c}}$ & Relative Energy State \\
\hline W & Weight \\
\hline WVR & Within Visual Range \\
\hline W/S & Wing Loading \\
\hline b & Wing span \\
\hline$\overline{\mathbf{c}}$ & Mean aerodynamic chord \\
\hline g & Acceleration due to gravity \\
\hline h & Altitude \\
\hline $\mathbf{n}_{\mathbf{z}}$ & Load factor \\
\hline $\mathrm{p}$ & Body axis roll rate \\
\hline$p_{\text {stab }}$ & Roll rate about stability $\mathrm{X}$ axis \\
\hline q & Body axis pitch rate \\
\hline $\mathbf{r}$ & Body axis yaw rate \\
\hline $\mathbf{r}_{\text {stab }}$ & Yaw rate about stability $\mathrm{Z}$ axis \\
\hline$\Theta$ & Euler pitch angle \\
\hline
\end{tabular}

xi 


$\begin{array}{ll}\Phi & \text { Euler roll angle } \\ \Psi & \text { Euler heading angle } \\ \Psi_{s s} & \text { Steady state rate of change of heading angle } \\ \alpha & \text { Angle of attack } \\ \beta & \text { Sideslip angle } \\ \gamma & \text { Flight path angle } \\ \phi_{\mathrm{T}} & \text { Angle between chord line and thrust line }\end{array}$




\section{INTRODUCTION}

\subsection{Background of Agility}

Fighter flying qualities and combat capabilities are currently measured and compared in terms relating to vehicle energy, angular rates and sustained acceleration. Criteria based on these measurable quantities have evolved over the past several decades and are routinely used to design aircraft structures, aerodynamics, propulsion and control systems. While these criteria, or metrics, have the advantage of being well understood, easily verified and repeatable during test, they tend to measure the steady state capability of the aircraft and not its ability to transition quickly from one state to another.

Though fighters engaged in close or within-visual-range (WVR) combat spend little time in steady state flight, the requirement to maneuver for a stable, rear quarter firing advantage has generally lead to extended engagements for which the traditional measures of merit are useful. However, the requirement for a stable, rear quarter firing solution has been dramatically reduced with the advent of lethal, reliable, all aspect, short range missiles of the AIM-9L class (Reference 1, 2, 3, 4, 5, 6, 7, 8, 9, 10, 38). Engagement times have been decreased by nearly an order of magnitude as pilots need only to point their weapons at the target in order to achieve a high probability of kill. 
New measures of merit or metrics are needed to quantify the short time scale capabilities that are now exploited during WVR, all aspect combat. A wide variety of measures have been proposed by pilots and researchers and are generally grouped under the catch all heading of Agility Metrics.

The promise of lethal point-and-shoot weapons has also prompted interest in controlled flight at angles of incidence well beyond that for maximum lift. High rate maneuvering in the low speed, high angle of attack part of the envelop is popularly referred to as supermaneuverability (Reference $11,12,13$, $14,15)$. Though supermaneuverability is motivated by the same new weapons technology and is being investigated by many of the same researchers, it is fundamentally different than agility. The successful application of supermaneuverability will depend on control effectors, pilot aids and propulsion performance that are not available today. Agility metrics, on the other hand, are intended to quantify and, eventually, influence the way fighters maneuver today in conventional flight while engaged in air-to-air combat. The current work reported in this document will address only the former problem of agility metrics. 


\subsection{Current State of Agility Research}

Fighter agility is a current topic that is receiving attention from a wide range of government and industry organizations across the country and overseas. Agility is being addressed simultaneously by academicians, manufacturers, flight testers and tacticians. The result is a broad based effort that occasionally suffers from lack of communication, coordination and even a commonly accepted vocabulary. Following is a description of the ongoing agility related work which has been made public.

The motivation for agility work originally came from the flying community and the Air Force Flight Test Center remains actively involved in measuring aircraft performance in the terms of agility metrics. Test Center pilots and Test Pilot School students have conducted limited flight tests to collect data and evaluate the utility of various proposed metrics. Their work has centered primarily of the F-16 but has included some F-15, F-4 and T-38 flights(Reference 16, 17). In addition, the Flight Test Center is working with NASA's Dryden Flight Research Facility to extend their agility evaluation to the X-29 (Reference 18, 19). NASA Dryden intends to study agility during flight test of the F-18 High Angle-of-Attack Research Vehicle (HARV). The Italian Air Force has also conducted an agility flight test study using light attack aircraft. 
The other central organization in agility work has been the Eidetics Corporation (Reference 8, 9, 11, 20). Eidetics has worked under contract to NASA, the Aeronautical Systems Division at Wright-Patterson AFB and the Armament Division at Eglin AFB. This work has involved the development of agility metrics, quantifying them via simulation, proposing agility enhancing modifications to existing aircraft and efforts to relate agility to combat effectiveness with multi-aircraft engagement simulations. Eidetics is currently seeking to expand the agility focus to include pilot interfaces and the effects of weapon constraints on the utility of enhanced aircraft agility. Eidetics is a small company that seeks to be a link between the operational users and the aircraft designers.

The idea of incorporating high agility into the fighter design process is being worked in numerous organizations. The Grumman Aircraft Company (Reference 21) and NASA's Langley Research Center are trying to relate agility requirements to the flight control design process. McDonnell-Douglas has established an Agility Working Group which includes flight controls, flying qualities, propulsion and structures engineers. McDonnell-Douglas has used its pilot-in-the-loop domed simulators to relate enhanced agility to combat effectiveness (Reference 22,23). Those efforts have, so far, focussed on lateral agility (increased roll rates and smaller roll time constants) and results have 
been disappointing. Large increases in lateral agility failed to produce statistically significant combat improvements.

Researchers at Boeing and Lockheed are using trajectory optimization approaches to look for maneuvers which best use the capabilities that enhanced agility might provide. Juri Kalviste at Northrop has postulated several new metrics that deal with large amplitude maneuvers (Reference 24, 25). Rockwell, in association with Messerschmitt-Boelkow-Blohm (MBB), has studied agility in the context of the unconventional flight modes to be explored by the X-31 program (Reference $4,5,12,26$ ). Dr Herbst of MBB has quantified agility as certain terms resulting from manipulation of the aircraft equations of motion in velocity coordinates. Interestingly, this development remains proprietary to MBB and unpublished.

The University of Kansas and Georgia Tech are the only universities now doing funded research in fighter agility. Researchers at Georgia Tech (funded by NASA Langley) are using optimization methods to minimize time to change heading by $180^{\circ}$ with level turns or half loop (split-s) maneuvers.

\subsection{Objectives of This Project}

On February 1989, NASA's Dry den Flight Research Facility funded the University of Kansas Center for Research Inc. (CRINC) to assess the current 
state of agility metric development and support their plans to conduct agility related flight testing. Specifically, CRINC was tasked to collect the various metrics that have been proposed and published in the literature and to evaluate them via simulation and with whatever existing flight data that could be obtained. NASA's F-18 HARV simulation was to be the primary analysis tool and a copy was provided to CRINC in MAY 1989.

Beyond this initial simulation effort, CRINC was also to evaluate the sensor requirements associated with the eventual agility flight tests at NASA. Finally, CRINC was asked to study pilot cues for agility maneuvers and to develop efficient data analysis routines for reducing agility test results.

The remainder of this report describes the results of CRINC's first year of work on fighter agility metrics. Traditional air combat measures of merit are described first in Section 2.1 so that the contrast with new agility metrics is clear. Proposed new agility metrics are discussed and organized into a logical framework in Section 2.2. A distinction is drawn between short time scale transient agility metrics and longer term functional metrics that are driven by aircraft performance rather than agility. A complete set of transient agility metrics is then evaluated with a high fidelity, nonlinear, six degree of freedom F-18 aircraft simulation and results are presented in Chapter 3. The simulation tool used at CRINC is described and thoroughly documented in Appendix C. 
Instrumentation needed to evaluate an aircraft's agility with these metrics during flight test and the sensitivity of the metrics to variations in pilot commands is evaluated in Chapter 4. 


\section{PROBLEM DEFINITION}

The new agility metrics are intended to supplement, not replace, the traditional measures of combat effectiveness. Therefore, it is appropriate to review the most widely used traditional measures. New agility metrics that address aspects of fighter capability not traditionally measured can then be identified from the many metrics published under the title of agility.

\subsection{Summary of Traditional Metrics}

A first order comparison of fighter airframe capability can be made with a set of well known parameters calculated at various flight conditions. The most common of these point performance metrics are summarized here.

a. Wing loading (W/S).

This parameter, with units of force per unit area, is the the ratio of aircraft weight to wing planform area. It is normally calculated at maximum gross weight or at some intermediate combat weight consisting of a partial fuel and weapons load. Since low wing loading reflects high wing area relative to aircraft weight, a fighter with low wing loading will generally have a high maximum lift-to-weight ratio and so be able to generate high instantaneous load factor or turn rate. This generalization, however, neglects the effects of differing airfoils and the efficiencies of 
maneuvering flaps or slats. In addition, wing loading does not account for the lift characteristics of modern, blended fuselage designs.

b. Thrust-to-weight ratio (T/W).

Thrust-to-weight ratio is usually calculated at the same aircraft weights used for the wing loading parameter and with the static, uninstalled, sea level thrust of the engine(s). The ratio thus calculated is much different than the thrust-to-weight ratio available to the pilot at any given flight condition since thrust is a function of altitude. In addition, inlets optimized for different flight speeds may cause a fighter with a relatively high thrust-to-weight ratio at high speed to be inferior at low speeds. Some wing loading values and thrust-to-weight ratios (calculated at take-off weight) for current fighters are given in Table 2.1 (Reference 27, 28). 


\begin{tabular}{||l|l|l||}
\hline \multicolumn{2}{|c|}{ Table 2.1: Typical Wing Loadings and Thrust-to-Weight Ratios } \\
\hline Aircraft & W/S (PSF) & T/W \\
\hline F-4E & 103 & .66 \\
\hline F-5E & 117 & .46 \\
\hline F-106 & 52 & .675 \\
\hline F-14A & 117 & .62 \\
\hline F-15C & 73 & 1.08 \\
\hline F-16A (no air-to-ground stores) & 78 & .98 \\
\hline F-18 (no air-to-ground stores) & 84 & .95 \\
\hline MiG-21 & 83 & .55 \\
\hline Saab-37 & 76 & .75 \\
\hline
\end{tabular}

c. Maximum Level Mach Number.

This number is usually quoted at sea level and at 36,000 feet (beginning of the standard atmosphere tropopause). For the aircraft 
listed in Table 2.1, maximum Mach numbers at 36,000 feet range from 1.64 for the F-5E to 2.5 for the F-15.

\section{d. Maximum Rate of Climb.}

This parameter is usually reported for sea level conditions. Rate of climb for the F-5E is 34,500 feet per minute. The F-15's maximum rate of climb is greater than 50,000 feet per minute.

e. Maximum Instantaneous Turn Rate $\left(\dot{\Psi}_{\text {ins }}\right)$.

This is the rate attained by turning at the maximum instantaneous load factor available at the given flight condition. The highest maximum instantaneous turn rate occurs at the airspeed for which the maximum lift line and the maximum structural limit line on the V-n diagram intersect (Figure 2.1). This airspeed is referred to as the corner velocity. A V-n diagram contains none of the thrust and drag information needed to determine sustained maneuverability. 


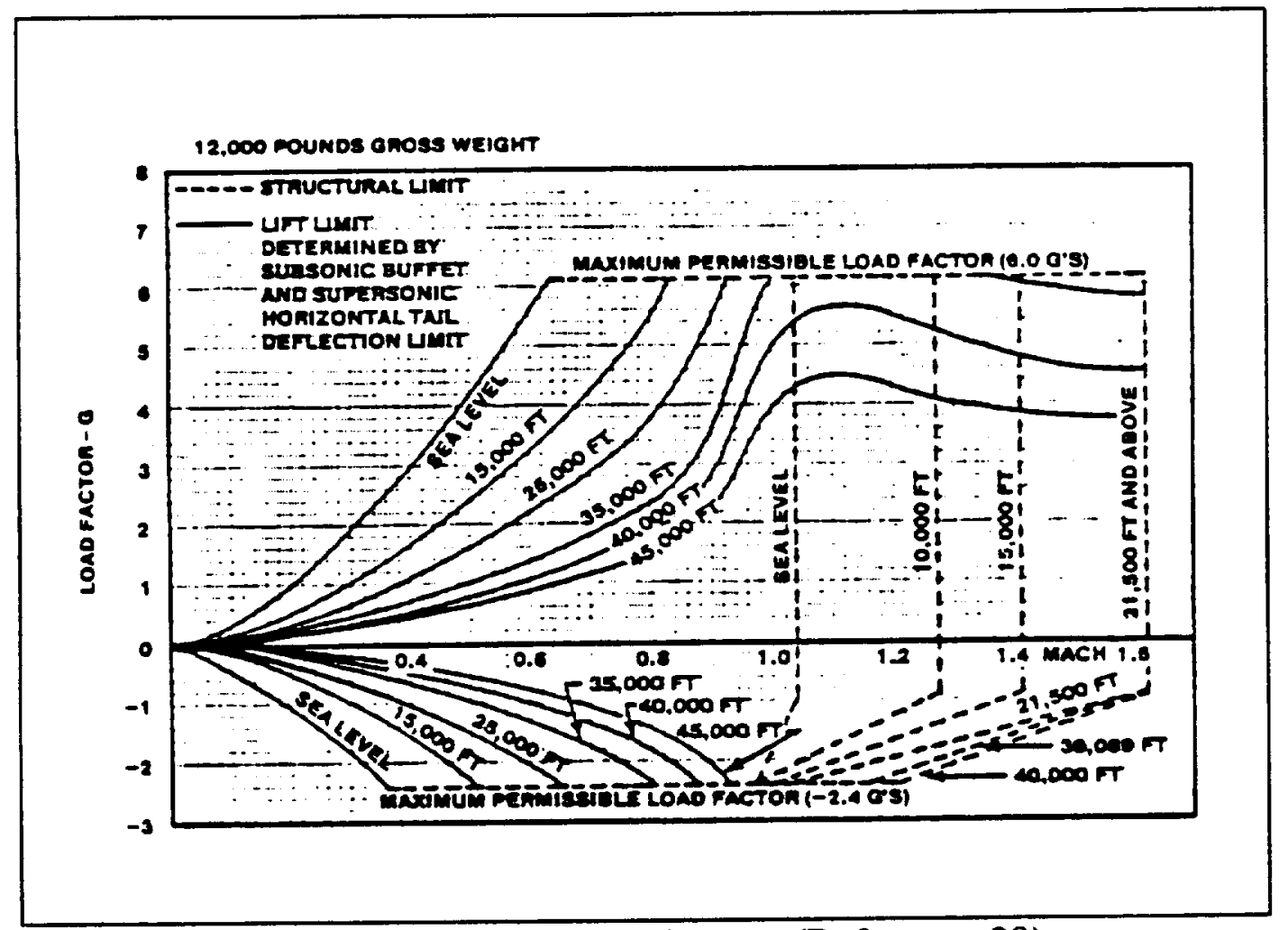

Figure 2.1: T-38 V-n Diagram (Reference 29)

f. Specific Excess Power, $\left(P_{S}\right)$.

Over the last fifteen years, energy maneuverability quantified in terms of $P_{S}$ (with units of feet per second) has been the primary tool for comparing fighter performance. Specific excess power represents an aircraft's ability to change its specific mechanical energy either by changing altitude or airspeed. By plotting the aircraft's $P_{S}$ at various points in the flight envelop (altitude, airspeed and load factor) and then 
comparing these values to those of competing aircraft, it is easy to visualize areas of advantage or disadvantage. $P_{S}$ can be calculated as

$$
P_{\mathbf{s}}=\frac{V\left(T \cos \left(\alpha-\phi_{T}\right)-D\right)}{W}
$$

Here V, T, D and W are the aircraft's velocity, thrust, drag and weight respectively. Angle of attack is $\alpha$ and $\phi_{T}$ is the angle between thrust line and the body $\mathrm{X}$ axis. In addition,

$$
P_{s}=\left(\frac{V}{g}\right)(\dot{V})+\dot{h}
$$

where $h$ is altitude, so $P_{S}$ is a measure of the aircraft's ability to accelerate at constant altitude or to climb at constant velocity.

Derivations of these expressions are given in Appendix A. A common method of plotting $P_{S}$ is shown in Figure 2.2.

In Figure 2.3, the $P_{S}$ capability of two dissimilar aircraft are compared. The contours represent levels of $\mathrm{P}_{S}$ advantage and the shaded portion of the plot shows areas of the flight envelope where only on of the aircraft is able or erate.

f. Sustained, or Constant Energy Turn Rate $\left(\dot{\Psi}_{s s}\right)$. 


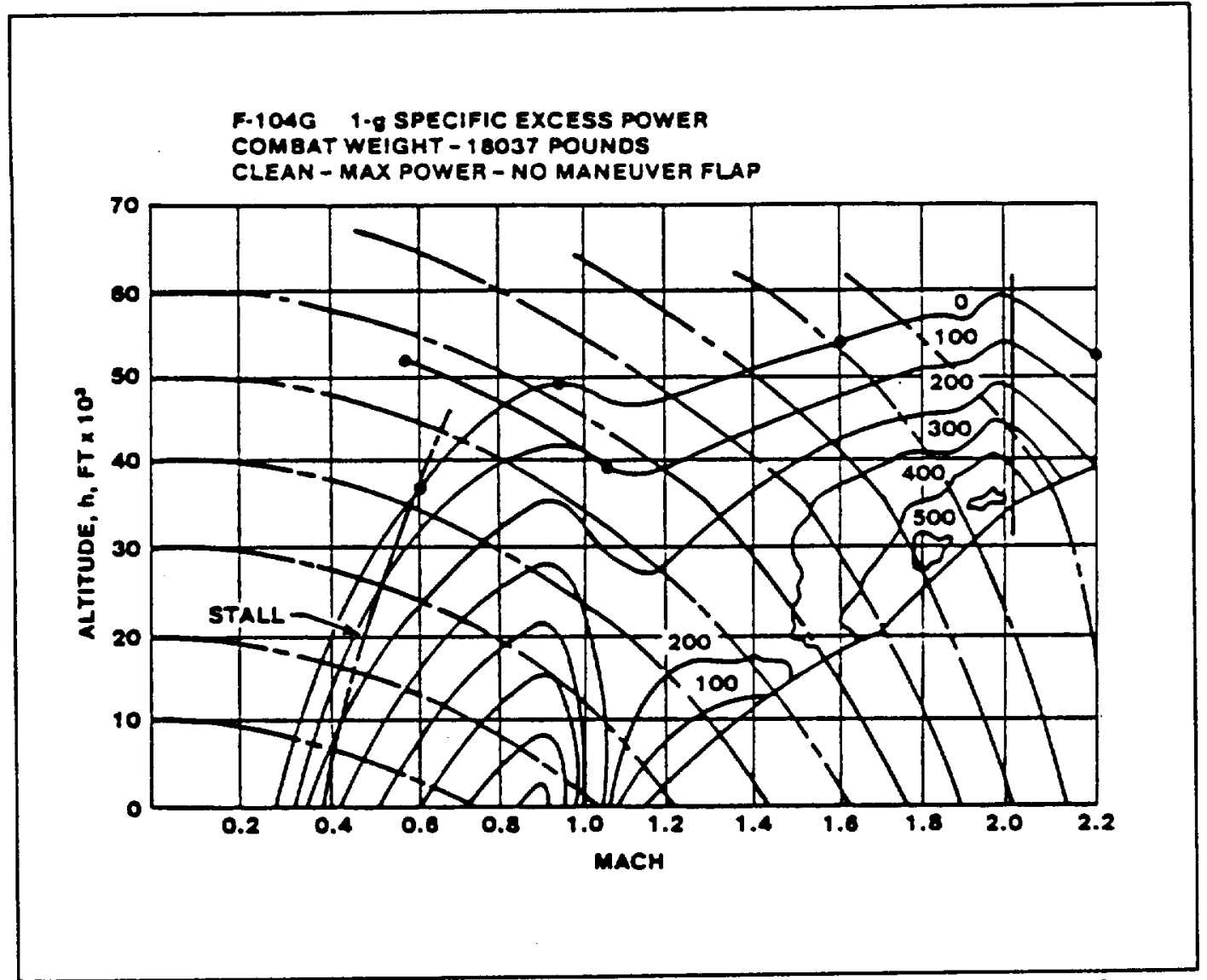

Figure 2.2: Typical $P_{S}$ Plot for a Single Aircraft (Reference 29)

This is the maximum tum rate in degrees per second that can be sustained without loss of either altitude or airspeed. In other words, it is the turn rate at a given altitude and Mach number for which $P_{S}$ is zero. Sustained normal load factor or turn radius are often used instead of sustained turn rate. The three terms are related since 


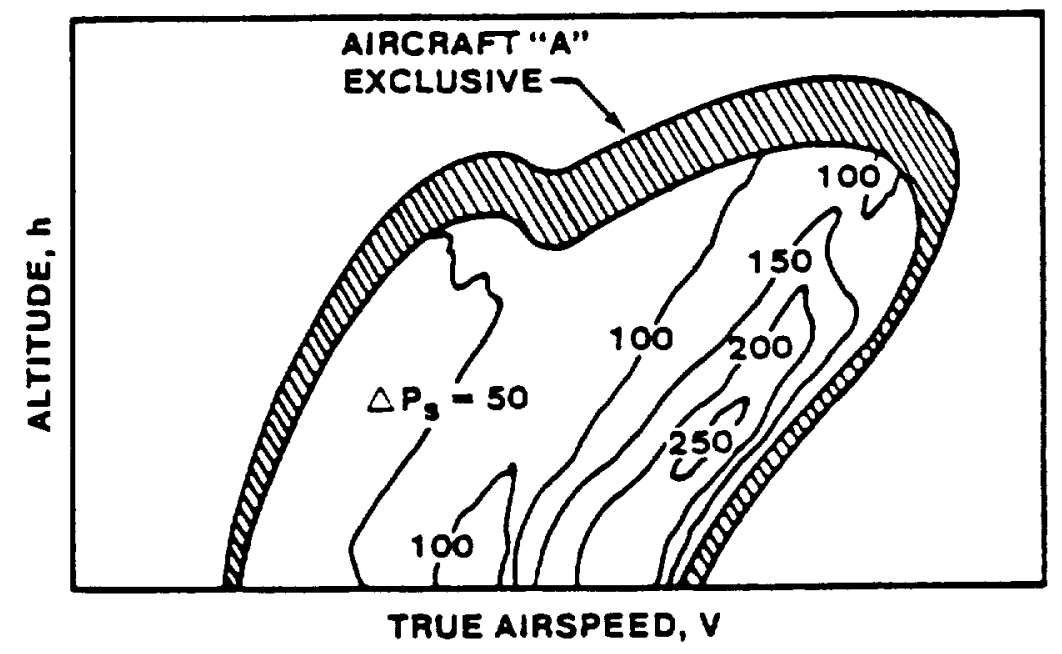

Figure 2.3: Differential Ps Plot (Reference 29)

$$
\mathrm{n}_{\mathrm{z}}=\sqrt{\left(\frac{\dot{\Psi} \mathrm{V}}{\mathrm{g}}\right)^{2}+1}
$$

and

$$
R=\frac{V^{2}}{g \sqrt{n_{z}^{2}-1}}
$$


where $n_{z}$ is load factor and $R$ is turn radius. These relationships are

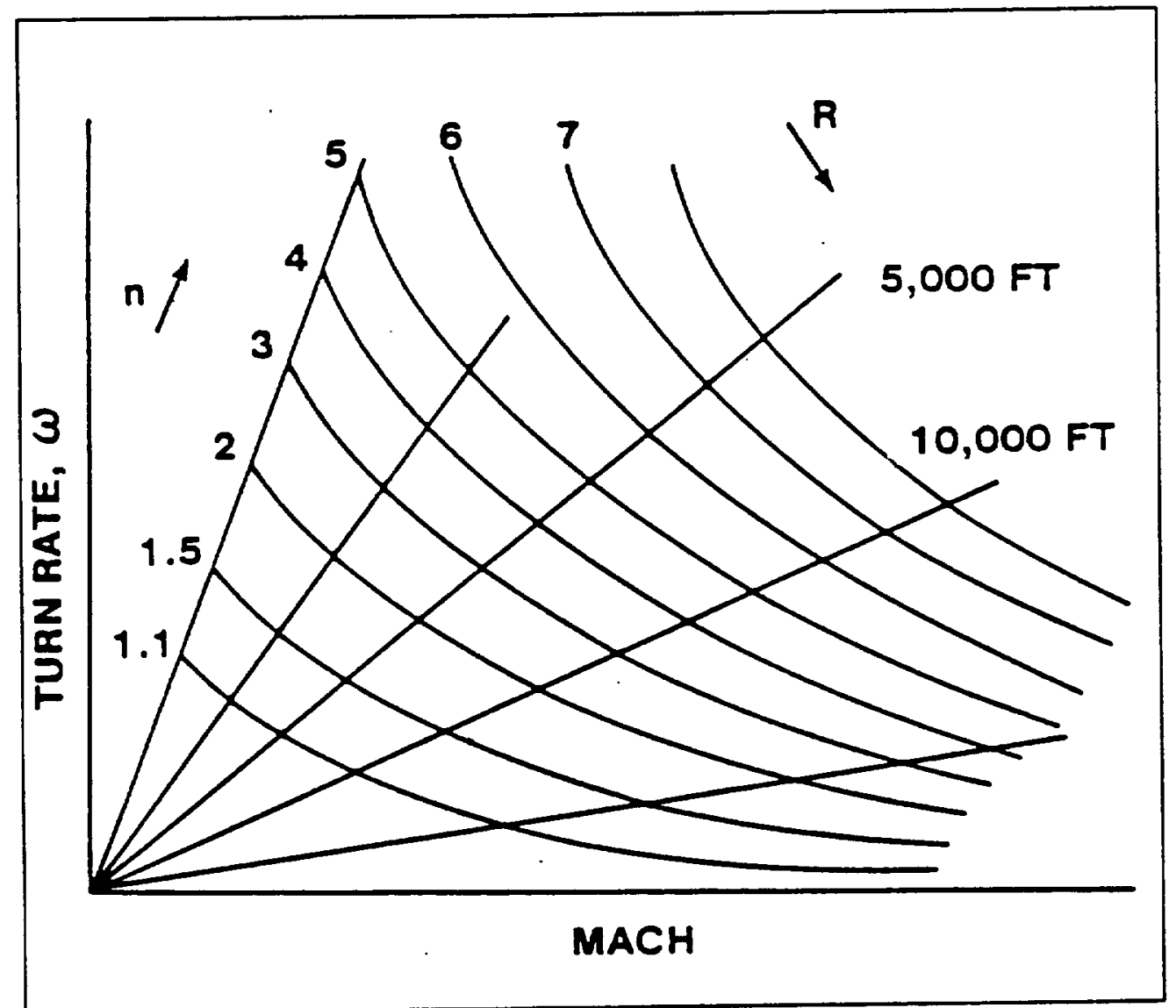

Figure 2.4: Turn Rate, Radius Relationships (Reference 29)

shown graphically in Figure 2.4 .

Constant energy turn rate or sustained load factor capability is calculated at a representative range of altitudes and airspeeds. Depending on the aircraft design and flight conditions, the maximum 
constant energy turn rate may be limited by available lift, available thrust or structural strength.

Turn performance for the F-5E at a single altitude and loading condition are shown in Figure 2.5. Complete charts like this for fighter aircraft are normally classified.

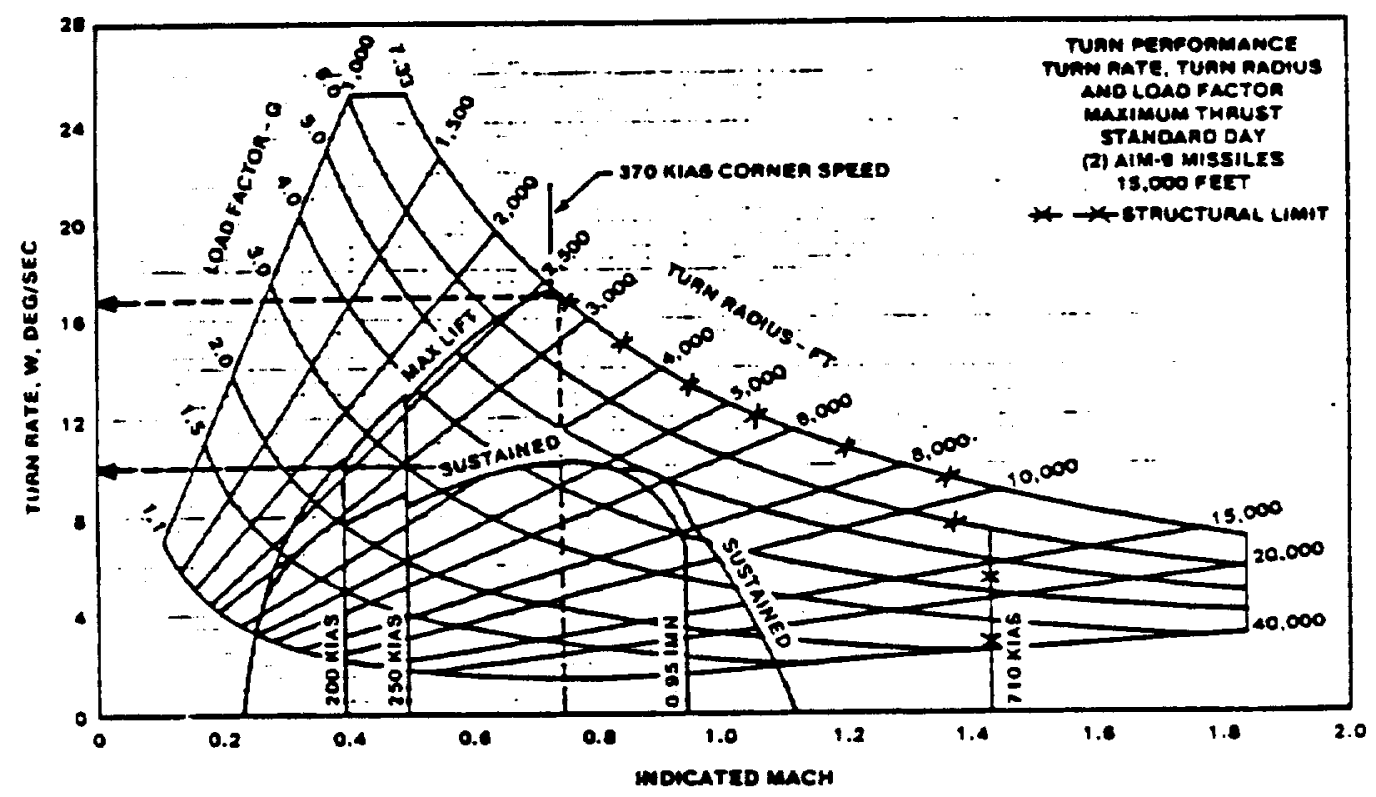

Figure 2.5: F-5E Turn Performance (Reference 29) 


\subsection{Published Agility Metrics}

Though numerous papers have discussed the need for new ways of measuring fighter agility characteristics, only a few authors have actually proposed new metrics that could be used to develop a quantitative measure of agility. A list and brief definition of each of the metrics that have been proposed in the open literature is presented below. A more detailed discussion of the metrics and some graphical examples is attached as Appendix B to this report.

Pitch Agility

$\mathrm{T}_{90}$

Torsional Agility

Axial Agility
Time to pitch to maximum load factor

plus time to pitch from maximum to zero load factor.

Time to roll to and capture a $90^{\circ}$ bank angle change

Turn rate divided by $T_{90}$

The difference between minimum and maximum $P_{S}$ available at a given flight condition divided by the time to transition between the two levels. 
Relative Energy

Combat Cycle Time

Pointing Margin

Dynamic Speed Turn

Agility Potential

Pitch Agility

Criteria

Roll Reversal

Agility Parameter
State Ratio of aircraft velocity to corner speed after a $180^{\circ}$ turn.

Time to complete a maximum acceleration turn and regain lost energy. Angle between the nose of an adversary and the line of sight when the friendly fighter is aligned with the line of sight.

Plot of $P_{S}$ versus turn rate.

Thrust to weight ratio divided by wing loading.

Coefficient of pitching moment due to control surface deflection scaled with wing area, aerodynamic chord and pitch axis inertia.

Product of time required to reverse a turn and the cross range displacement that occurs during the turn. 
Since the pilots, engineers and researchers now involved in agility have, as yet, not reached a commonly accepted definition of the term, it is not surprising that the proposed agility metrics deal with many different aspects of fighter capability. The various metrics proposed to measure agility deal in units of time, velocity, angular rate, distance and combinations of time, rate and distance. Some framework for organizing the metrics that have emerged from different points of view is now needed.

After collecting and reviewing the metrics now available in the literature, it is apparent that they may be categorized in two ways. First, the new metrics can be grouped by time scale into classes referred to by some authors as functional and transient (Reference 1, 16). Secondly, the new metrics may be classified according to type of motion involved, i.e. translational (axial), longitudinal, and lateral.

Each of these two schemes of metric classification are discussed below. The resulting framework is then presented in a matrix format.

\subsubsection{Transient, Functional, Potential}

Regardless of the motion variables involved or the units chosen to measure the result, all of the proposed new metrics that deal with actual aircraft maneuvers can be grouped into one of two time scales. Agility in the context 
of the short time scale, on the order of one to three seconds, is frequently called transient agility (Reference $1,8,9$ ). The transient agility metrics are new ways to quantify the fighter's ability to generate controlled angular motion and to transition quickly between minimum and maximum levels of specific excess power.

A second group of time dependent metrics called large amplitude metrics (Reference 1) or functional agility metrics (Reference 16) deals with a longer time scale of ten to twenty seconds. This class seeks to quantify how well the fighter executes rapid changes in heading or rotations of the velocity vector. Emphasis is on energy lost during turns through large heading angles and the time required to recover kinetic energy after unloading to zero load factor. Many of these functional metrics involve maneuvers made up of a sequence of brief segments that could each be evaluated with a transient agility metric. For example, the combat cycle time metric proposed by B. F. Tamrat of Northrop (Reference 10) consists of a pitch to maximum load factor, a turn at maximum load factor to some specified new heading angle, a pitch down to zero load factor and acceleration to the original airspeed. The net effect of combining a sequence of maneuvers and flight segments into a single metric is that conventional aircraft performance, that is, thrust to weight ratio and sustained load factor or turn rate capability, dominates the metric. The transient agility 
characteristics have only a minor impact on the numerical value of the functional metric (Reference 16). In addition to measuring the aircraft capability, these long term metrics also depend heavily on complex pilot inputs which in turn will be influenced by the pilot's skill, experience, the aircraft's flying qualities and the effect of cockpit displays and cues.

A third group of metrics has appeared which are independent of time and so are neither transient or large amplitude. They deal not with the aircraft characteristics demonstrated via flight test or simulation but with the agility potential that results from sizing and configuration choices. These agility potential metrics serve to highlight the (sometimes obvious) relationships between thrust, weights, inertias, control power and agility. While they have the advantage of using data available early in the aircraft design cycle, they do not reflect the impact of cross axis nonlinearity or flight control system response characteristics (Reference 30).

\subsubsection{Lateral, Pitch, Axial}

Agility metrics may also be classified according to the type of aircraft motion being studied independent of time scale. Lateral metrics include those that deal primarily with rolling motion, especially rolling at high angles of attack. Longitudinal metrics involve only pitching motion and normal 
acceleration. Finally, a number of metrics have been proposed to quantify the ability of the aircraft to transition between energy states or $P_{S}$ levels. These are commonly referred to as axial metrics and involve only translational motion.

When these two approaches to agility metric classification are simultaneously applied, the result is a matrix as seen in Figure 2.6. With two exceptions, each metric can be uniquely placed within this classification matrix. One exception, Eidetic's Torsional Agility, is deliberately formulated to mix pitching and rolling characteristics and is the ratio of turn rate to the time to roll and capture a $90^{\circ}$ bank angle change (Reference 9). The other exception, Agility Potential, is the ratio of two traditional performance metrics, wing loading, which is related to longitudinal maneuverability, and thrust to weight ratio. Again, each of the metrics listed in Figure 2.6 is described in more detail in Appendix B.

In the current report each of the transient agility metrics is evaluated with the F-18 simulation described in the next section. Results are then presented in Chapters 3 and 4. 


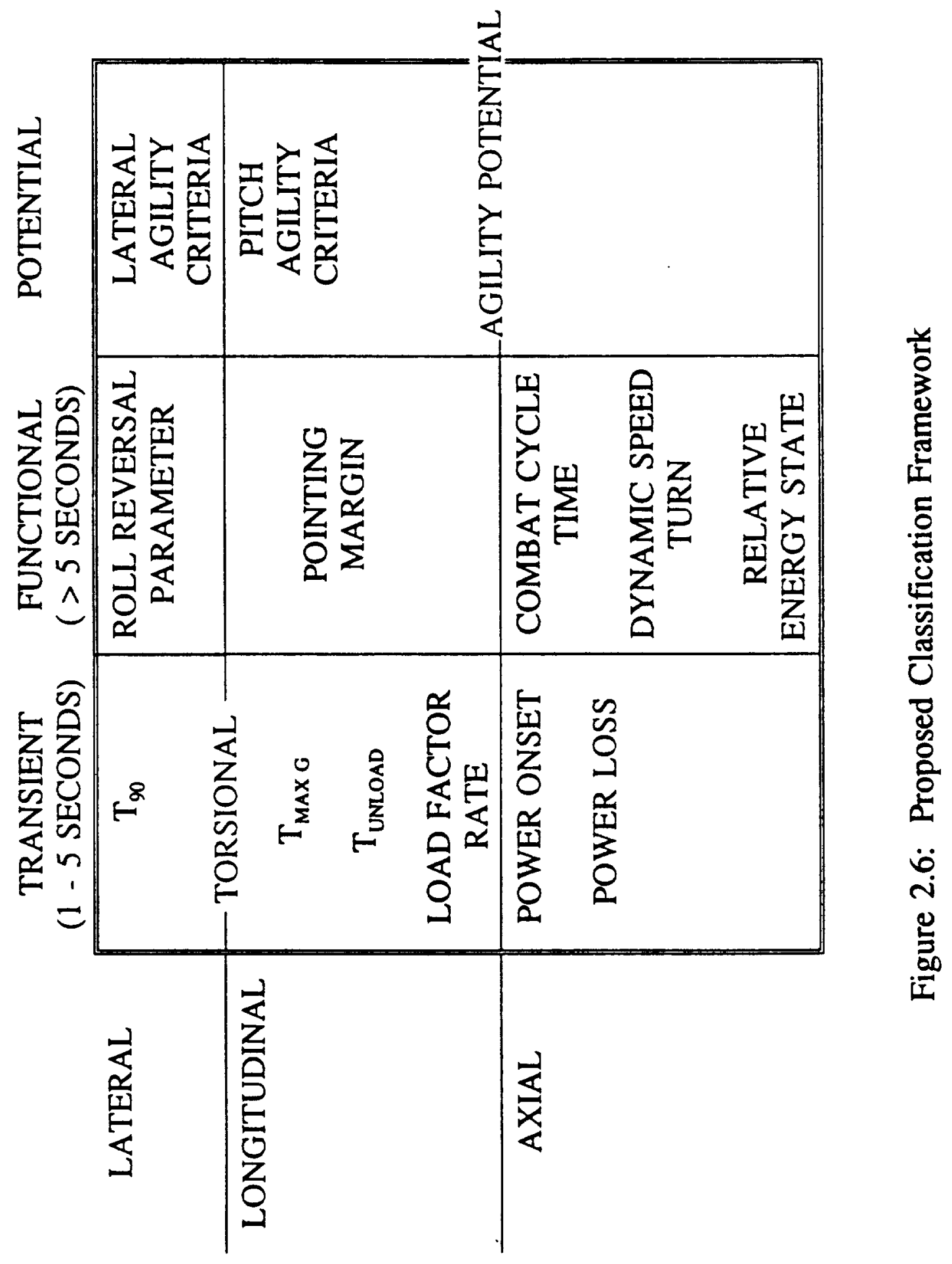




\subsection{Vehicle Description (F-18 HARV) and Simulation Overview}

The McDonnell-Douglas F/A-18 is a single seat, twin engine, supersonic fighter currently in service with the United States Navy, Marine Corps and several foreign countries. It has a maximum take off weight, when configured for an air to ground mission, of more than 49,000 pounds and is powered by two General Electric F404 low bypass turbofan engines. Planform and external dimensions are shown in Figure 2.7 (Reference 44).

NASA Dryden's High Angle of Attack Research Vehicle (HARV) is one of the aircraft from the F-18 Full Scale Development test program. Except for thrust vector paddles that are now in the process of being installed, the aircraft has no significant aerodynamic differences from the fleet configuration even though the missile rails on the wing tips have been replaced with instrumentation pods, fences on the wing leading edge extensions have not been installed and the leading edge flap chord is two inches longer (Reference 31 ). The plane is equipped with the current fleet flight control laws though these also will be modified to accommodate the new thrust vectoring capability. 

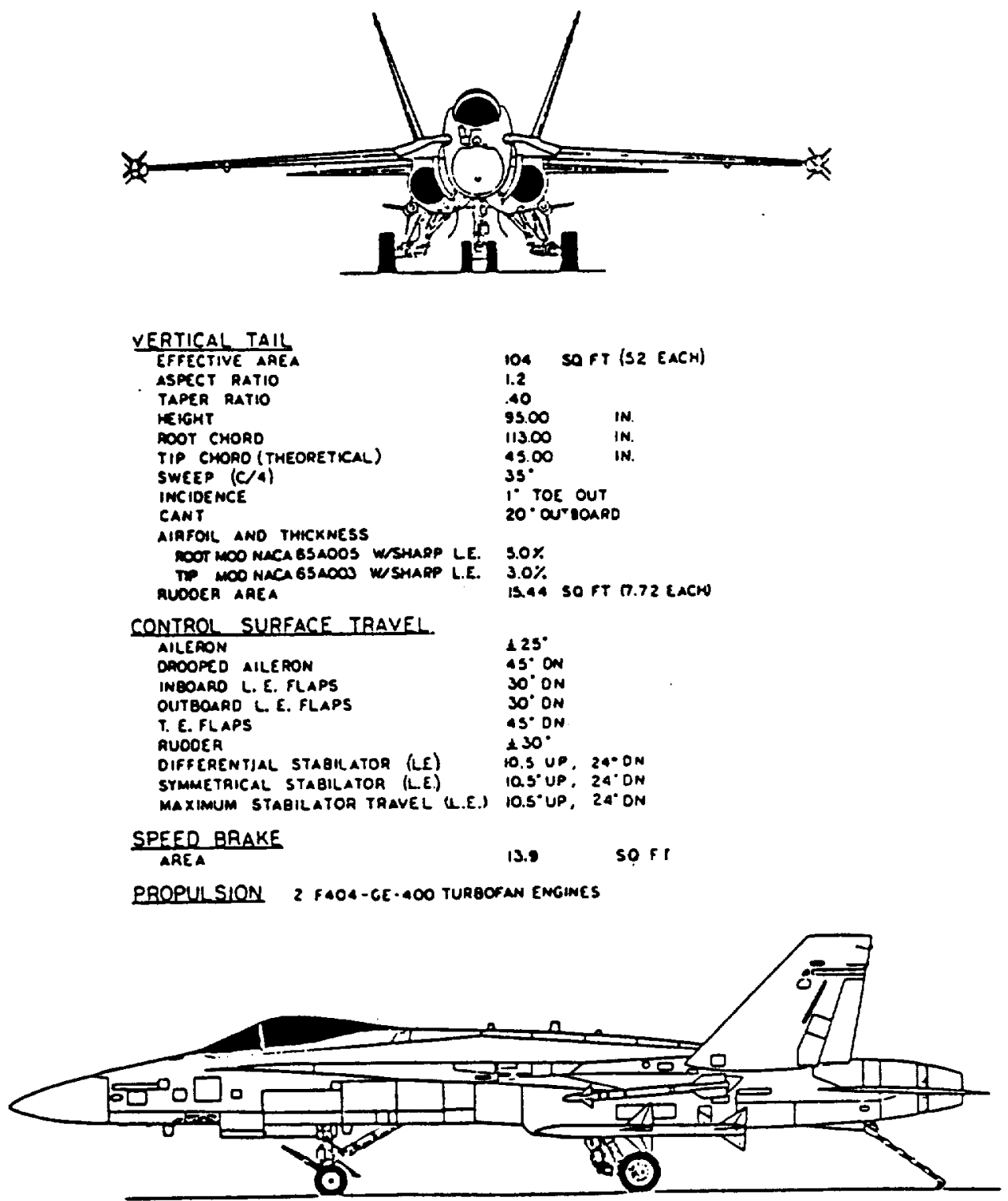

Figure 2.7: F-18 Physical Characteristics (Ref. 44) 


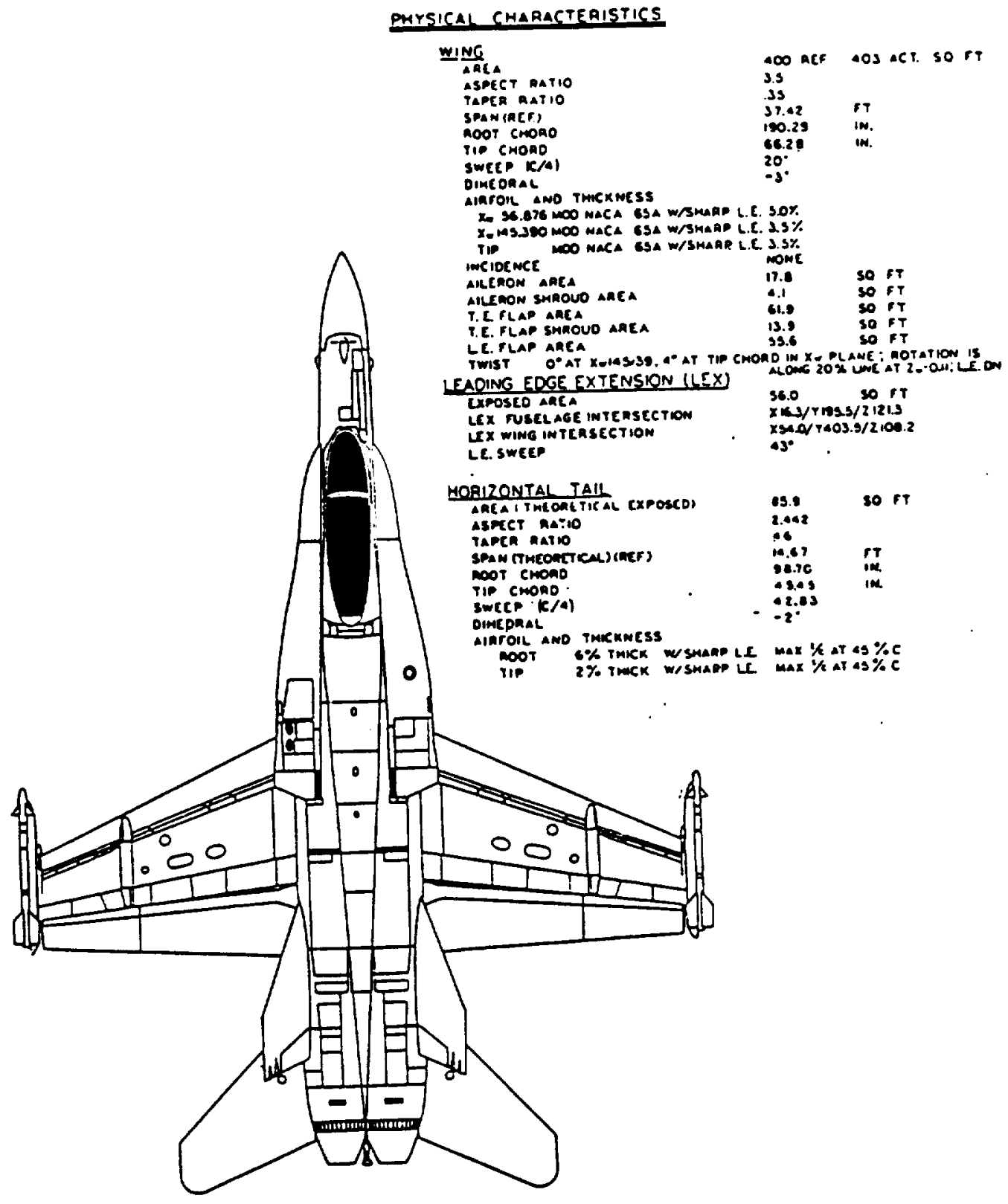

Figure 2.7 (continued) 
Because the NASA Dryden Flight Research Center intends to conduct a flight test study of aircraft agility with their F-18 High Angle of Attack Research Vehicle, their nonlinear six degree of freedom F-18 simulation was chosen to study the selected agility metrics. A Fortran listing of NASA Dryden's simulation was provided with limited documentation to the KU Flight Research Laboratory. The program includes a complete, nonlinear aerodynamic package with data to seventy degrees angle of attack and a detailed model of the F-18 flight control system (version 8.3.3) as described in Reference 45. None of the thrust vectoring modifications are included in the current version of the simulation. It should be noted that while the aerodynamic model of the F-18 is fully nonlinear, it is does not include any unsteady effects which may be significant during highly dynamic maneuvers typical of agility testing.

Because the simulation was run interactively at NASA to support their manned simulation, an extensive amount of reprogramming was required to adapt the it to the computer hardware at the University of Kansas. The simulation now runs in a batch mode on an Apollo workstation and has been validated against check cases provided by NASA Dryden. A simplified flow diagram is included here as Figure 2.8. A detailed diagram including all subroutines is in Appendix C. Documentation and user instructions for the 
Apollo version of the simulation, along with check case results, are also included in Appendix C. The math models, equations of motion and data structures are all documented in Reference 46. 


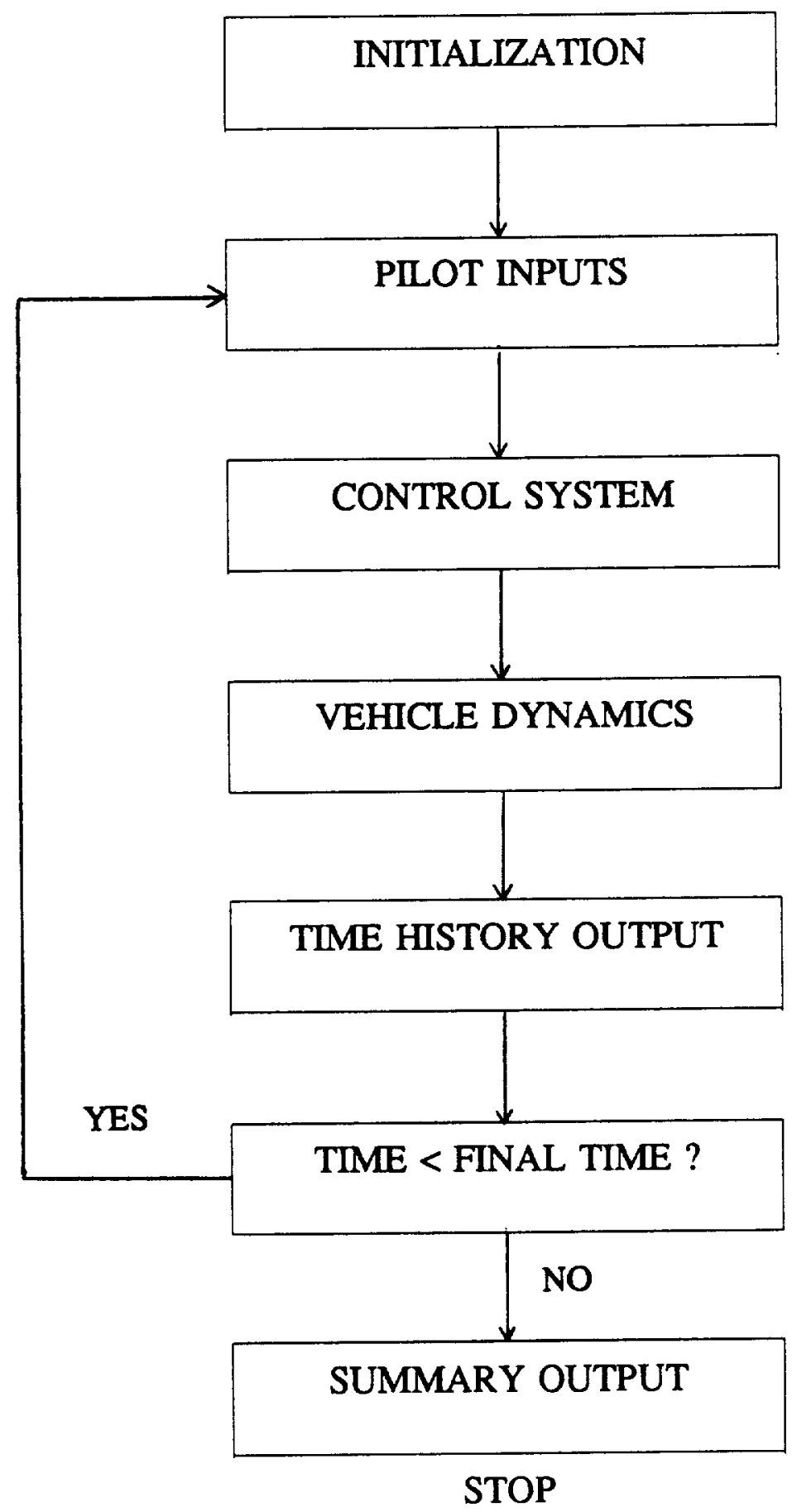

Figure 2.8: Generalized Simulation Flow Diagram 


\subsection{Simulation Plan}

While each of the proposed new agility metrics has been qualitatively discussed in the literature, no systematic, quantitative study has been done before now. Since, as described in Section 2.2 , the transient agility metrics deal with the fundamental capabilities on which the longer time scale, functional metrics are based, a detailed study of these metrics is the logical first step.

In the following sections, each class of transient agility metric is discussed and published metrics from each are evaluated with the F-18 simulation at a representative range of subsonic flight conditions. In section 3.1 the axial agility metrics of power onset and power loss are studied. Section 3.2 is an evaluation of several transient pitch agility metrics including time to maximum and zero load factor, time rate of change of load factor and positive and negative pitch rates. Section 3.3 addresses the $T_{90}$ lateral agility metric. Strengths and limitations of each metric are discussed. The test maneuvers used in the simulation study are described. Each is a straightforward maneuver that could be flown in actual flight test.

The flight test maneuvers needed to measure agility will involve large angular rates and short time scales. Steering cues developed on a ground based simulator may be used to assist the pilot in executing the test maneuvers 
accurately and repeatably. The sensitivity of the agility metric values to deviations in pilot responses to the steering cues are studied in Chapter 4. 


\section{SIMULATION STUDY}

\subsection{Axial Agility}

\subsubsection{Introduction}

Traditional methods of quantifying the longitudinal translation capability of fighter aircraft, hereafter called axial capability, have generally consisted of thrust-to-weight ratio, maximum level Mach number, maximum rate of climb and $\mathrm{P}_{\mathrm{s}}$ as discussed earlier in Chapter Two. These point performance measures of merit only quantify performance at discrete aircraft states. They are not indicative of the capability of an aircraft to change its energy rate rapidly. Axial agility metrics provide a measure of this capability.

\subsubsection{Axial Agility Metrics}

Eidetics International has suggested that transient agility is an important additional measure of a fighter aircraft's success in the modern air battle when all-aspect infra-red missiles are employed (Reference 9). The transient axial agility metrics measure the rate of change of $P_{s}$. These metrics also conform well to the idea of agility being the rate of change of maneuverability (Reference 8). Instead of knowing only what level of $P_{S}$ an aircraft possesses at a particular point, axial agility reflects how effectively the aircraft can transition to another $P_{S}$ level. Both the magnitude of the $P_{S}$ change involved 
in transitioning from minimum to maximum levels and the time required to make that transition are important. The aircraft with superior axial agility will be able to quickly generate large positive and negative $P_{S}$ at a given flight condition. The axial agility metrics measure the combined effects of engine spool time, maximum thrust and drag due to speed brakes. Thus, an aircraft having greater axial agility possesses superior velocity control (both acceleration and deceleration). For instance, consider two aircraft with similar energy maneuverability levels but significantly different engine spool times. A traditional comparison of energy maneuverability levels will not reflect this difference. However, measuring both the positive and negative rate of change of Ps will highlight the advantage of quicker engine response.

\subsubsection{The Power Onset and Power Loss Parameters}

Eidetics International has proposed two parameters to quantify axial agility. The first, the power onset parameter, is defined as the increment of specific excess power $\left(\Delta \mathrm{P}_{\mathrm{s}}\right)$ in going from a minimum power/maximum drag condition, to a maximum power/minimum drag condition, divided by $\Delta t$, the time in seconds required to complete the transition (Reference 9). The aircraft begins the maneuver in level flight decelerating at fligh idle power with speedbrake extended. At the test Mach number, the throttle is advanced to the 
maximum power setting while the speedbrake is simultaneously retracted. The resulting acceleration is maintained until the maximum net axial force (thrust minus drag) is attained.

The power loss parameter is the second metric and is also defined as $\Delta \mathrm{P}_{\mathrm{s}} / \Delta t$, but here $\Delta \mathrm{P}_{\mathrm{s}}$ is the increment of specific excess power in going from a maximum power/minimum drag configuration to a minimum power/maximum drag configuration. Prior to the start of the maneuver, the aircraft is accelerating in level flight at maximum throttle setting with speedbrake retracted. The throttle is then reduced to flight idle while the speedbrake is simultaneously extended. Thrust reversers would also be deployed if the test aircraft were so equipped. The deceleration is maintained until the minimum net axial force (i.e. thrust minus drag) is attained. The axial agility parameters could be easily extended to account not only for how well an aircraft accelerates and decelerates, but also for any unique capabilities which may be used to effect velocity changes. These capabilities may consist of engines with very fast response to throttle commands, thrust vectoring or thrust reversing nozzles, or even nozzles which permit vectoring in forward flight (VIFFING). Since a pilot engaged in air combat would likely make maximum use of his aircraft's capabilities, the axial agility parameters appear to be an important 
addition to the traditional point performance methods for determining the axial capabilities.

\subsubsection{Axial Agility Test Cases Description}

The computer simulations necessary to determine the axial agility parameters where run on the F-18 HARV simulation. The test case for the power onset parameter begins with the aircraft setting-up at steady level trimmed flight with speedbrake extended at a Mach number slightly greater than the test Mach number; typically $M_{S T A R T}=M_{T E S T}+0.03$. The throttle is then ramped down to flight idle setting over one second. A one second ramp was used to reduce unwanted, large transitory thrust responses. The aircraft begins decelerating in a minimum thrust/maximum drag configuration. When the test Mach number is reached, a step command is applied to the throttle, from the flight idle setting to maximum afterburner, while simultaneously retracting the speedbrake (Figure 3.1). The resulting acceleration is maintained, holding altitude constant, until the net axial force reaches amaximum value. This typically requires approximately three seconds from the beginning of the maneuver. 


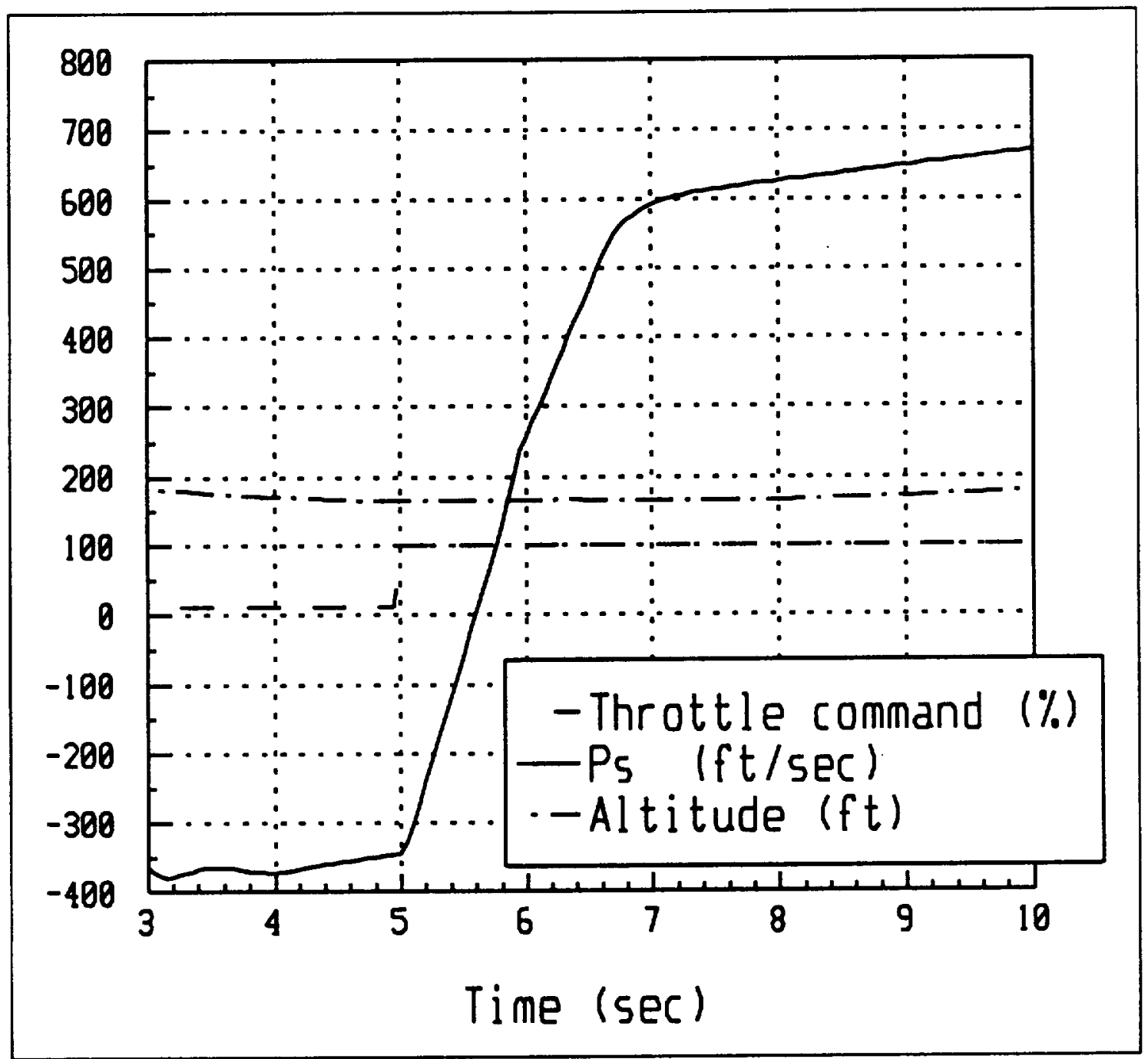

Figure 3.1: Axial Acceleration Example, Mach .6, S.L. 
The entire test case from dynamic settling (trim), set-up, and maneuver requires approximately ten seconds. A typical family of $P_{3}$ curves is displayed

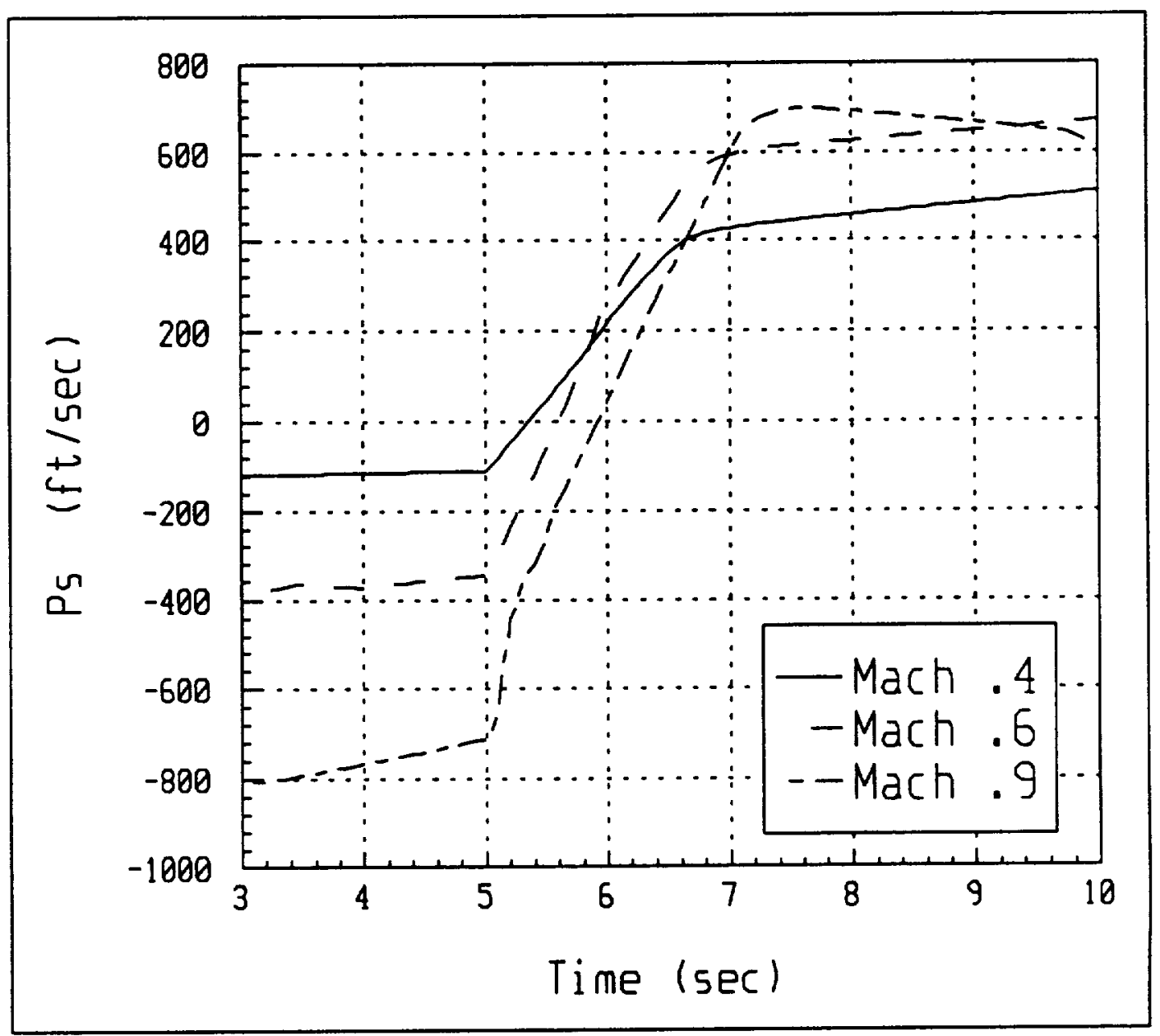

Figure 3.2: Axial Acceleration, Mach .4 - .9, S.L.

in Figure 3.2.

The test case for the power loss parameter is similar to that of the power onset parameter, except that the aircraft accelerates up to the test Mach number 


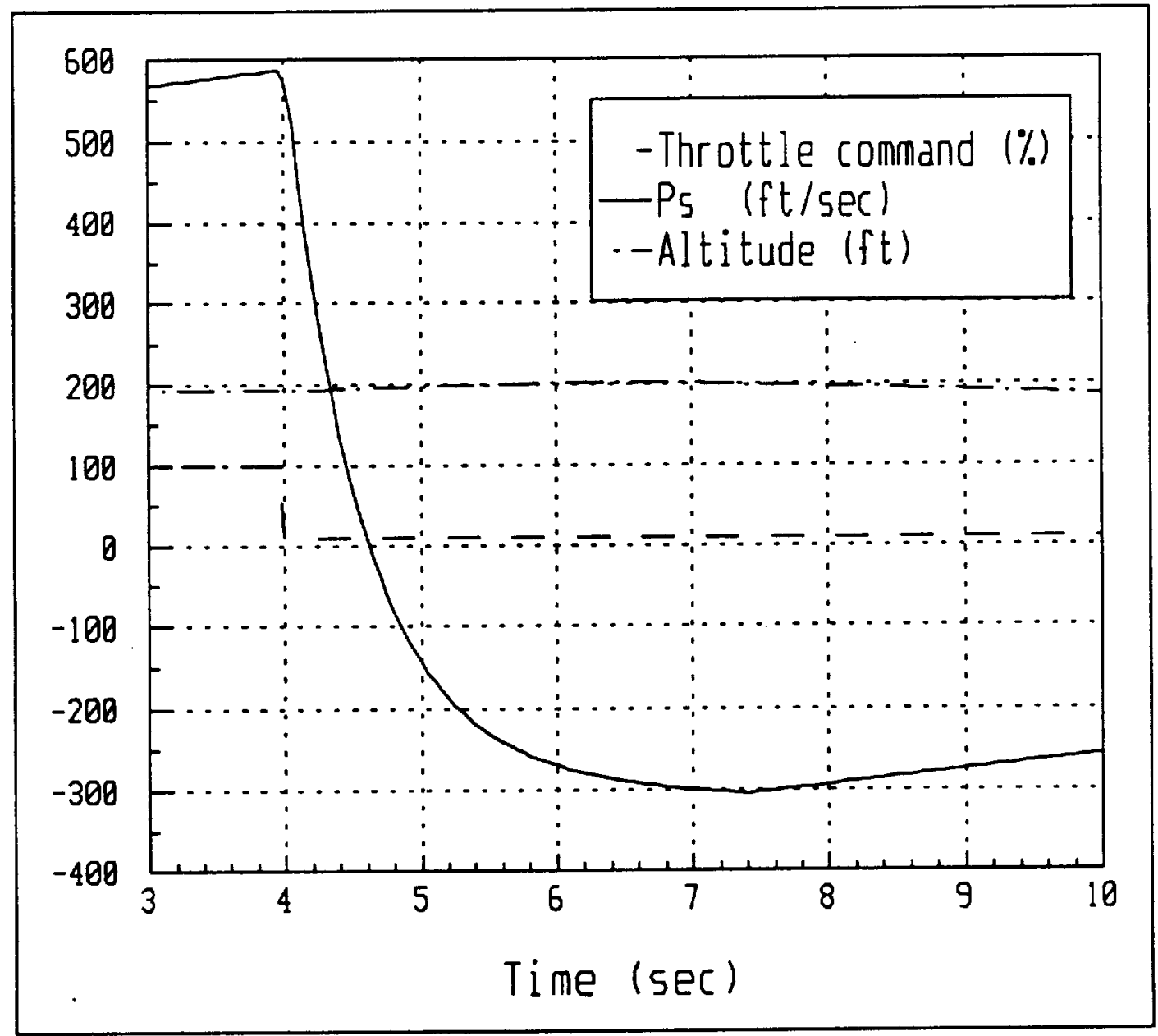

Figure 3.3: Axial Deceleration Example, Mach .6, S.L.

at maximum throttle setting with the speedbrake retracted. Upon reaching $\mathrm{M}_{\mathrm{TEST}}$, the throttle command is stepped from maximum setting to flight idle while simultaneously extending the speedbrake (Figure 3.3). Thrust reversing would be also engaged at this point if the aircraft was so equipped. Altitude is held constant during the deceleration using the altitude hold mode of the autopilot until net axial force reaches a minimum. This requires approximately 


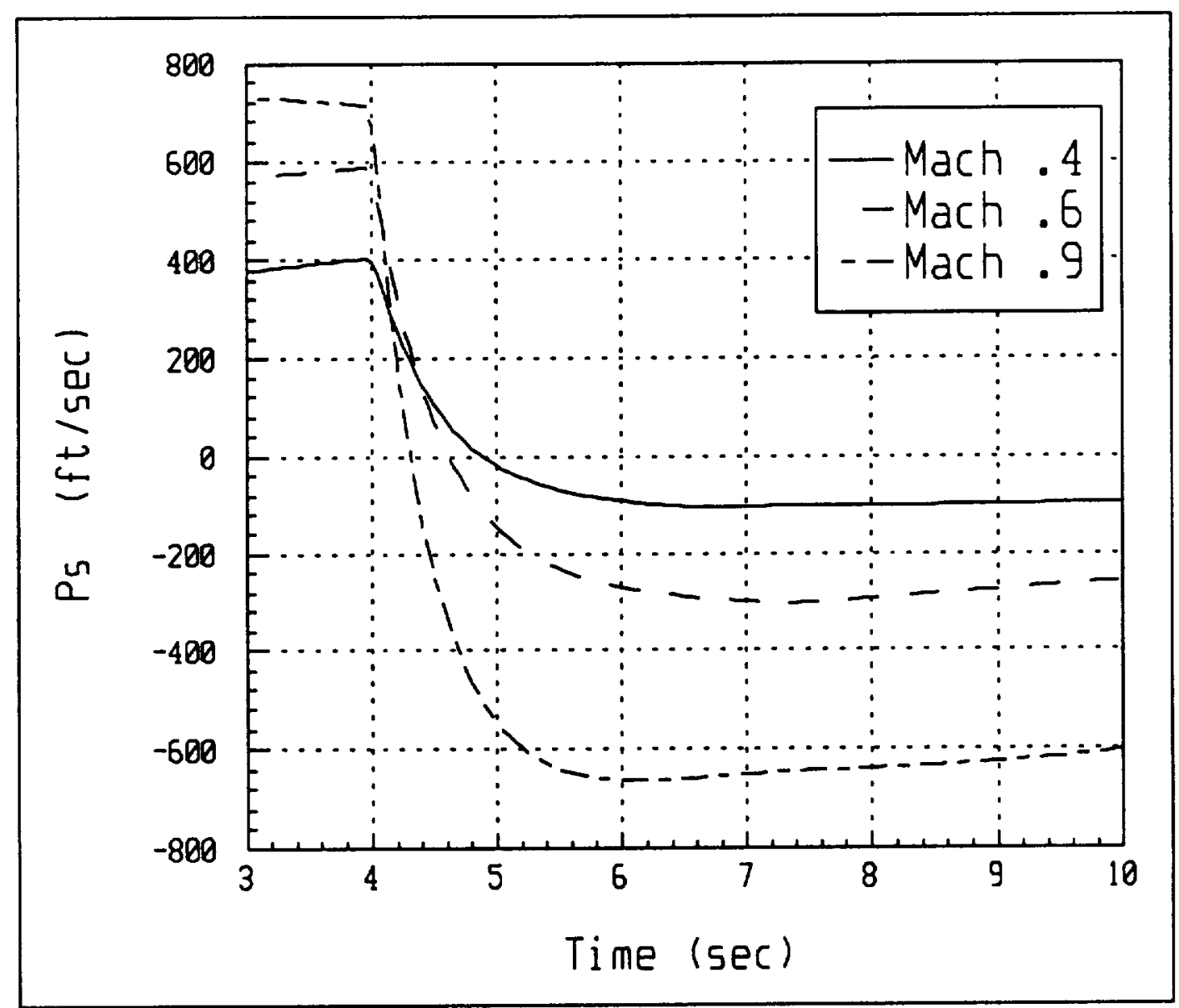

Figure 3.4: Axial Deceleration, Mach .4 - .9, S.L.

three seconds. The entire test case from dynamic settling, set-up, and maneuver requires approximately ten seconds. A typical family of $P_{S}$ curves is displayed in Figure 3.4.

The power loss parameter is intended to measure the effectiveness and response times of the engine and drag producing devices of the aircraft. While 
it is possible to generate large amounts of drag very quickly by pitching to high angles of attack, such a maneuver was not considered here.

Both the power onset parameter and the power loss parameter tests were simulated at sea level, 15,000 feet and 30,000 feet and at Mach numbers from 0.4 to 0.9 . The Mach numbers were selected to be representative of the range of speeds at which aircraft would most likely be engaged in close air combat. The altitudes were selected with air combat in mind also. Sea level, 15,000 feet and 30,000 feet were chosen. The 15,000 feet altitude was specifically selected because Eidetics International presents much of their data at this condition (Reference 9). Both the acceleration and deceleration maneuvers described in this Section are designed to quantify the agility of the airframe. The utility or acceptability of the maneuvers to an operational pilot and the flying qualities he would encounter during the maneuver are not addressed here.

\subsubsection{Axial Agility Data Reduction Methods}

The data reduction methods for the power onset and power loss parameters are straightforward in concept but can contain some uncertainty. In order to automate the data reduction process, the simulation was programmed to output time histories of $P_{S}$ and net axial force every 25 milliseconds in addition to the usual time histories of state variables. 
The equation for the power onset parameter is

$$
\frac{\Delta P_{s}}{\Delta t}=\frac{P_{s_{f}}-P_{s_{i}}}{t_{f}-t_{i}}
$$

where

$$
\begin{aligned}
& P_{s_{i}}=P_{s} \text { at the minimum value of thrust minus drag } \\
& P_{s_{f}}=P_{s} \text { at the maximum value of thrust minus drag } \\
& t_{i}=\text { time at which thrust minus drag is minimum } \\
& t_{f}=\text { time at which thrust minus drag is maximum }
\end{aligned}
$$

Whereas thrust minus drag attains easily identifiable minimum values, the maximum values in many instances are approached asymptotically. Clearly, a criteria are required to define the maximum value in such instances. A method which is easy to use and gives the best results is to examine the difference between successive values of thrust minus drag. When four successive data points are identified which do not differ by more than approximately ten pounds between any successive point, the fourth point is selected to represent the maximum value. The value of ten pounds was chosen so that the maxima that are apparent when the data is examined visually closely match those calculated by the simulation algorithm. With respect to th a magnitudes and time intervals of the data, ten pounds is a reasonable tolerance band. Figure 3.5 displays the 


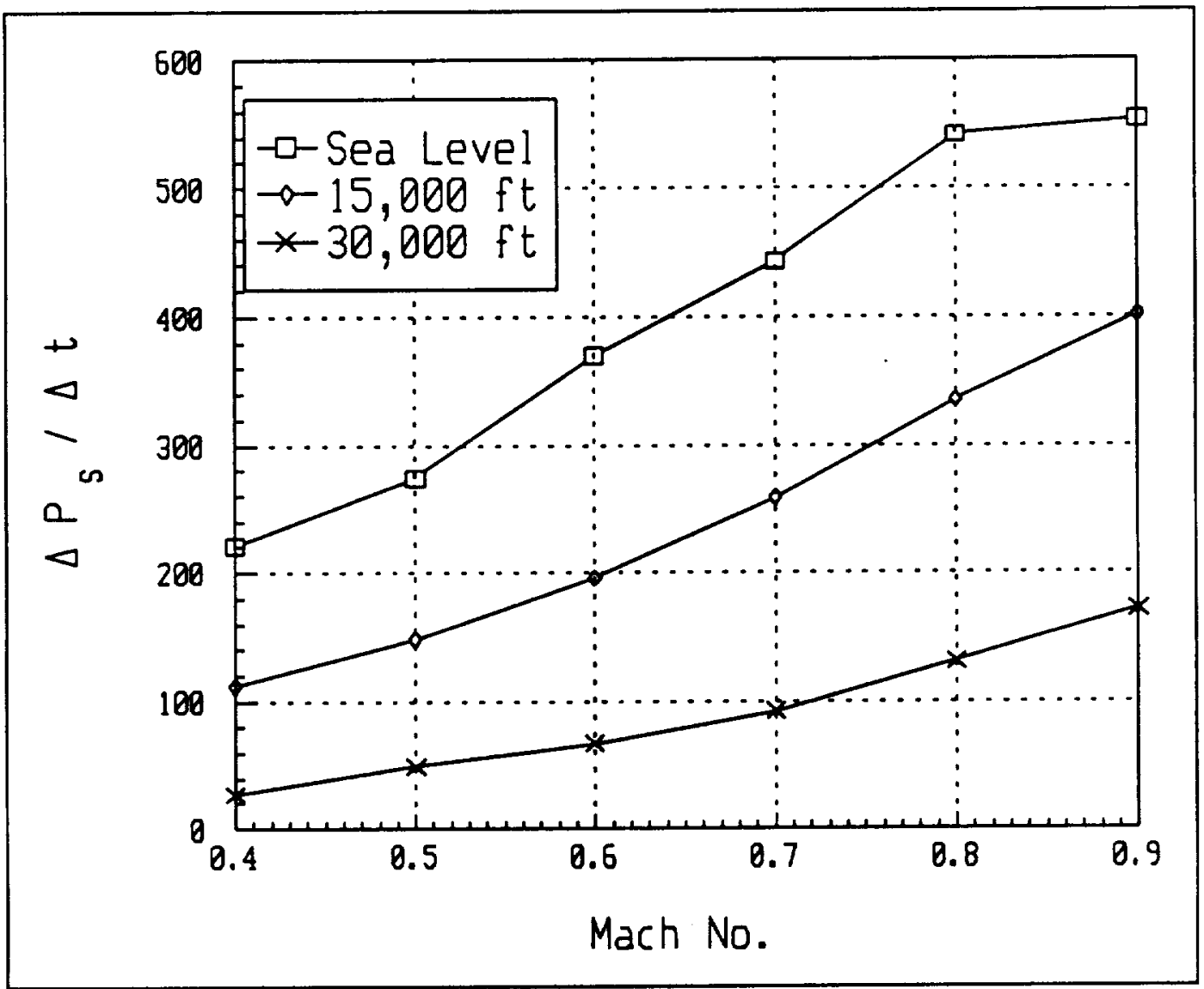

Figure 3.5: Power Onset Parameter

power onset parameter in curves of constant altitude for different Mach numbers. At lower altitudes, the F-18 possesses a greater acceleration capability. This is due to the larger difference between flight idle thrust and maximum thrust at these altitudes. As expected, the acceleration capability is proportional to Mach number for a given altitude.

The computation of the power loss parameter is completely analogous to that of the power onset parameter. The power loss parameter is plotted 


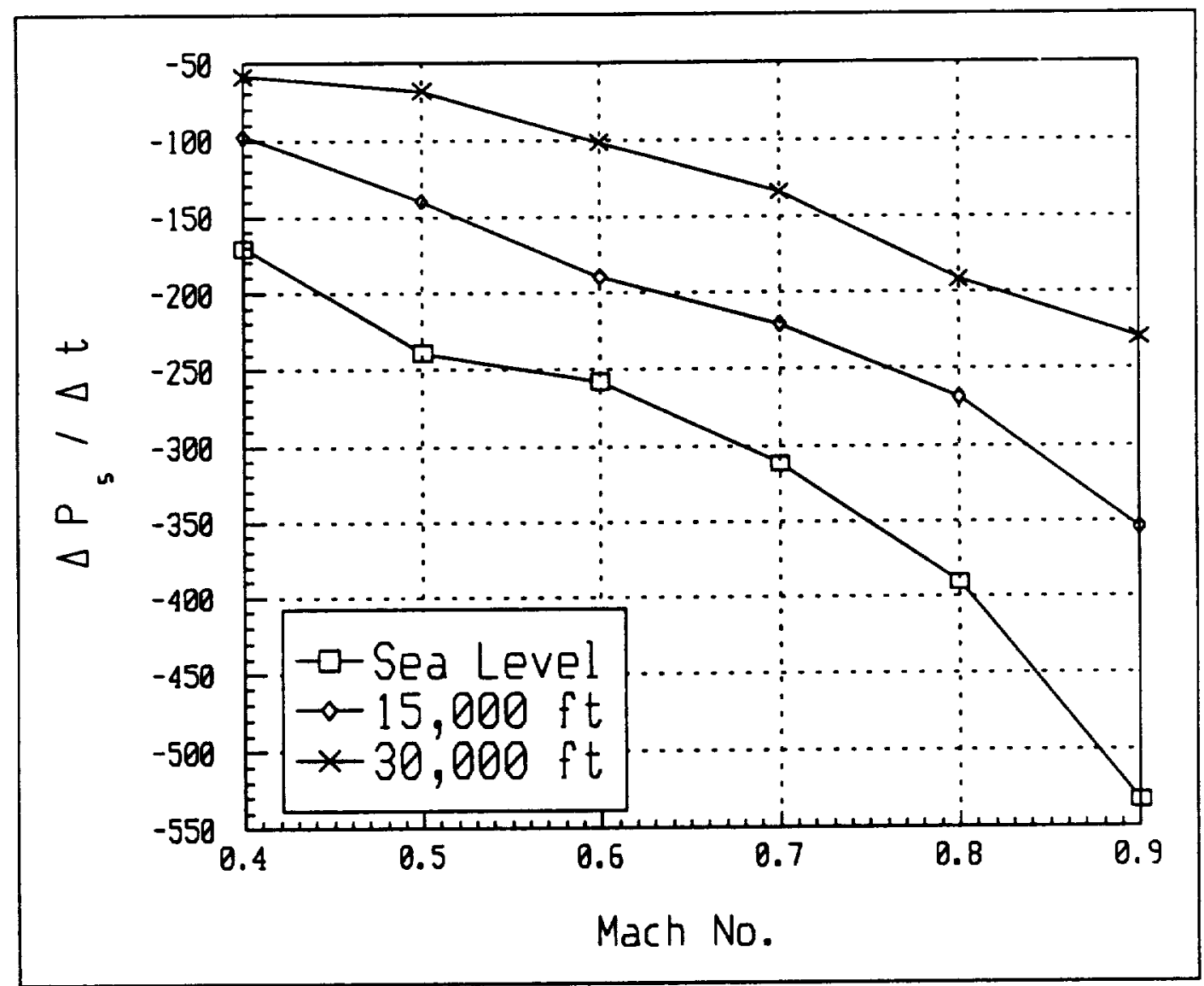

Figure 3.6: Power Loss Parameter

versus Mach number for curves of constant altitude in Figure 3.6. The greatest deceleration capability is seen to be at lower altitudes, due again to the larger difference between flight idle thrust and maximum thrust and the increased drag at higher dynamic pressures. The deceleration capability is again proportional to Mach number for a given altitude. 


\subsection{Pitch Agility}

\subsubsection{Introduction}

Pitch agility as originally postulated by Eidetics consists of "time required to pitch up to maximum lift or to unload to zero g's or to rapidly change to any desired angle of attack" (Reference 9). Alternate ways of measuring pitch agility are

1) MBB's curvature agility (Reference 26),

2) the time derivative of load factor (Reference 26),

3) the time to capture an angle of attack,

4) the time to change pitch attitude (Reference 16), and

5) maximum nose up and nose down pitch rates (Reference 9).

During subsequent discussion of pitch agility (at the AFFDL Agility Workshop, Aug 89, for example), time to capture a specified angle of attack was generally rejected as a useful metric. Its primary disadvantage is the difficulty in accurately capturing a specified angle of attack during flight test. A secondary disadvantage is that the time to capture angle of attack is not an appropriate quantity for comparison among dissimilar aircraft. Also, aircraft normal acceleration is generated by lift, which is a function angle of attack and lift curve slope. This metric neglects the lift curve (lift versus angle of attack) 
characteristics of the aircraft. For these reasons, the time required to capture a specified angle of attack is not studied further in this report.

Time to change pitch attitude has been flight tested by students at the USAF Test Pilots School (Reference 16). During that study, pitch angle changes of $-45^{\circ}$ to $45^{\circ}$ and $-30^{\circ}$ to $30^{\circ}$ were flown. Pilots and flight test engineers involved in that evaluation concluded that time to change pitch attitude was unsuitable due to the large changes in airspeed and altitude that occurred during the maneuver.

The time derivative of load factor, though difficult to measure directly, can, in theory, be extracted from flight test or simulation time histories. Since both pitch up and pitch down capability are tactically important, the rate of change of load factor during both types of maneuvers are investigated in this report. It has been shown (Reference 26) that time histories of load factor derivative and MBB's curvature agility metric are virtually identical when scaled to account for different units. No further discussion of curvature agility is included in this report since its technical definition and derivation are not available in the open literature. 


\subsubsection{Published Pitch Agility Metrics}

Based on this discussion, three of the published metrics that quantify pitch agility are investigated here:

1) time to load to maximum load factor and to unload to zero load factor,

2) positive and negative load factor rate, and

3) pitch rates during maximum authority pitch up and pitch down maneuvers.

All three measures of agility are extracted from the same simulation runs. At each flight condition investigated the aircraft was trimmed to straight and level flight. Step inputs of 5 inches (maximum aft deflection) were applied to the longitudinal stick and held for two seconds. Forward stick was then applied to pitch down to zero load factor. A typical simulation time history from one these runs is shown in Figure 3.7. Time to load, unload and the associated pitch rates and load factor rates are then extracted and plotted.

Note that the test technique described above is adequate only for aircraft like the F-16 and F-18 whose flight control systems incorporate hard load factor limiters. Applying full aft stick in an F-4 or F-15 will, at many flight condition, result in an over stressed aircraft and pilot. As a result, it is difficult to directly compare the pitch agility of two aircraft like the F-18 and F-15 

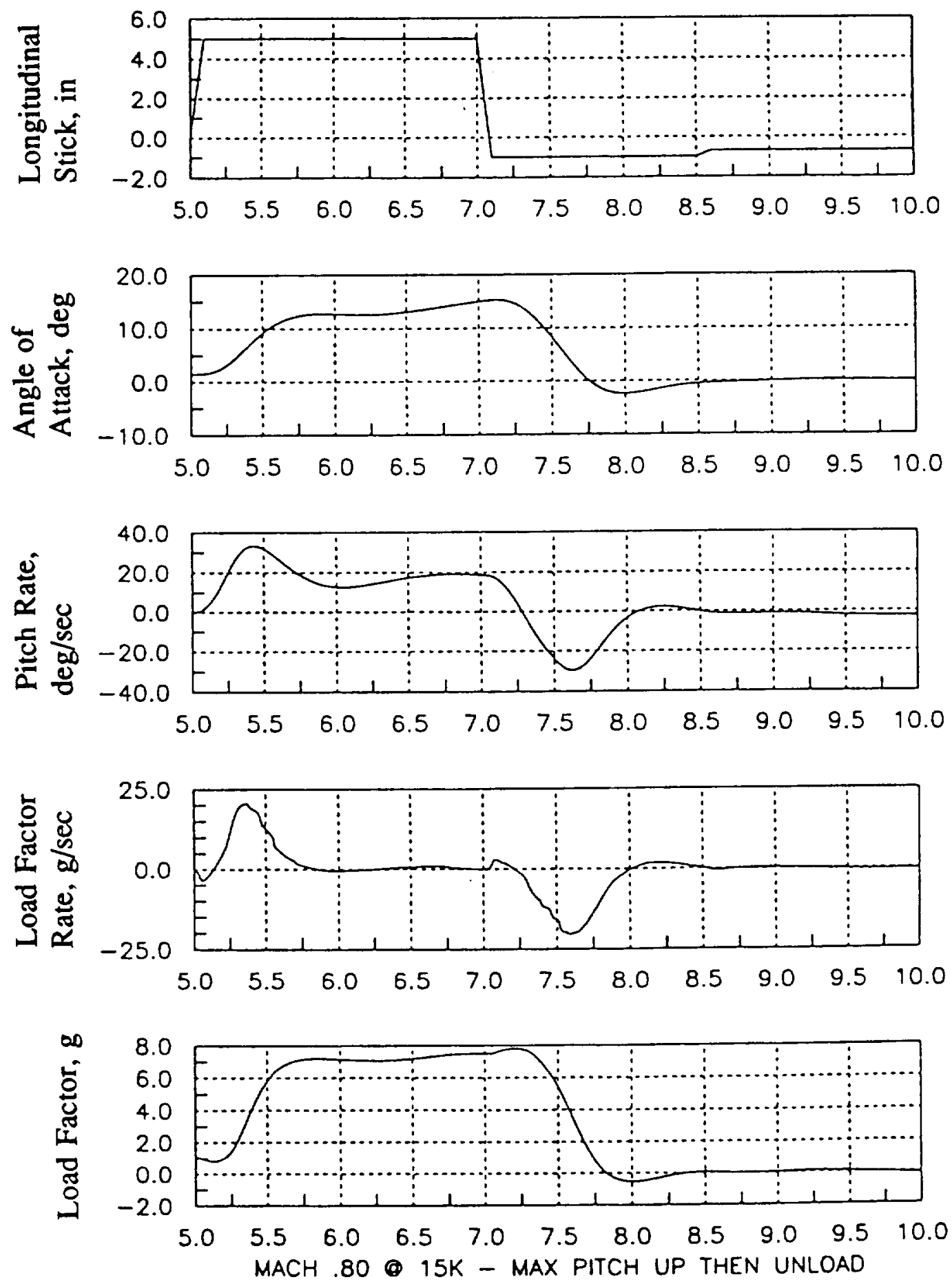

Figure 3.7: Maximum Pitch Up Time History 
whose flight control systems are fundamentally different. One option is to define the maximum surface deflection permissible for each aircraft at a given flight condition and then base the agility measurement on that deflection rather than on maximum stick input. This would make flight test much more difficult since the pilot has only indirect control of surface deflection and no information about surface position is available to the pilot during flight. Also, this method would not account for the effects of surfaces like maneuvering flaps that operate on the F-18 but are not available on the F-15.

In the following paragraphs each of the three published metrics is evaluated in both the nose up and nose down directions. Results are shown at three representative altitudes over a range of subsonic Mach numbers.

First, time to attain maximum load factor and time to unload from maximum load factor are plotted against Mach number for altitudes of $0,15,000$ feet and 40,000 feet in Figures 3.8 and 3.9. These two figures show that pitch agility, as measured by the time to achieve maximum load factor and the time to unload from maximum load factor, is a strong function of Mach and altitude. At any altitude, the aircraft's normal acceleration due to angle of attack increases with Mach number so the resulting time to both load and unload is smaller, even in cases where the pitch rates at each Mach number are nearly the same. 


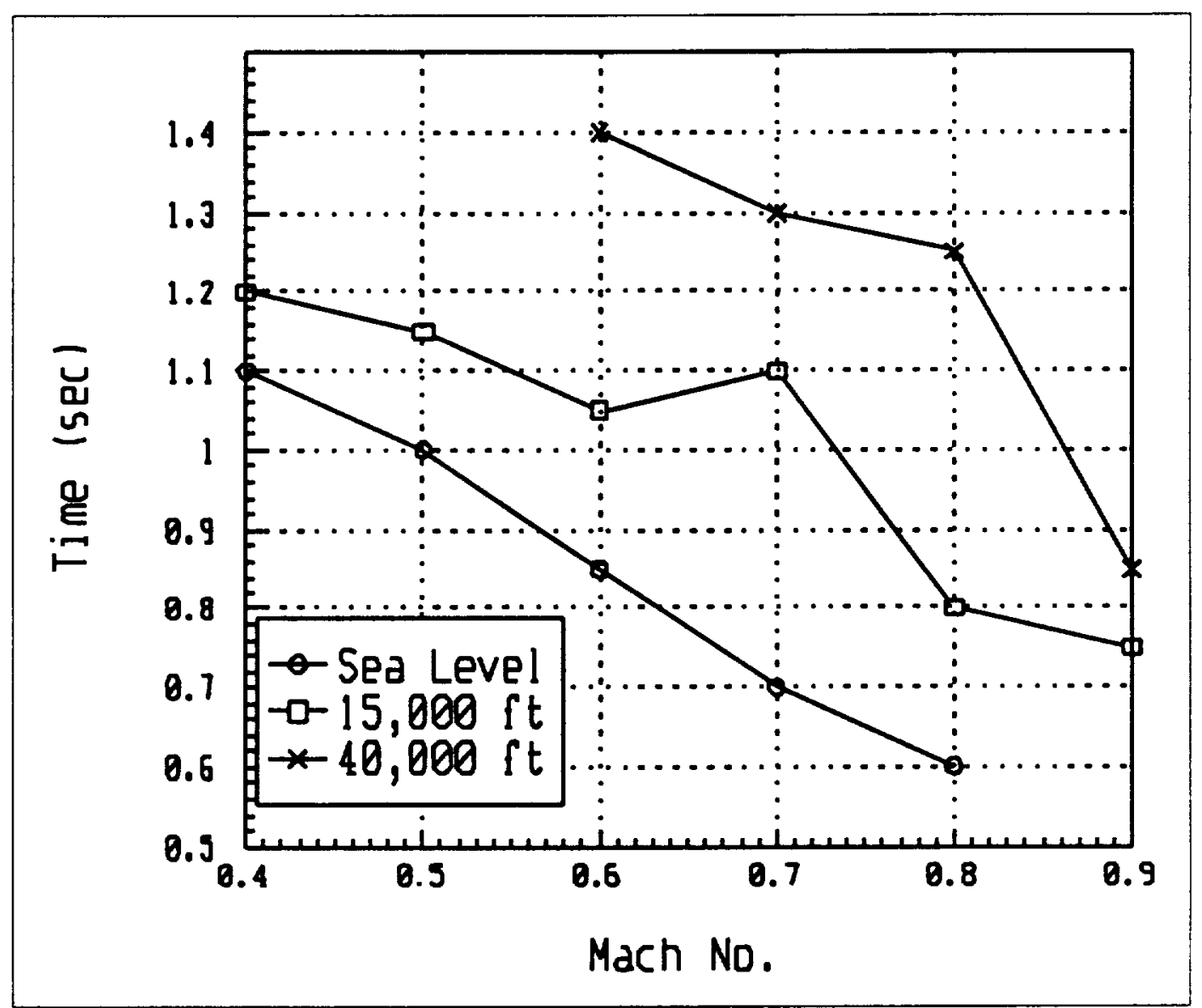

Figure 3.8: Time to Pitch to Maximum Load Factor

The 15,000 feet line in Figure 3.8 illustrates a shortcoming of the timeto-maximum load factor metric. Contrary to the indications from Figure 3.8, the F-18 is not slower to achieve positive load factor at Mach .7 then it is at Mach .6. Load factor onset is actually faster at Mach .7 but the maximum peak load factor is higher so the time to reach that peak is slightly longer. If the time to maximum load factor is used to compare the agility of dissimilar 


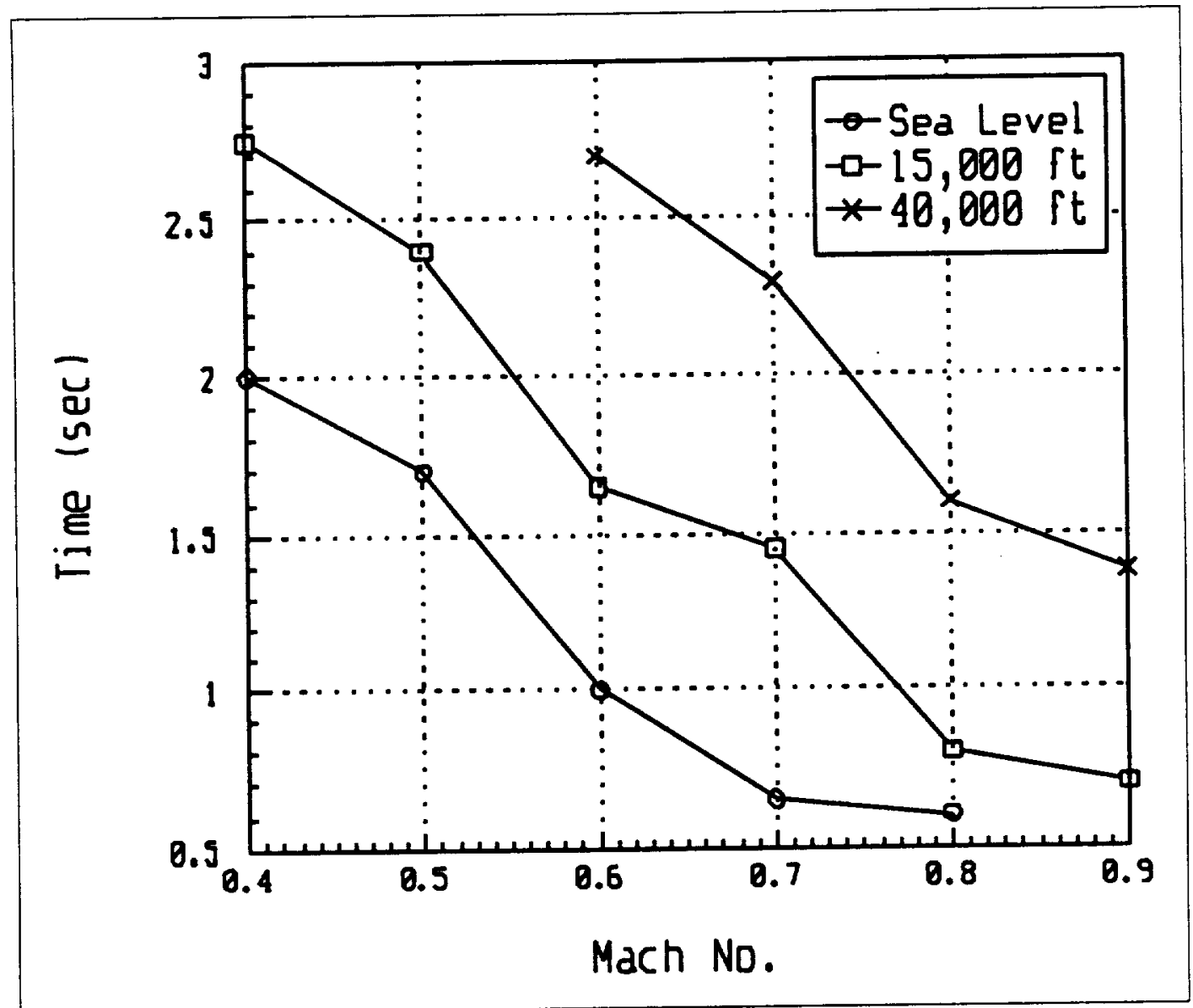

Figure 3.9: Time to Pitch From Max Load Factor to $0 \mathrm{G}$

aircraft, misleading results could occur at flight conditions where the maximum load factors of the aircraft are different.

A comparison of Figure 3.8 to Figure 3.9 also suggests that the F-18 is significantly more agile in the nose up direction then in nose down pitching motion. At lower Mach numbers, the aircraft requires about twice as long to unload from maximum $\mathrm{n}_{\mathrm{z}}$ as it does to pitch from straight and level flight to 
maximum load factor. This result was also noted by Eidetics International (Reference 9). Their brief analysis of several current fighter aircraft indicates that all of them possess much less nose down than nose up pitch agility. If pitch agility in both directions is important to an operational pilot, then nose down pitch authority is a promising candidate for improvement.

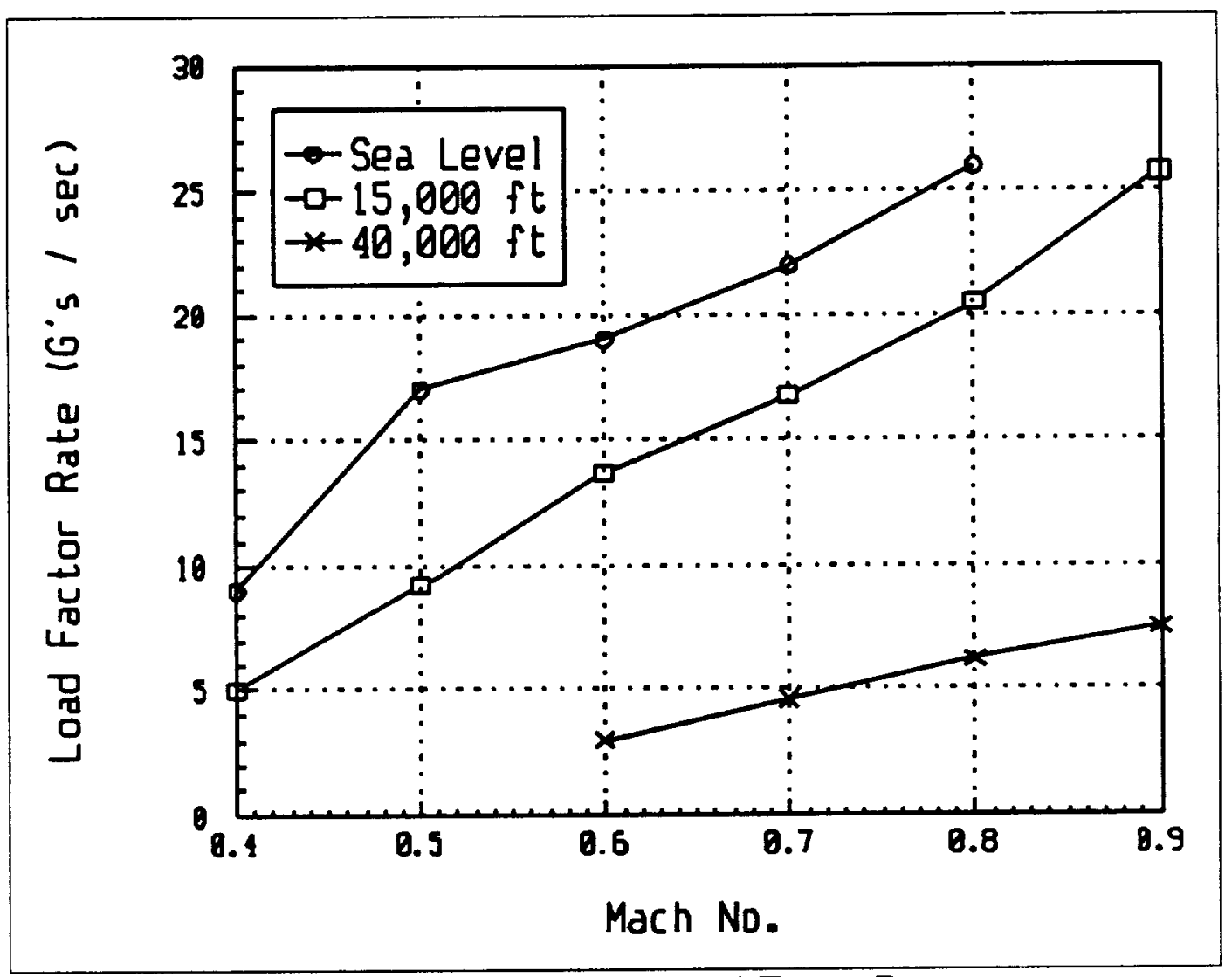

Figure 3.10: Maximum Load Factor Rate

Next, the maximum positive load factor rate generated during pitch up and the maximum negative rate generated during an unloading maneuver are 


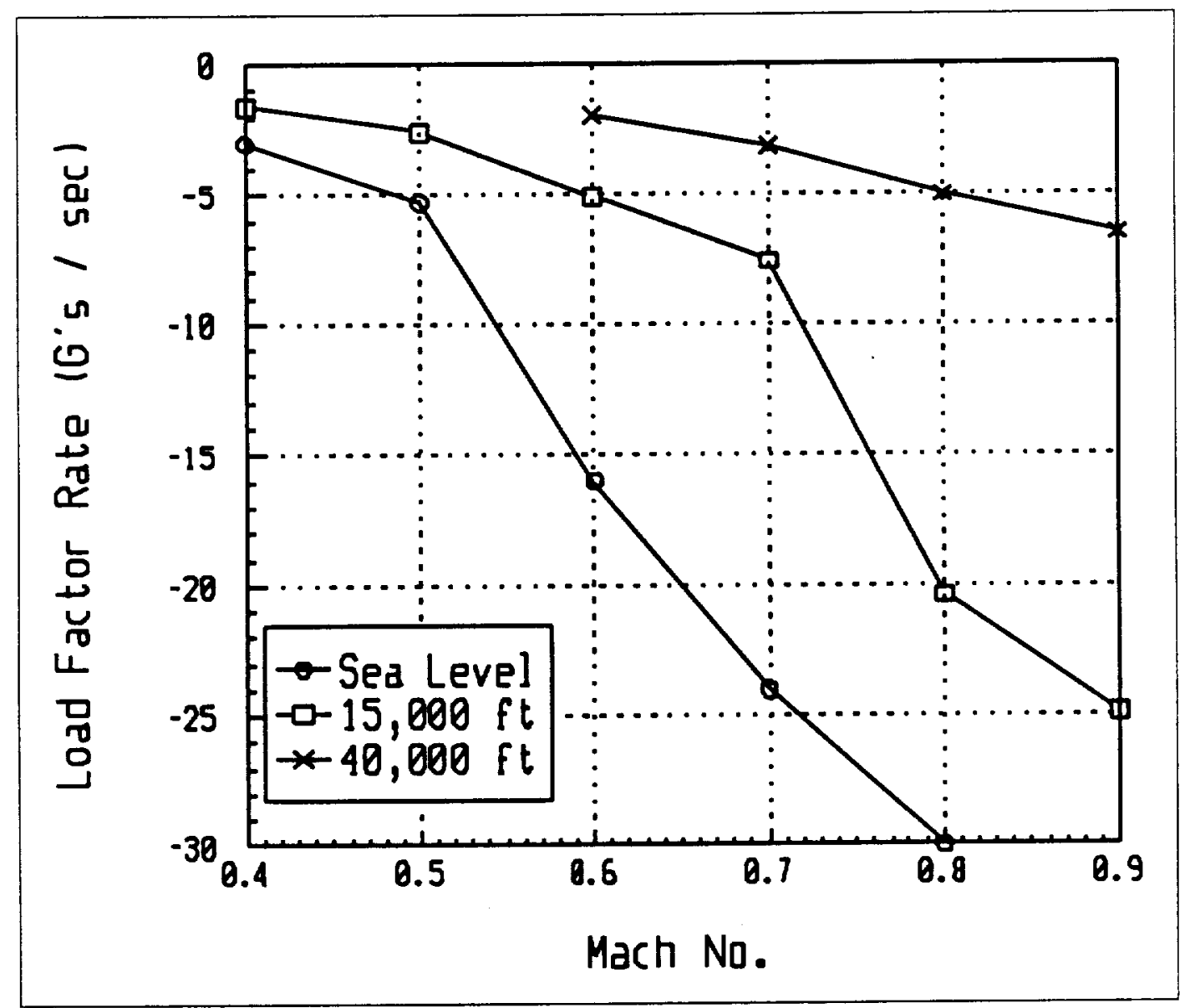

Figure 3.11: Minimum Load Factor Rate

again plotted against Mach and altitude in Figures 3.10 and 3.11. These figures reflect the same dependence on Mach and altitude that was seen in the "time-toload-factor" results of the previous paragraph. The load factor rate data shown here was obtained from the simulation with a simple differencing scheme since load factor rate is not available either as a term in the dynamic model of the aircraft or as an output of a modelled sensor. A similar approach would be 
needed to obtain this data from a flight test maneuver. In the simulation with no random atmospheric inputs, buffet or sensor noises applied, the differencing algorithm produced usable load factor rate data. Application of a differencing scheme to obtain load factor rate information from flight test would require extensive smoothing and may not be feasible. Finally, the maximum nose up pitch rate generated when pitching to maximum load factor and the maximum nose down pitch rate encountered while pitching down from maximum to zero load factor are again plotted against Mach and altitude in Figures 3.12 and 3.13. 


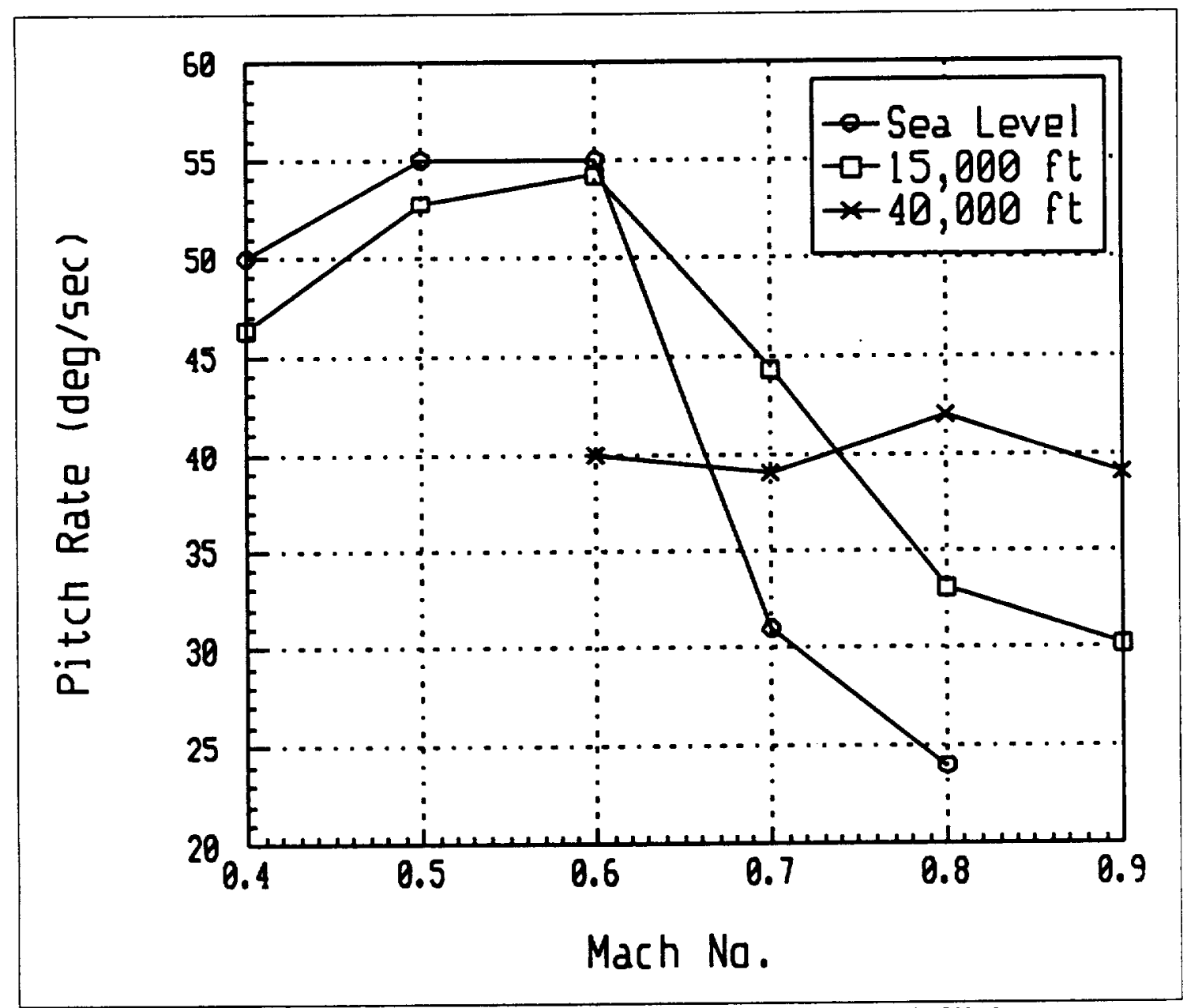

Figure 3.12: Max Pitch Rate From Steady Level Flight 
The effects of limiters in the flight control system are evident in these figures. At sea level and at 15,000 feet, pitch rate is reduced above Mach .6 to prevent the aircraft from exceeding its limit load factor (see Figure 2.1). At 40,000 feet the aircraft is restricted by available lift to less than its structural limit so no flight control limiting is needed. High positive and negative pitch capability is available throughout the subsonic Mach range at this altitude.

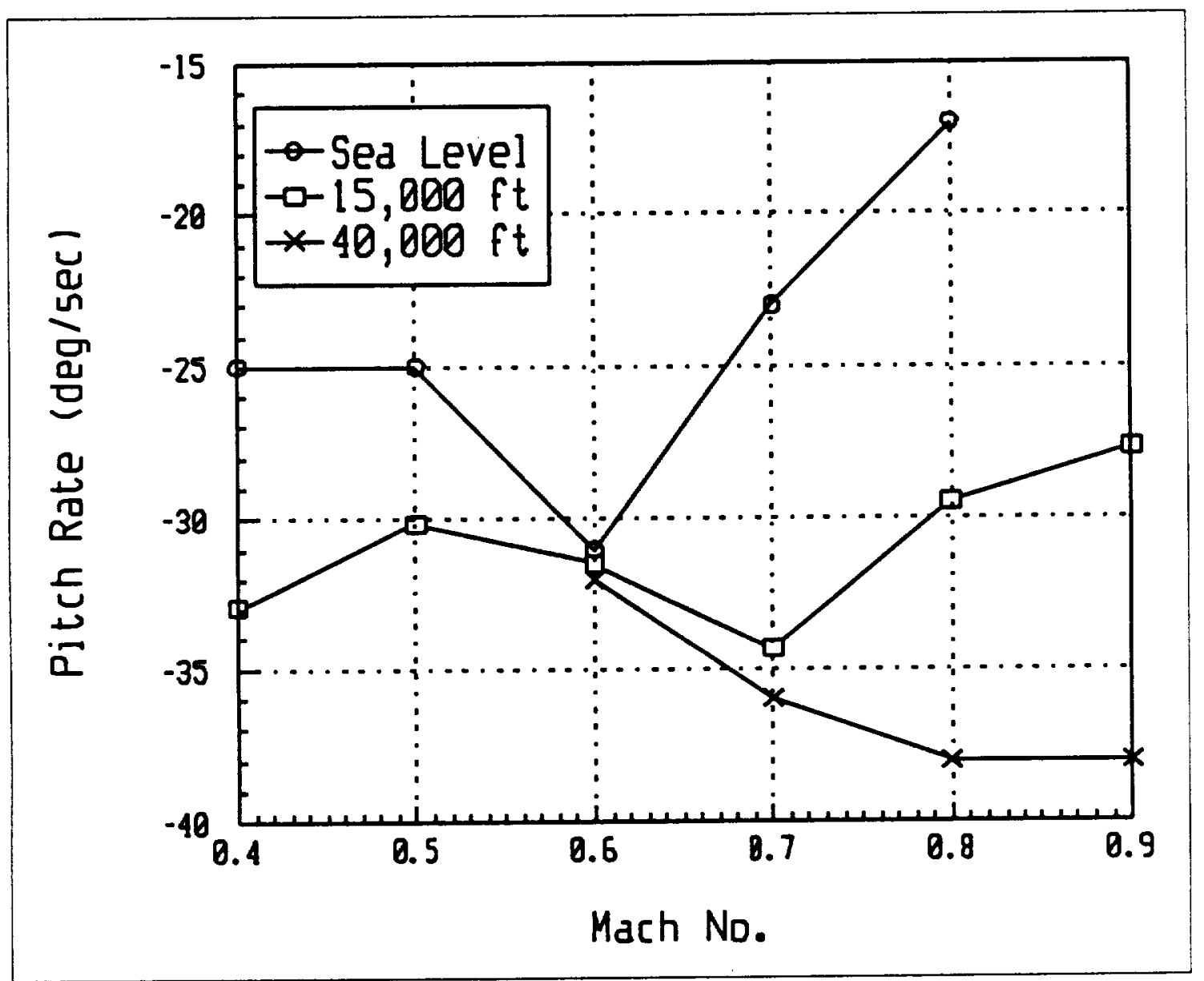

Figure 3.13: Max Neg. Pitch Rate During Unload 
At many flight conditions, maximum load factor cannot be held during the two second input step. In these cases, aircraft deceleration causes load factor to decrease immediately after the peak is achieved and before the pitch down command is initiated. Time to pitch down as shown here is calculated from the time forward stick is input not from the time that load factor begins to decay due to airspeed loss. This method minimizes the influence of aircraft drag characteristics on pitch agility measurements and emphasizes nose down pitch authority.

The time to achieve maximum load factor and the time to unload metrics may have limited value for comparison among dissimilar aircraft or even among various flight conditions for the same aircraft because the maximum load factors themselves are different. For example, consider two dissimilar aircraft, one with a $5 \mathrm{~g}$ limit and the other with a $9 \mathrm{~g}$ capability at the same flight condition. If each were equally agile in terms of load factor rate, the first aircraft would have a smaller time to maximum load factor since the maximum is lower. Likewise, the F-18 simulation at 15,000 feet altitude demonstrates the same time to maximum load factor at Mach .6 and Mach .7. The reason for this apparent anomaly is that at Mach .7 the aircraft has both a higher load factor rate and a higher maximum load factor. 
In light of the shortcomings of the time to achieve load factor and the load factor rate metrics, maximum positive and negative pitch rate appear to be the most useful measures of longitudinal transient agility. Pitch rate is only an indirect measure of the aircraft's ability to generate normal acceleration and to unload to zero load factor quickly. Differences in lift curve slopes are neglected as they would be in measuring time to capture angle of attack. However, pitch rate is a direct measure of the pilot's ability to move the nose of his aircraft which is a significant capability particularly during within-visualrange engagements.

\subsubsection{Pitch Rate versus Angle of Attack Metric}

If maximum positive and negative pitch rates are used to quantify pitch agility, then the flight maneuvers used previously are not adequate to fully evaluate this capability. A full deflection aft stick input followed by pitch down to zero load factor results in pitch rate data at only one angle of attack for each flight condition. A more complete picture would show pitch rate versus initial angle of attack at representative flight conditions. A proposed flight test maneuver consists of pitching the aircraft with incremental longitudinal stick inputs. Then sull aft (or forward if nose down rates are being studied) stick is applied. Maximum pitch rate is recorded and plotted against 


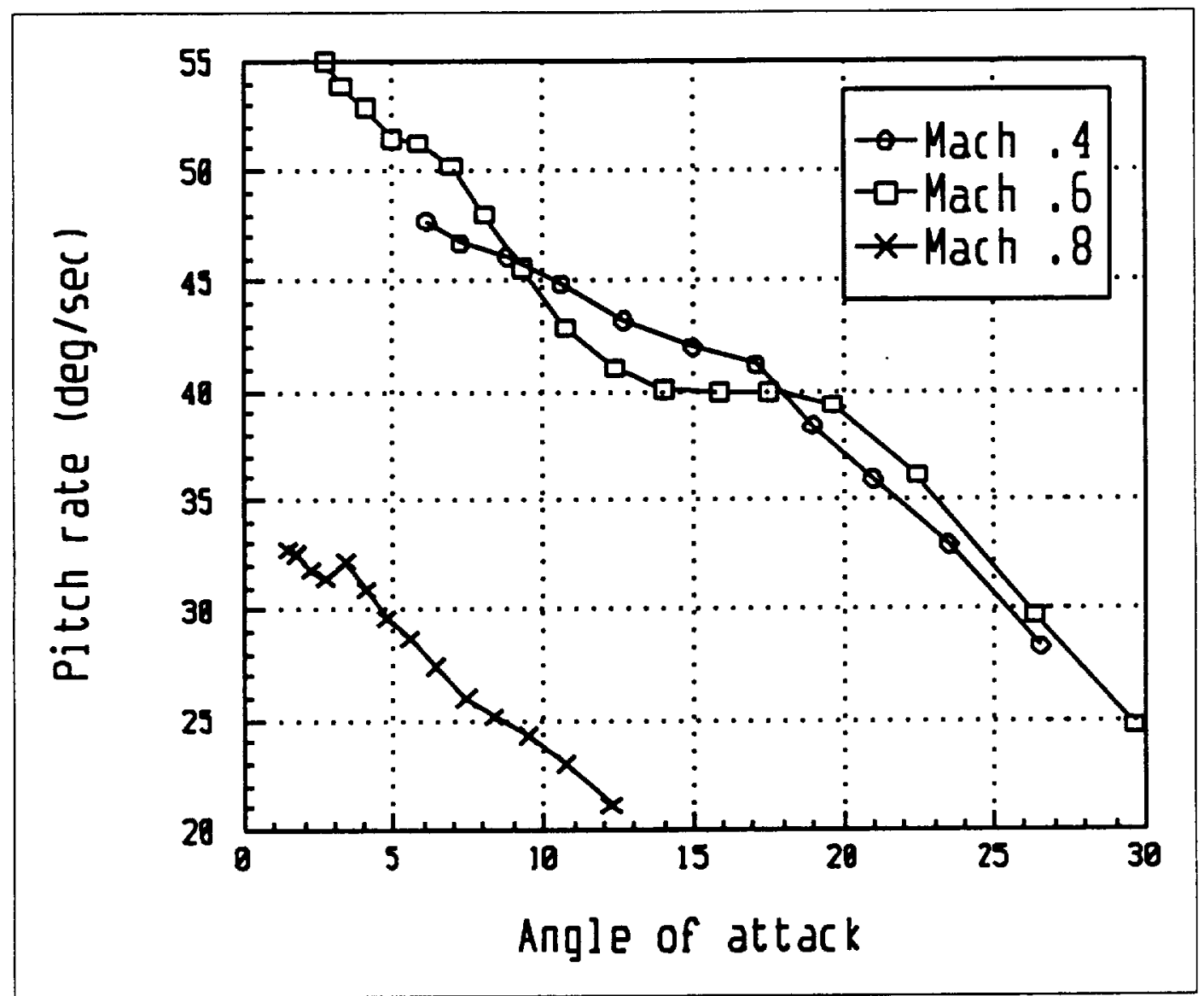

Figure 3.14: Maximum Pitch Rate Capability, 15,000 ft

the angle of attack from which the maximum rate command was initiated. The full deflection inputs should follow the initial incremental steps quickly enough that aircraft Mach and altitude remain within acceptable flight test tolerances. The simulation results from this procedure at 15,000 feet are summarized in Figures 3.14 and 3.15 .

The trends for each Mach number in Figure 3.14 show that as the initial angle of attack is increased, the pitching moment authority remaining available 


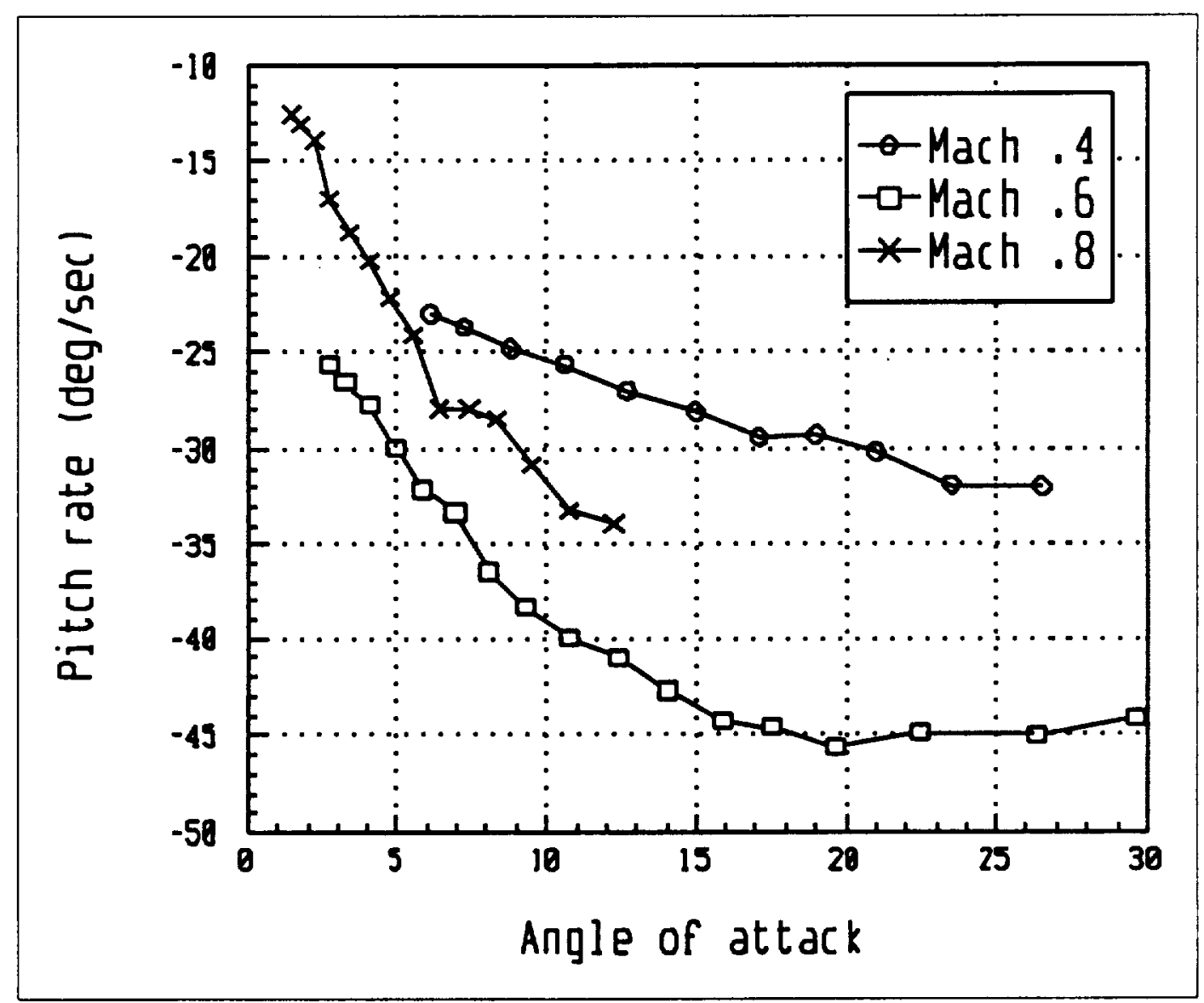

Figure 3.15: Minimum Pitch Rate Capability, 15,000 ft

to generate nose up pitch rate is reduced. The effect of flight control limiting is also evident in this Figure. Pitch rates at Mach .8 are restricted to prevent the aircraft from exceeding its structural limit. At Mach .4 and .6 at 15,000 feet altitude, maximum lift will not over stress the aircraft so pitch rate needs not be limited.

Figure 3.15 shows hat available nose down pitch rate is greater when the maneuver is initiated from higher angles of attack. This is due both to the 
natural stability of the aircraft (negative $\mathrm{Cm}_{\alpha}$ ) and the larger net pitch control surface deflections made when pitching down from higher angles of attack. Some pitch rate limiting is also evident in Figure 3.15 since nose down pitch rates at Mach .8 are consistently slower than for Mach .6

Advantages of the pitch rate versus angle of attack approach are first, that a more complete picture of the aircraft's nose pointing ability is available. Secondly, since the pilot is not required to capture a specific angle of attack or load factor, his inputs are simpler and more repeatable. Aircraft characteristics are highlighted and the impact of individual pilot technique is minimized. The ability to quickly and accurately capture a desired pitch attitude is, of course, important. However, that is a flying qualities problem as well as to an agility issue and is measured with well known Handling Qualities During Tracking (HQDT) methods (Reference 32, 33).

Just as in the axial case, these longitudinal metrics and the maneuvers described here are designed to quantify the agility of the aircraft. The acceptability of such maneuvers to an operational pilot and all the associated issues of flying qualities, pilot discomfort and g-induced loss of consciousness require further research. 


\subsection{Lateral Agility}

\subsubsection{Introduction}

Lateral agility is a measure of an airplane's agility in the roll axis. This agility is a function of Mach number, angle of attack and altitude. A roll that is performed while holding angle of attack, and thus load factor, is called a "loaded roll." A coordinated roll (zero sideslip) performed at constant angle of attack is often called a "roll about the velocity vector" or a "wind axis roll." Lateral agility measures an airplane's ability to perform a loaded roll maneuver and is limited by both the roll authority of the aircraft and the ability of the pilot and flight control system to counter the effects of cross axis coupling into the pitch and yaw axes. Coupling is introduced through aerodynamic terms (e.g. yawing moment due to aileron deflection, rolling moment due to yaw rate, etc.), and kinematic cross coupling and inertial cross coupling.

Figure 3.16 graphically describes the kinematics of a loaded roll (Reference 34). Assuming, for this illustration, that the aircraft rolls about its body axis (that is, neglecting the influence of stability and inertia), the initial positive angle of attack is converted to an equal sideslip angle as the aircraft rolls from position I to II. If the roll is continued, negative angle of attack and sideslip also result. Ass ıming small angles and omitting $\mathrm{Y}$ and $\mathrm{Z}$ axes forces, the angle of attack and sideslip rates induced by kinematic coupling are 


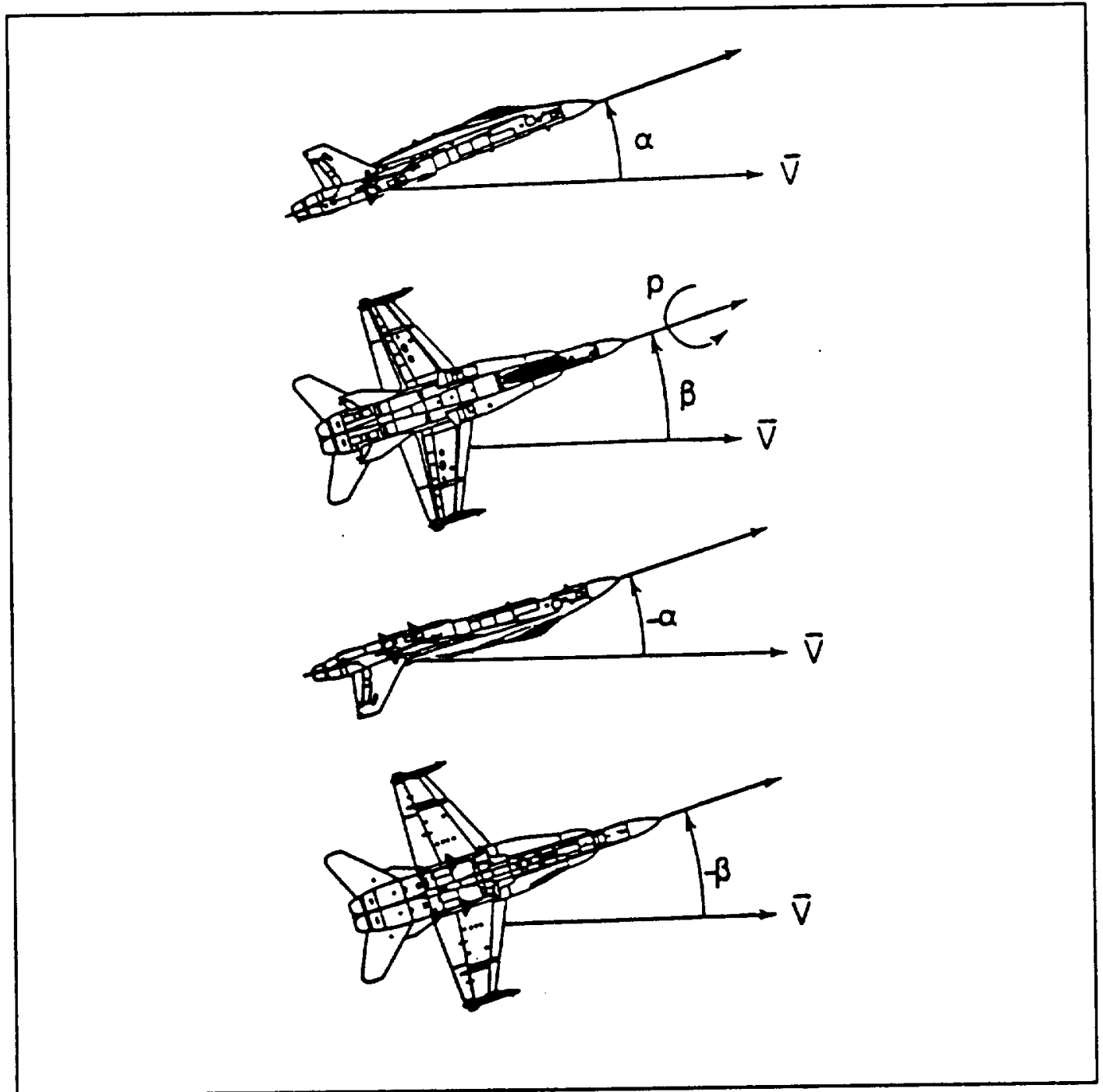

Figure 3.16: Kinematics of a Loaded Roll

approximated by

$$
\dot{\boldsymbol{\alpha}}=\mathbf{q}-\mathbf{p} \boldsymbol{\beta}
$$

and 


$$
\dot{\boldsymbol{\beta}}=\mathbf{p} \boldsymbol{\alpha}-\mathbf{r}
$$

The origins of inertial coupling can be seen in those terms of the moment equations of motion where rotation rates about two axes cause rotational accelerations about the third axis. Those terms are extracted from the full equations of motion and are listed below.

$$
\dot{p}_{\text {coupling }}=-q r\left(\frac{\left(I_{z}-I_{y}\right)}{I_{x}}\right)+(t+q p) \frac{I_{x z}}{I_{x}}
$$

$$
\dot{q}_{\text {coupling }}=-p r\left(\frac{\left(I_{x}-I_{z}\right)}{I_{y}}\right)-\left(p^{2}-r^{2}\right) \frac{I_{x z}}{I_{y}}
$$

$$
\dot{r}_{\text {coupling }}=-p q\left(\frac{\left(I_{y}-I_{z}\right)}{I_{z}}\right)-(q r-\dot{p}) \frac{I_{x z}}{I_{z}}
$$

The first term in earh expression above indicates that inertial coupling is proportional to the difference between the aircraft's $\mathrm{Z}$ axis moment of inertia 
and its $X$ axis moment of inertia $\left(I_{z}-I_{x}\right)$. As fighter designs have evolved toward shorter, thinner wings with more mass concentrated along the longitudinal axis, this difference has become more significant.

Cross coupling into all three axes of rotation is also introduced through the product of inertia term, $I_{x z}$, in each of the equations above. ( $I_{x y}$ and $I_{y z}$ also appear in the complete equations of motion but are equal to zero for aircraft symmetric about the $x-z$ plane.) The $I_{x z}$ term can be viewed as a measure of how the mass is distributed above and below the plane formed by the aircraft's $\mathrm{X}$ and $\mathrm{Y}$ axes. The line about which $\mathrm{I}_{\mathrm{xz}}$ is zero is called the inertial axis and a rolling maneuver about any other axis (e.g. the stability $X$ axis) will result in pitch and yaw accelerations through the $\mathrm{I}_{\mathrm{xz}}$ terms in Equations 3.5 and 3.6.

Many ways of measuring lateral agility have been proposed in the literature (Reference $1,9,11,25$ ). The choice of a particular lateral agility metric may be influenced by:

- the facilities used for testing (non-real time simulator, piloted simulator, flight test),

- the particular aspect of a rolling maneuver of interest (roll acceleration, capturing a small or large bank angle change), 
- the flight regime of interest (high or low alpha, high speed or low speed),

- the use of the data (for design, evaluation or tactics).

\subsubsection{Time-to-90 Metric}

The most widely used metric today is the minimum time to capture a 90 degree bank angle change while holding a prescribed angle of attack. The symbol used for this metric is $T_{90}$. The metric is best suited for piloted simulators and flight testing, and is appropriate for all flight regimes except possibly at high angles of attack. Its utility to fighter pilots and designers is currently the subject of research by the Air Force Flight Test Center and several aircraft manufacturers (Reference 22, 35).

The $T_{90}$ metric is best suited for man-in-the-loop testing since it requires the judgement of a pilot to choose a realistic and often complex control input sequence. Rolling an airplane while holding an angle of attack requires body axis yaw rate to keep sideslip from building due to kinematic coupling during the roll. Figure 3.17 shows the required body axis roll and yaw rates for a perfectly coordinated wind axis roll. For example, at 20 degrees angle of attack, a wind aris roll of $100 \mathrm{deg} / \mathrm{sec}$ requires a body axis roll rate of 94 $\mathrm{deg} / \mathrm{sec}$ and a body axis yaw rate of $34 \mathrm{deg} / \mathrm{sec}$. Control power during a loaded 


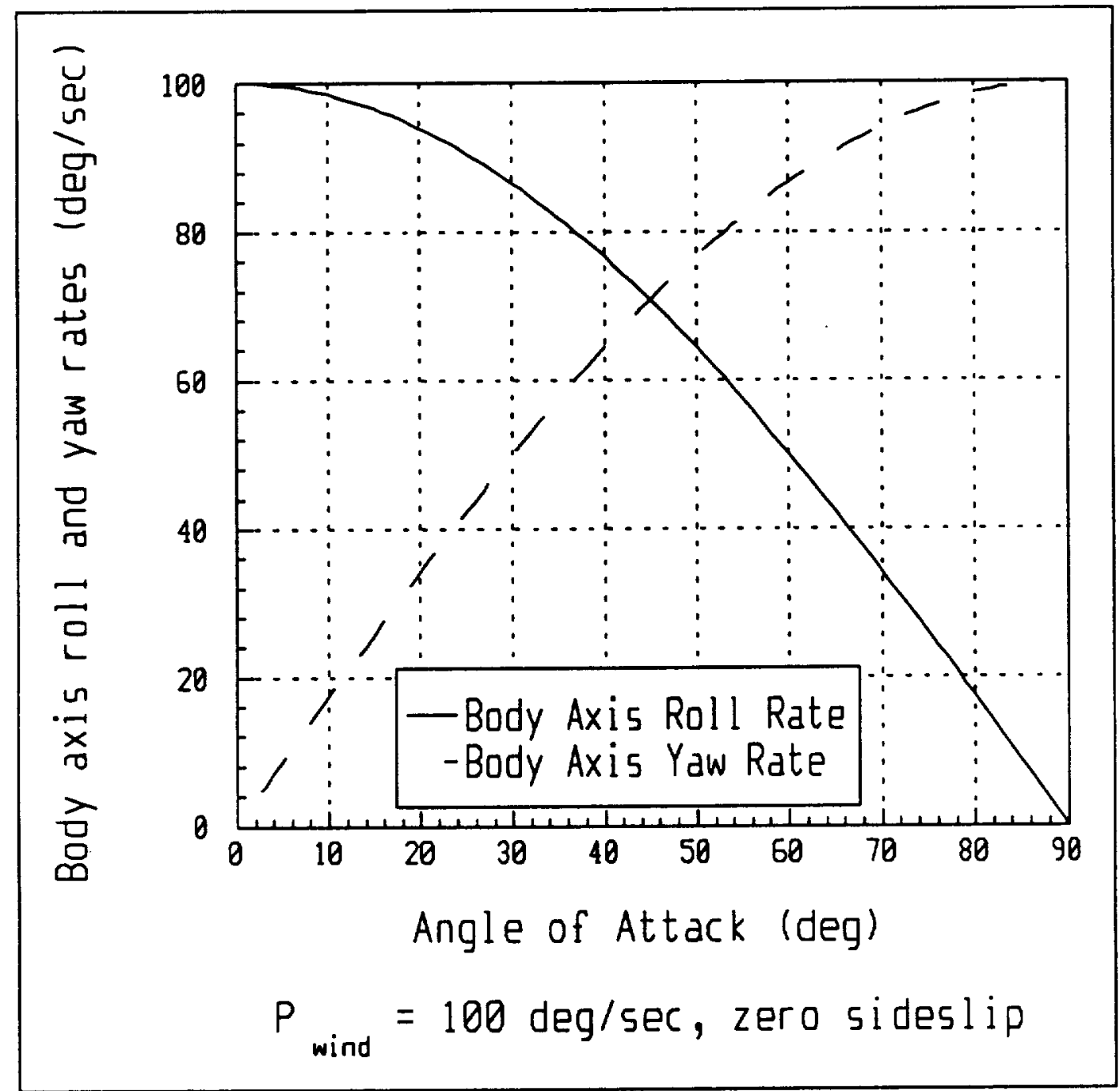

Figure 3.17: Body Axis Rates for Wind Axis Rolls

roll is required both to generate the angular rates needed to coordinate the maneuver and to counter the moments stemming from inertial and aerodynamic cross coupling.

At low angles of attack, the flight control systems of today's fighters command enough yaw rate to keep sideslip small even at high roll rates. When 
using maximum roll control inputs at medium and high angles of attack, several things can happen that allow sideslip to build up to 5 to 10 degrees. First, the flight control system's roll-yaw interconnect may not provide enough yaw rate thus requiring the pilot to use the rudder pedals. Second, the airplane will eventually run out of control power to generate the yaw rate that is required when rolling at elevated angles of attack. At this point the pilot or the flight control system must use less body axis roll rate to keep the required body axis yaw rate within the capabilities of the airplane or accept significant sideslip excursions.

The maneuver for the $T_{90}$ metric can be performed on a non-real time, unpiloted simulation at lower angles of attack where complex pilot control inputs are not required. This was done on the F-18 HARV simulation by using step commands of lateral stick position and constant longitudinal stick position.

The choice of reference frames may significantly effect the $T_{90}$ metric at high angles of attack. Since the metric measures the time to capture the Euler roll angle $\Phi$, it is the integral of $\Phi$ that is important, not the integral of body axis or wind axis roll rate. The equation for $\Phi$ is (Reference 35) 


$$
\Phi=P+R \cos \Phi \tan \Theta+Q \sin \Phi \tan \Theta
$$

When performing a loaded roll at high angles of attack and low to medium speeds, pitch angle $(\Theta)$ can become large enough so that the third term of equation 3.2 above becomes significant. This term is purely kinematic and has nothing to do with lateral agility of a particular aircraft design. As angle of attack increases, this term increases $\Phi$ which reduces the time to capture $\Phi$ while the true rolling ability of the airplane continues to decrease.

\subsubsection{Test Method}

The F-18 HARV simulation described in earlier sections was used to evaluate the $T_{90}$ agility metric. After the simulation was trimmed to a steady flight condition, a longitudinal stick command was ramped in over one second. This set the airplane at a given angle of attack. Two seconds later, with the airplane settled on the commanded angle of attack, full positive lateral stick (3 inches on the F-18) was ramped in over 0.1 seconds. After holding this command for a short time, the stick was ramped to full negative lateral stick over 0.1 seconds. Later the stick was ramped to the neutral position over 0.1 seconds. Figure 3.18 shows a typical time history of the lateral stick 

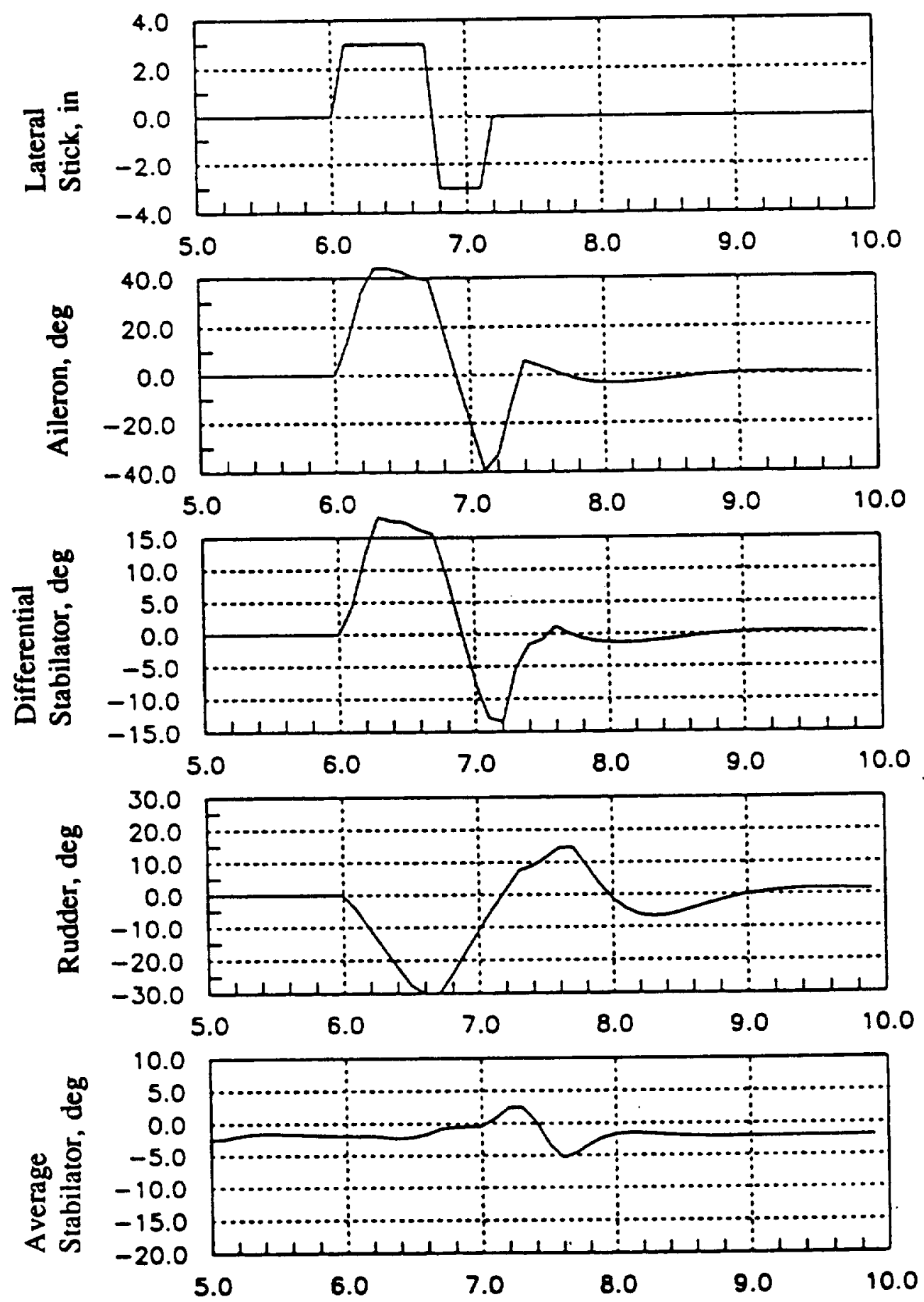

Figure 3.18: Cuntrol Time History for Typical $T_{90}$ Maneuver, Mach .5, 15,000 ft 
commands. The amount of time the lateral stick was held in each position was determined iteratively to obtain a fast and accurate capture of a 90 degree bank angle. The throttle was also adjusted manually to maintain the test Mach number throughout the maneuver.

\subsubsection{Data Reduction and Analysis}

The simulation was programmed to calculate the time to capture 90 degree bank angle and the average Mach number, angle of attack and load factor during the roll to 90 degrees. The time at which the lateral stick begins to move is the beginning of the maneuver and the time at which the airplane reaches a maximum bank angle is the end of the maneuver. The program does not determine if that maximum bank angle is "captured." This must be done by the engineer analyzing the data.

Since it is very difficult for either the simulation user or a test pilot actually flying the maneuver to stop at an exact bank angle (Reference 16), the time to reach the maximum bank angle is normalized to a bank angle change of exactly

$$
\mathrm{T}_{90}=\mathrm{T}_{\bullet}-\frac{\Phi_{\max }-90}{\dot{\Phi}_{\max }}
$$


90 degrees. Equation 3.8 is used for that normalization and was originally proposed by the Eidetics Corporation (Reference 9). The accuracy of this method hinges on the assumption that during both the nominal 90 degree bank angle maneuver and the test maneuver to be normalized the aircraft's maximum bank angle rate of change is attained. The impact of this assumption is explored in Section 3.4. The resulting time to capture 90 degrees is plotted at the average Mach number and angle of attack.

\subsubsection{Simulation Results}

Figure 3.19 shows the results of testing the $T_{90}$ metric at $15,000 \mathrm{ft}$ altitude. Results at 30,000 feet are presented in Figure 3.20. The effect of Mach number and altitude on the $\mathrm{T}_{90}$ metric is straightforward. At higher dynamic pressure the control surfaces are more effective and can give the airplane higher roll acceleration and, thus shorter $T_{90}$ values.

The effect of angle of attack is due to kinematic coupling and the roll and yaw rate capabilities of the airplane. At low angles of attack, the maximum roll capability of the airplane (and control system) is used in capturing the 90 degree bank angle. Some rudder coordination is required but it is within the rudder's control power limit. 


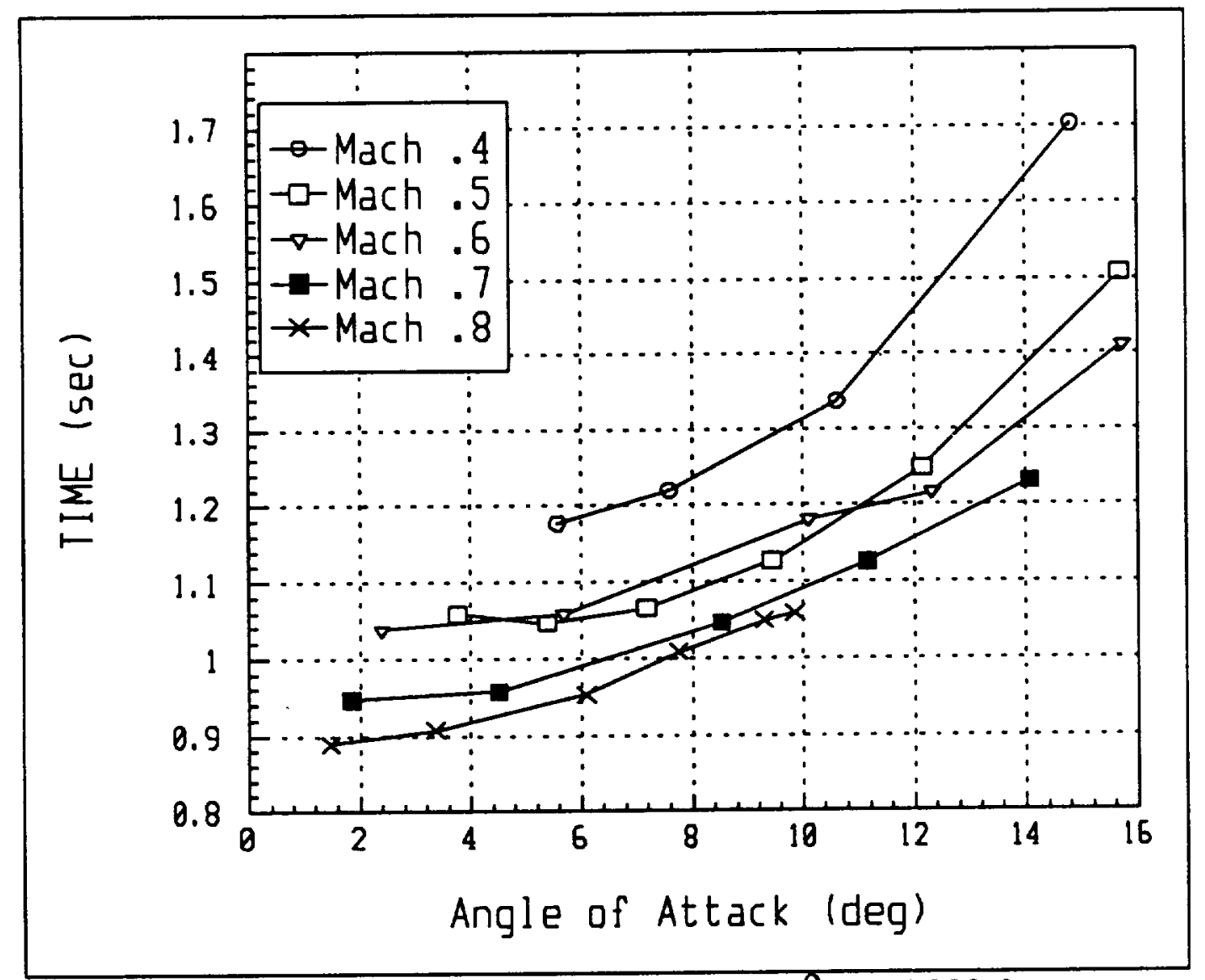

Figure 3.19: Time to Capture $\Phi=90^{\circ}$ at $15,000 \mathrm{ft}$

As the angle of attack of the maneuver increases, so does the yaw rate required to maintain a coordinated roll. This yaw rate requirement soon saturates the rudder. At angles of attack where the rudder can become saturated, the F-18 control system limits the roll rate to maintain a reasonably coordinated roll and thus the $\mathrm{T}_{90}$ values are increased.

A comparison of Figures 3.19 and 3.20 shows the effects of altil 1 de on the $\mathrm{T}_{90}$ metric: Though dynamic pressure at constant Mach is reduced almost 


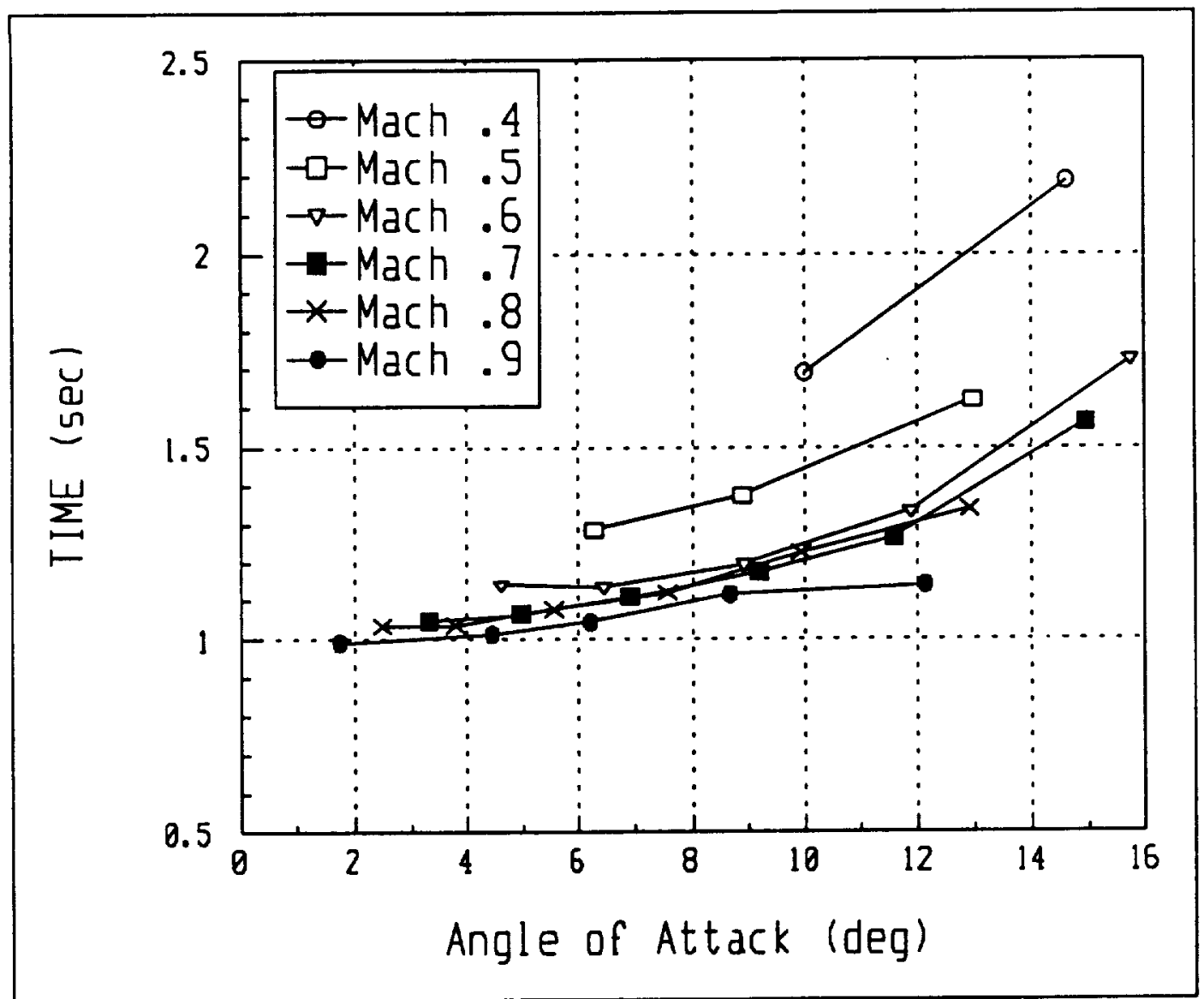

Figure 3.20: Time to Capture $\Phi=90^{\circ}$ at $30,000 \mathrm{ft}$

$50 \%$ between 15,000 feet and 30,000 feet, the flight control system is able to maintain $\mathrm{T}_{90}$ values below 2 seconds for all but the lowest speed tested. The largest difference in $\mathrm{T}_{90}$ between the two altitudes is less than $30 \%$.

An underlying assumption to all the lateral agility metrics proposed in the literature is that faster is better at all angles of attack. Lower values of $T_{90}$ imply a faster maximum roll rate and a smaller roll mode time constant. When the roll mode time constant and maximum roll rate are chosen to provide good 
flying qualities as defined by MIL-F-8785C or its successor, MIL-STD-1797, the design's $T_{90}$ values follow as a direct consequence. Thus, lower values for $\mathrm{T}_{90}$ must be traded against increased lateral sensitivity. The impact of that increased sensitivity on pilot orientation and flying qualities, especially at high angles of attack requires further research. 


\section{Flight Test Issues}

\subsection{Background}

While Simulation is useful to evaluate agility metrics and data reduction techniques, flight test is required to accurately measure the agility of real aircraft. Flight test results are also needed to verify that the simulation methods provide accuracy sufficient to warrant their use in future agility research. Both the NASA Dryden Flight Research Center and the Air Force Flight Test Center have conducted limited flight tests of several agility metrics. During 1987, a team of pilots and flight test engineers enrolled in the USAF Test Pilots School flew a small number of sorties with T-38's and F-16's. Their goal was to evaluate flight test techniques, data measurement and analysis methods and data presentation formats to quantify aircraft agility. Pitch and lateral maneuvers were flown to evaluate metrics about both these axes. Since theirs was a Test Pilot School student project, time and resources were very limited. However, the work is thoroughly documented in a final report (Reference 16). In 1988, a number of lateral agility maneuvers were flown with NASA Dryden's F-18 HARV aircraft. Results were analyzed both in-house at NASA and by the Eidetics Corporation. Briefing charts from a March 1989 Dryden Agility Rrview represent the only known documentation of this effort. 
Since these two test programs used different aircraft types and quantified agility with different metrics, direct comparisons of their results are not possible. However, a significant conclusion of both studies was that the flight maneuvers required to measure agility in terms of any of the tested metrics are very difficult to perform accurately and repeatably. The greatest difficulties were encountered while executing the loaded rolls required by the proposed lateral agility metrics. In the case of the Test Pilot School study, at least, the maneuvers were difficult to fly properly even after they were practiced in ground based simulators. In both programs, pilots flew the test maneuvers with only standard cockpit displays. No specialized displays or cuing systems were developed for these test programs.

A typical loaded roll maneuver used to evaluate lateral agility involves pitching the aircraft to a target load factor and then rolling to and stopping at a specified bank angle while holding the desired load factor. This differs from the Mil Standard Flying Qualities requirement of rolling through a specified bank angle change at other than a one-g condition (Reference 37). Hence, this maneuver requires precise lateral and longitudinal flight control inputs. Flight test time histories and pilot comments indicate that adequate accuracy is difficult to achieve in both axes simultaneously. Pilots found it difficult to maintain the desired normal acceleration during the rolling maneuver. 
Specifically, buffet made the $\mathrm{T}-38 \mathrm{~g}$ meter fluctuate rapidly and the digital $\mathrm{g}$ information displayed by the F-16 heads up display was unsuitable for capturing and holding a desired acceleration. Pilots also found it difficult to stop the roll rate precisely at the target bank angle. As a result, pilots often commanded less than full roll rate in order to gain a more accurate capture of bank angle. The trade between roll rate and bank angle accuracy, when left to the pilot's discretion, produced large variations in metric values. Again, only standard cockpit displays of bank angle were available to the pilots.

Alternative techniques investigated at the Test Pilot School included rolling with constant aft stick force or at constant angle of attack. Constant stick force was found impractical without a force gauge. Constant angle of attack was more flyable only because the angle of attack gauge in both the T-38 and F-16 is less sensitive than the $\mathrm{g}$ meter.

In summary, agility flight testing involves transient, highly dynamic maneuvers that depend on precise, repeatable but complex pilot input sequences. Preliminary test experience has shown that sufficient accuracy and repeatability is difficult to obtain. New approaches to cockpit displays or pilot cues developed specifically for agility flight testing may reduce test pilot workload and enhance the validity of the test results. New display concepts and cuing methods may also be required in operational cockpits to enable tactical pilots 
to fully utilize the ideas of agility and supermaneuverability (Reference 41,42 , 43).

\subsection{Analysis of Cuing Method}

There are two fundamentally different ways to approach the problem of providing better information to the pilot for agility flight testing. The first is to limit the development of displays and cuing methods to those that can be implemented with the hardware and software capabilities now available on the F-18 HARV and in NASA Dryden's flight test facilities. The other is to postulate new displays and cues without considering the limitations of current capability. For example, an easily programmable head up display could allow rapid implementation of displays tailored for specific tests (Reference 31 ). Such a system would permit the development of innovative pilot cues for agility flight testing but specialized displays of this type are not likely to be available for the F-18 HARV in the near future. Discussion in this report, therefore, will be restricted to the use of existing equipment cues for agility flight testing will be passed to the flight test pilot through hardware now available on the aircraft and over information channels that already exist. The key issue, then, is how accurately does the flight test pilot have to follow the cuing di ection in order to produce useful agility data. 
The most logical means to assist the pilot during agility test maneuvers involve the transmission of cues to the steering needles on the F-18's Attitude Direction Indicator (ADI) from Dryden's ground based flight test facility. This technique for passing information to the cockpit during flight test has been used before and requires no new equipment. The steering cues are developed on the ground as the test pilot practices the agility test maneuvers in Dryden's real time man-in-the-loop simulation. When a satisfactory maneuver is flown on the simulation, the stick inputs that produced the maneuver are recorded and saved. During flight test these inputs are transmitted in real time to the F-18 HARV and displayed to the pilot as steering commands on the ADI. By tracking these commands, the pilot replicates the stick inputs applied earlier in the ground based simulator. The test can be reflown as often as necessary to produce consistent, repeatable maneuvers.

The results of this procedure, however, depend on the pilot's ability to follow the steering needles accurately. The level of accuracy required depends on the sensitivity of the agility metric to variations in stick input and is the subject of the following sections. 


\subsection{Sensitivity to Cue Following Errors}

The F-18 simulation at the University of Kansas was used to assess this sensitivity for the pitch and lateral agility metrics discussed in previous sections. Since no stick commands are required while testing the axial agility metrics (power onset and power loss parameters), sensitivity to pilot errors in following steering cues does not apply to those metrics.

\subsubsection{Sensitivity of Pitch Agility Metrics}

As discussed in Section 3.2, three approaches to measuring pitch agility have been proposed. These consist of (1) the time to pitch to maximum load factor and the time to pitch down from maximum to zero load factor, (2) the maximum load factor rate during a pitch to maximum load factor and the maximum negative load factor rate during a pitch down from maximum to zero load factor and (3) the maximum positive and negative pitch rates generated during a pitch up to maximum load factor followed by a pitch down to zero. All three metrics could be evaluated with the same test maneuver.

Typical stick inputs for such a maneuver were shown in Figure 3.7. If these are the nominal commands passed to the pilot with the cuing system described earlier, the actual pilot inputs could deviate in the following ways. 
1. The initial aft stick input could be applied at a different rate than directed by the steering cues.

2. The aft stick input could be less than the full deflection command directed by the cues.

3. The forward stick input could also be applied at a different rate.

4. The size of the forward stick input may not match the cues.

Each of these errors was imposed, one at a time, on the pitch maneuvers used to evaluate the published pitch agility metrics (time to load factor, load factor rate and pitch rate) described in Section 3.2. Runs were made at 15,000 feet altitude to illustrate the behavior. The tested deviations from nominal are summarized in Table 4.1 below. Forward stick deflection (the fourth error type) was increased rather than reduced because if the forward deflection was reduced by $20 \%$ the maneuvers failed to achieve the zero load factor as required by the metric definitions. 


\begin{tabular}{||c|c||}
\hline \multicolumn{2}{|c||}{ Table 4.1: Deviations for Pitch Sensitivity Tests } \\
\hline Error Type & Magnitude \\
\hline Aft Stick Rate & Reduced 20\% \\
\hline Aft Stick Deflection & Reduced 20\% \\
\hline Forward Stick Rate & Reduced 20\% \\
\hline Forward Stick Deflection & Increased 20\% \\
\hline
\end{tabular}

Only the first two errors listed above, aft stick rate and aft stick deflection, have an impact on the pitch up portions of the agility metrics. Changes in the forward stick command rates or magnitudes have no effect on the time to maximum load factor, positive load factor rate or positive pitch rate since they occur after the pitch up portion of the test maneuver. Similarly, only the last three errors above have a direct impact on the pitch down parts of the agility metrics. The rate at which the initial nose up command is applied does not effect the pitch down maneuvers. The size of the initial aft stick deflection, however, effects the attitude from which the pitch down is initiated. Deviations in the forward stick commands clearly impact the nose do ' $n$ parts of the metrics. 


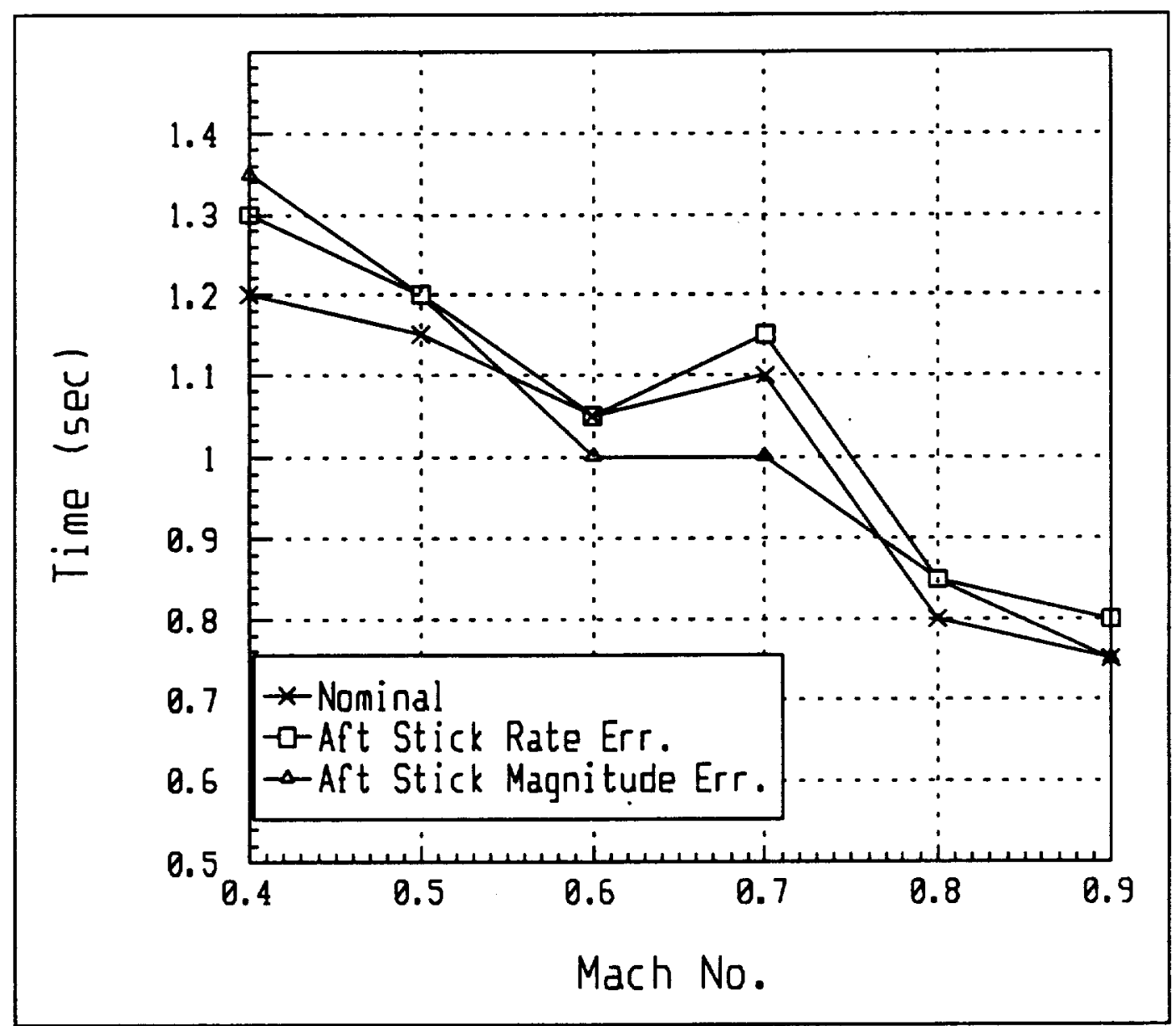

Figure 4.1: Time to Max Load Factor Error

Sensitivity, $15,000 \mathrm{ft}$

Figure 4.1 indicates that the time to maximum load factor metric is very insensitive to the errors in aft stick rate or in aft sick deflection. As expected, reducing the aft stick deflection rate increases the metric but the maximum change is only 0.15 seconds. Applying four inches of aft stick instead of five 
has an even smaller effect on this metric since it measures only the time to maximum load factor and not the size of the load factor itself.

Maximum load factor rate generated in the pitch up portion of the maneuver is virtually unchanged by either of the deviations in aft stick rate or aft stick magnitude as shown by Figure 4.2. Neither of these deviations had significant effects on this metric. 


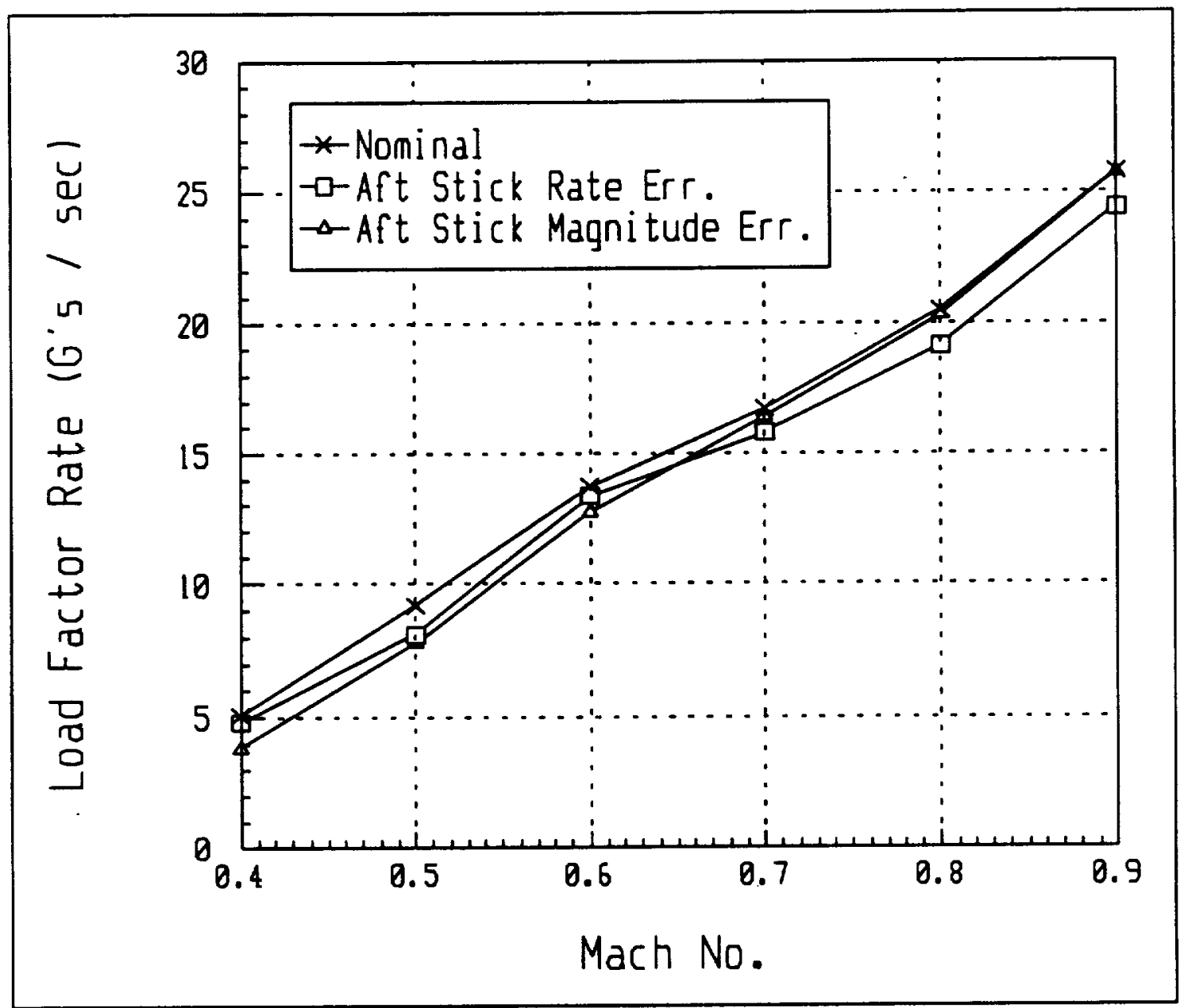

Figure 4.2: Pitch Up Load Factor Rate Error

Sensitivity, $15,000 \mathrm{ft}$ 
As seen in Figure 4.3 , the slower aft stick rate also has practically no effect on the maximum pitch rate encountered during the pitch up. However,

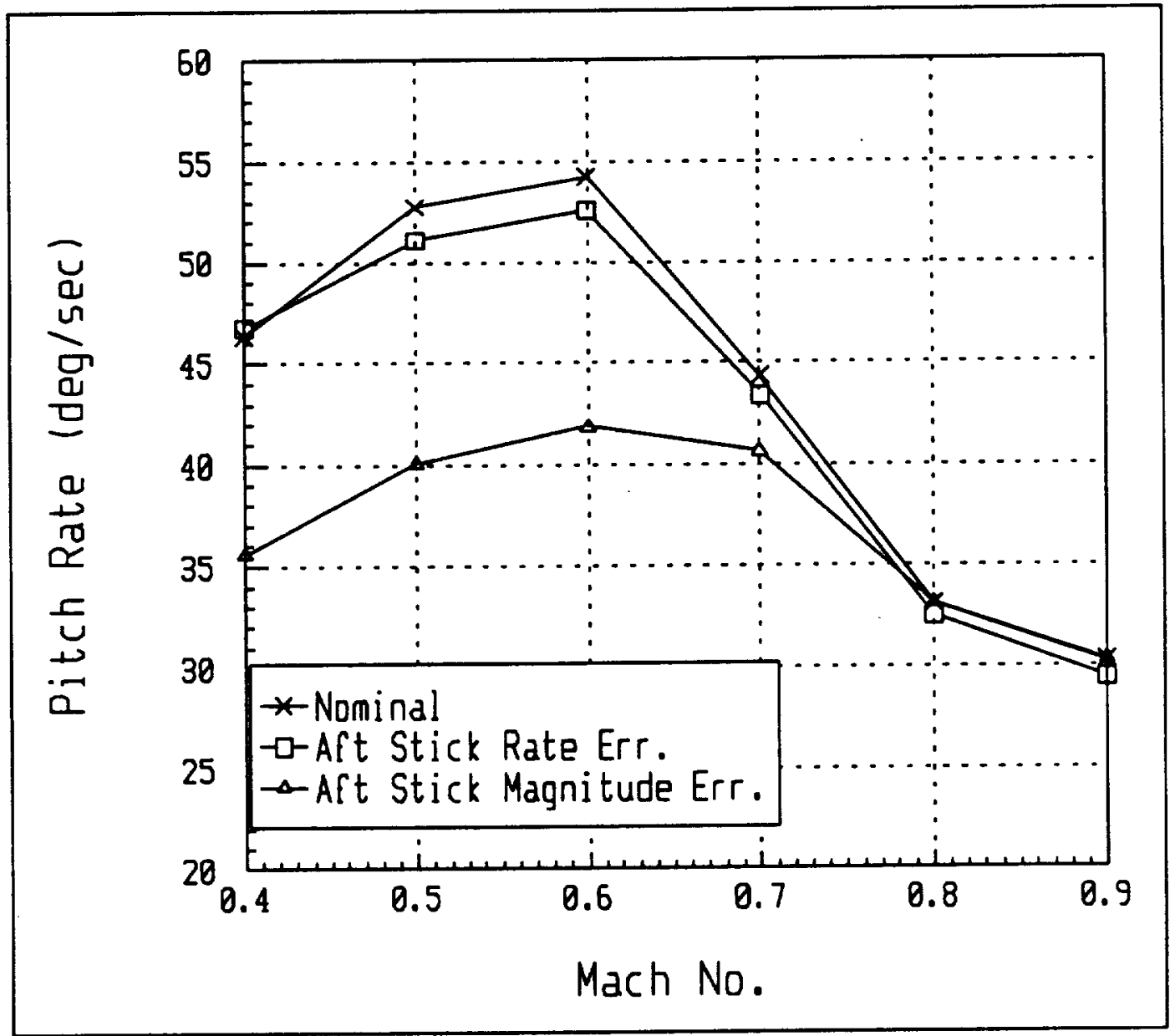

Figure 4.3: Nose Up Pitch Rate Error Sensitivity,

\section{$15,000 \mathrm{ft}$}

when the maximum stick deflection is only four inches, maximum pitch rate is significantly reduced at the lower Mach numbers. The reason this deviation can 
have a pronounced effect on maximum pitch rate but no impact on the other metrics is that the value of each metric is established at a different point in the time history of the maneuver. Maximum load factor rate occurs very quickly, while pitch rate is still relatively small. The instant of maximum load factor is later in the maneuver when load factor rate is zero and after pitch rate has peaked and has begun to decline.

As discussed earlier, three of the four deviations from nominal, forward stick rate, aft stick magnitude and forward stick magnitude, have an effect on the nose down part of the pitch agility metrics. However, only one of these causes a significant change in the time to pitch down to zero load factor (Figure 4.4). Applying $20 \%$ more forward stick than for the nominal case causes the aircraft to reach zero load factor quicker at lower Mach numbers.

As in the nose up case, load factor rate is virtually unaffected by any of the deviations applied here as can be seen in Figure 4.5.

The effects of changes in forward stick rate, aft stick magnitude and forward stick magnitude on nose down pitch rate are seen in Figure 4.6. Commanding more than the nominal forward stick deflection causes slightly higher nose down rates, while applying the stick input at a slower rate reduces the resulting pitch rate magnitude. In no case, however, are the changes large or unpredictable. 


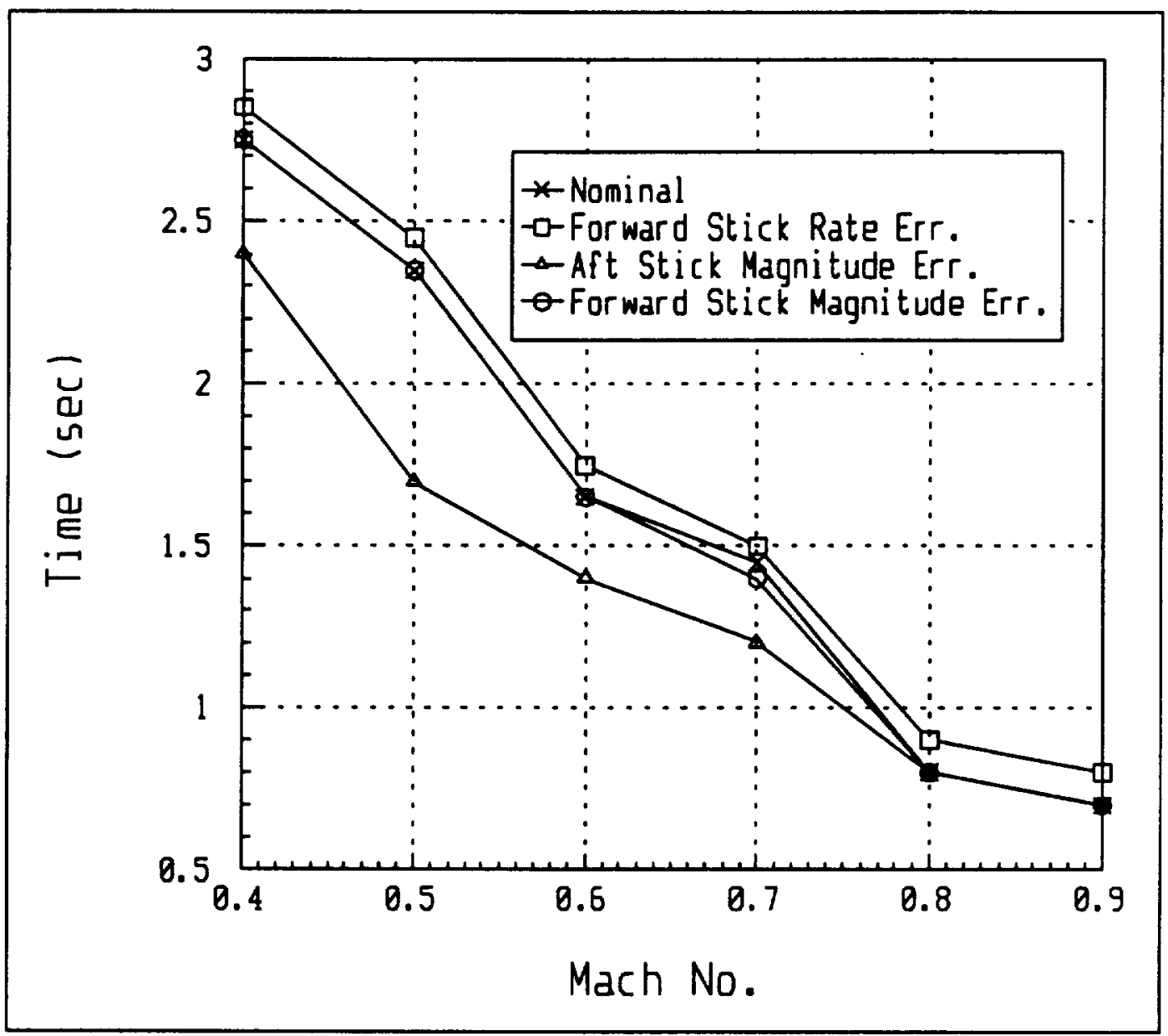

Figure 4.4: Time to Zero Load Factor Error

Sensitivity, $15,000 \mathrm{ft}$

This analysis indicates that none of the published metrics for quantifying pitch agility is unusually sensitive to deviations from the nominal sequence of stick commands. In the nose up direction, pitch rate is reduced by approximately ten degrees per second if four incles of aft stick is applied rather than five. During the pitch down portion of the maneuvers, zero load factor is 


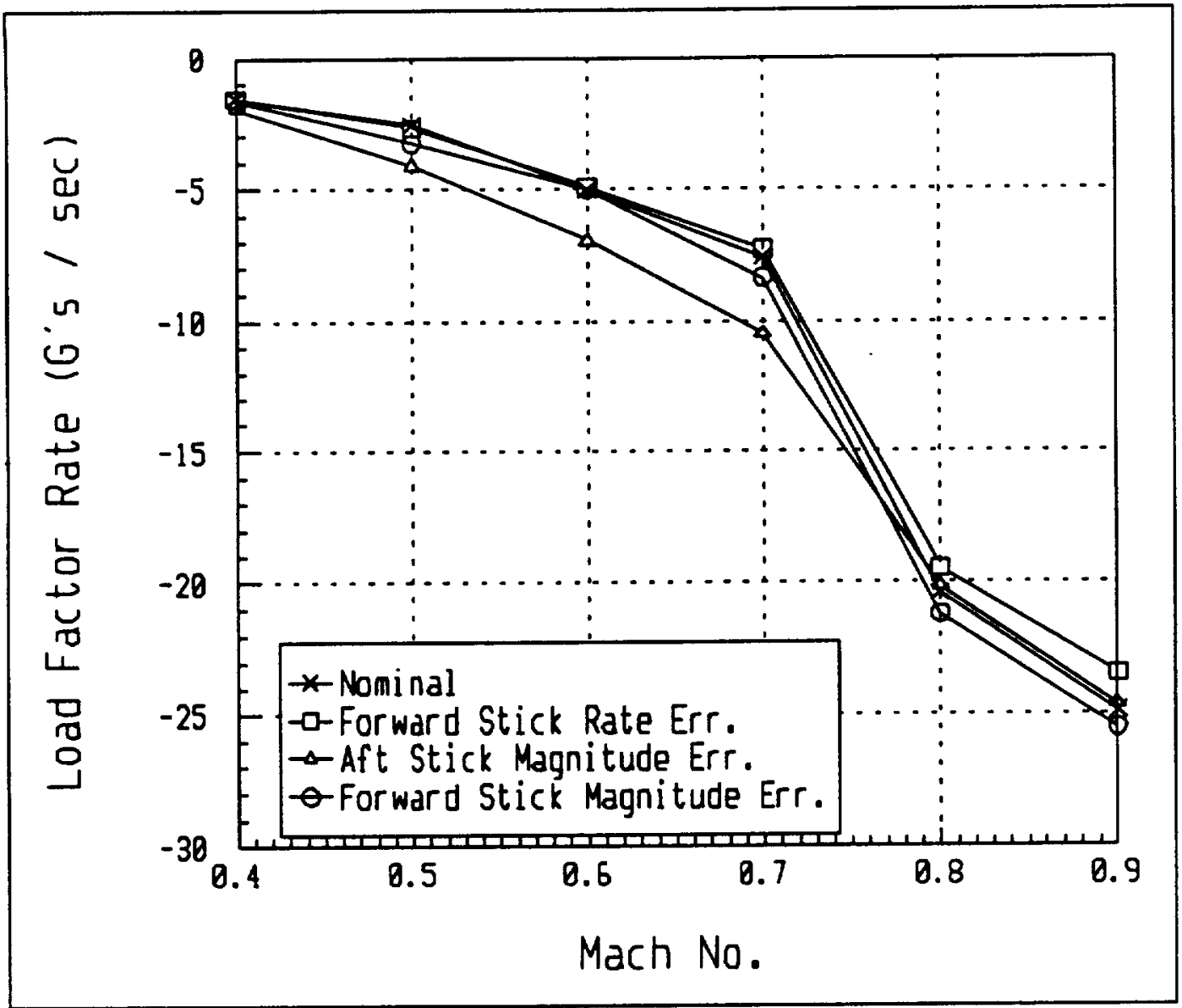

Figure 4.5: Pitch Down Load Factor Rate Error

Sensitivity, $15,000 \mathrm{ft}$

achieved faster when more forward stick is used. Except for these two instances, the input deviations studied here had no significant impact. This shows that useful data for the time to achieve maximum load factor and load factor rate metrics can be generated with a reasonable tolerance for pilot variations. When attempting to collect data to measure aircraft pitch rate or the 


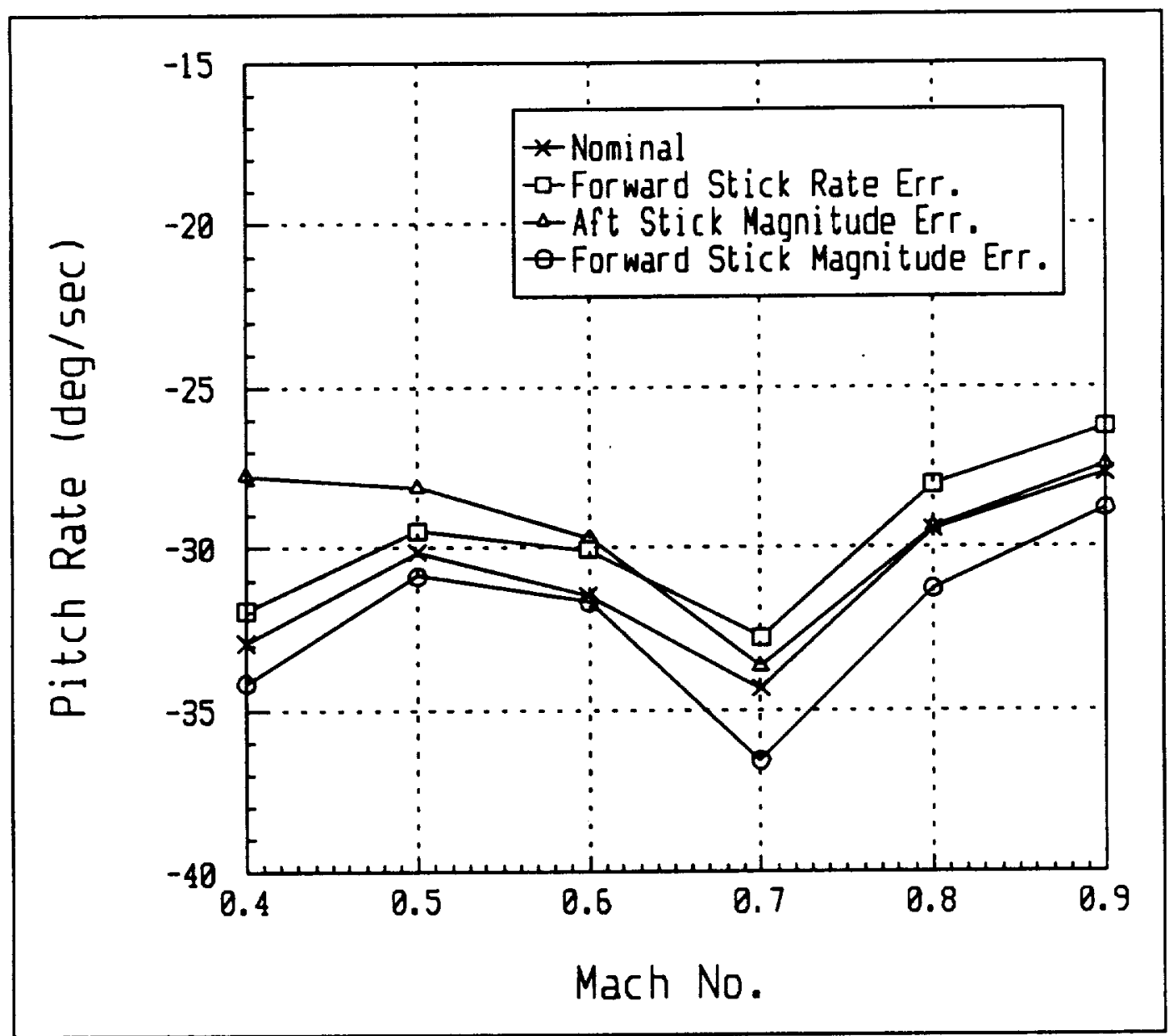

Figure 4.6: Nose Down Pitch Rate Error Sensitivity,

$15,000 \mathrm{ft}$

time to achieve zero load factor, special displays may be warranted due to the sensitivity of these metrics. 


\subsubsection{Sensitivity of Lateral Agility Metrics}

The lateral and longitudinal stick commands for a typical loaded roll maneuver are shown in Figure 4.27. If these inputs represent the desired pilot

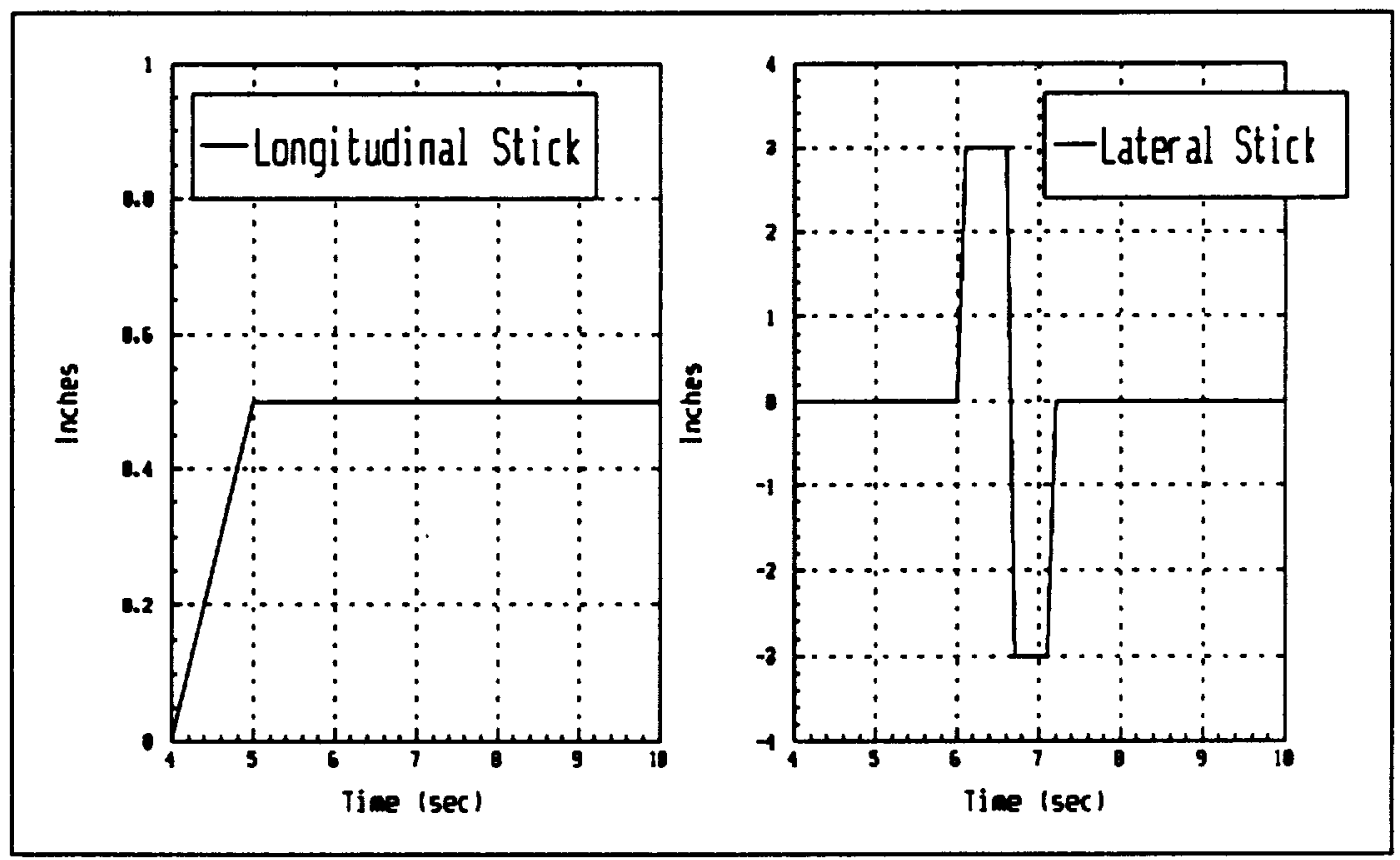

Figure 4.7: Stick Deflections for Typical $\mathrm{T}_{90}$ Maneuver

commands for a given maneuver, then the actual commands could deviate in any one or a combination of the following ways.

1. Aft stick can be relaxed during the roll instead of held constant. This type of deviation was prevalent during the F-18 HARV test.

2. Less than full lateral stick can be used to initiate the roll. 
3. Less than full lateral stick in the opposite direction can be used to stop the roll.

4. Stick inputs may be applied at a different rate than directed by the steering cues.

5. Lateral stick deflection can be held too long either while initiating the roll or while stopping the roll with opposite stick.

A deviation of the last kind will result in the roll being stopped at some bank angle other than the target angle. This error will be corrected by the data reduction algorithm presented in the earlier Lateral Agility section and will not effect the resulting value of the agility metric. Each of the other deviations from the ideal pilot input could result in an erroneous value of lateral agility, the magnitude of which depends on the type, size and sensitivity of the deviation introduced. The errors and their sizes are summarized in Table 4.2. 


\begin{tabular}{|c|c||}
\hline \multicolumn{2}{|c|}{ Table 4.2: Deviations for Lateral Sensitivity Tests } \\
\hline \hline Error Type & Magnitude \\
\hline Longitudinal Stick Position & Reduced 50\% \\
\hline Positive Lateral Stick Deflection & Reduced 20\% \\
\hline Negative Lateral Stick Deflection & Reduced 20\% \\
\hline Lateral Stick Rates & Reduced 50\% \\
& (All Directions) \\
\hline
\end{tabular}

Each of these four errors was introduced to the loaded roll maneuvers previously used to assess lateral agility. As in the previous section, runs were made at 15,000 feet altitude to illustrate the method. First, instead of being held constant as in the nominal maneuver, the aft stick was reduced to half its initial value when the roll command was reversed. Figures 4.8 to 4.12 indicate that this input error produced a negligible change in $T_{90}$ values. Averaged over all test cases, the deviation from nominal maneuvers was less than $2 \%$. Closer inspection of the simulation results show that peak adverse sideslip occurs early in the roll before the aft stick command is reduced. As a result, the forward 


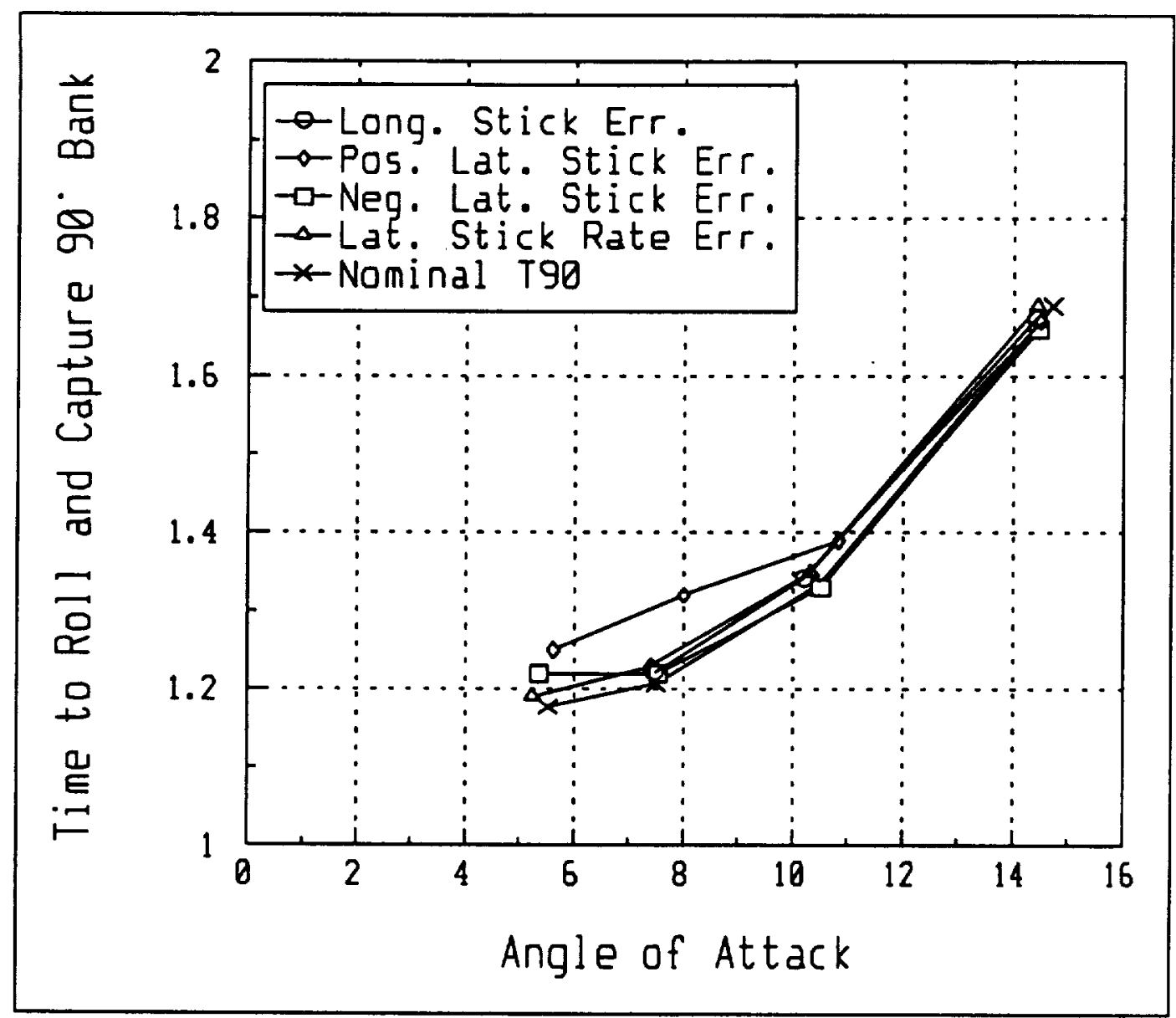

Figure 4.8: $T_{90}$ Error Sensitivity,

Mach $.4,15,000 \mathrm{ft}$

stick motion does little to speed the roll response even though angle of attack is reduced during the last half of the maneuver.

Next the effect of initiating the roll with less than nominal lateral stick deflection was investigated. Without changing the timing of the stick inputs or the size of the longitudinal stick commands, the magnitude of the initial roll 


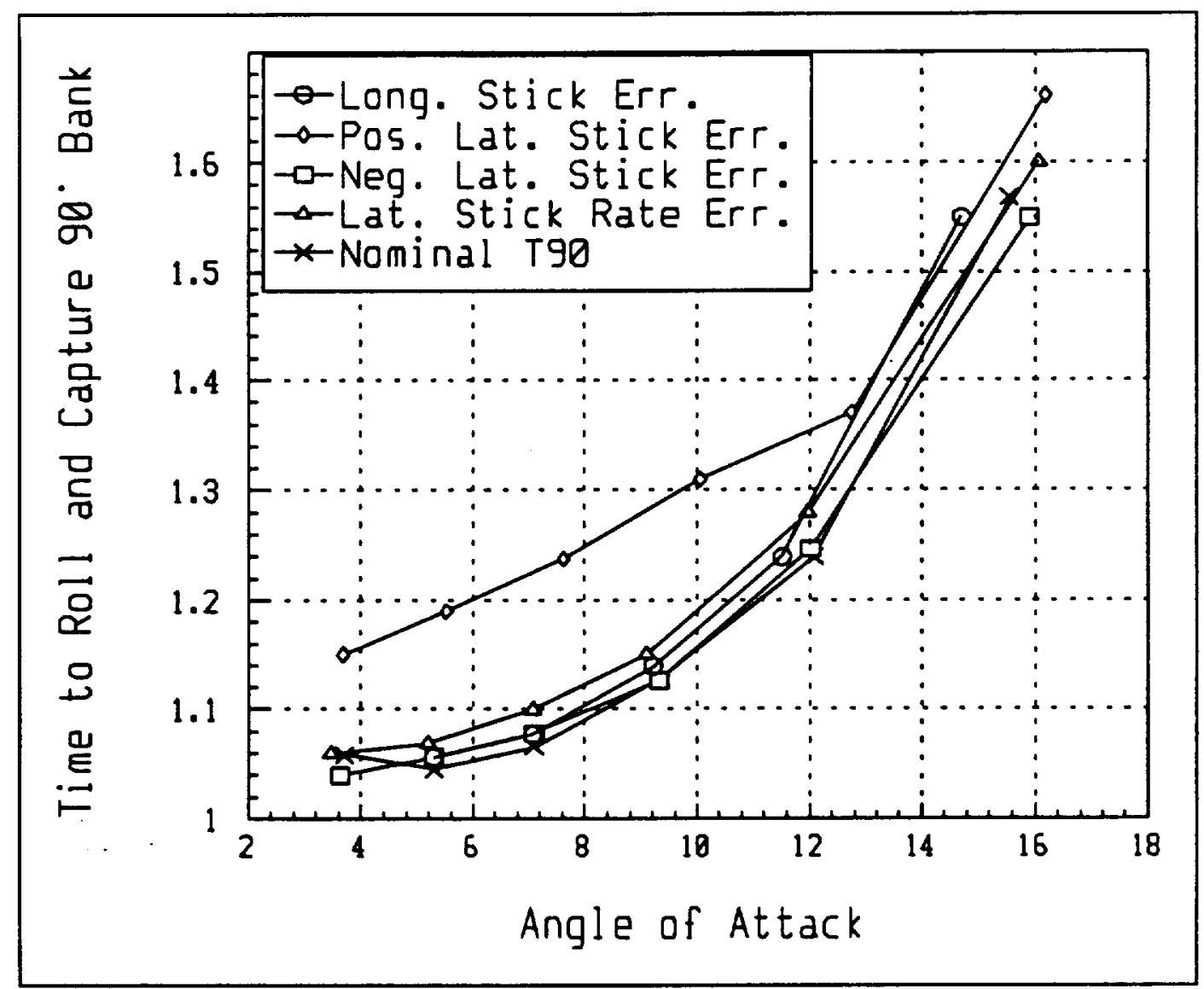

Figure 4.9: $\mathrm{T}_{90}$ Error Sensitivity,

Mach $.5,15,000 \mathrm{ft}$

commands was reduced by $20 \%$. As expected, this change produced a roll angle capture short of the desired $90^{\circ}$. Results at 15,000 feet altitude show that a $20 \%$ reduction in lateral stick deflection reduced the final captured bank angle by an average over all test cases of $29^{\circ}$. It is possible to use the data reduction algorithm presented in the lateral agility section to correct for errors in the final bank angle and calculate a value for $\mathrm{T}_{90}$. However, that algorithm assumes that 


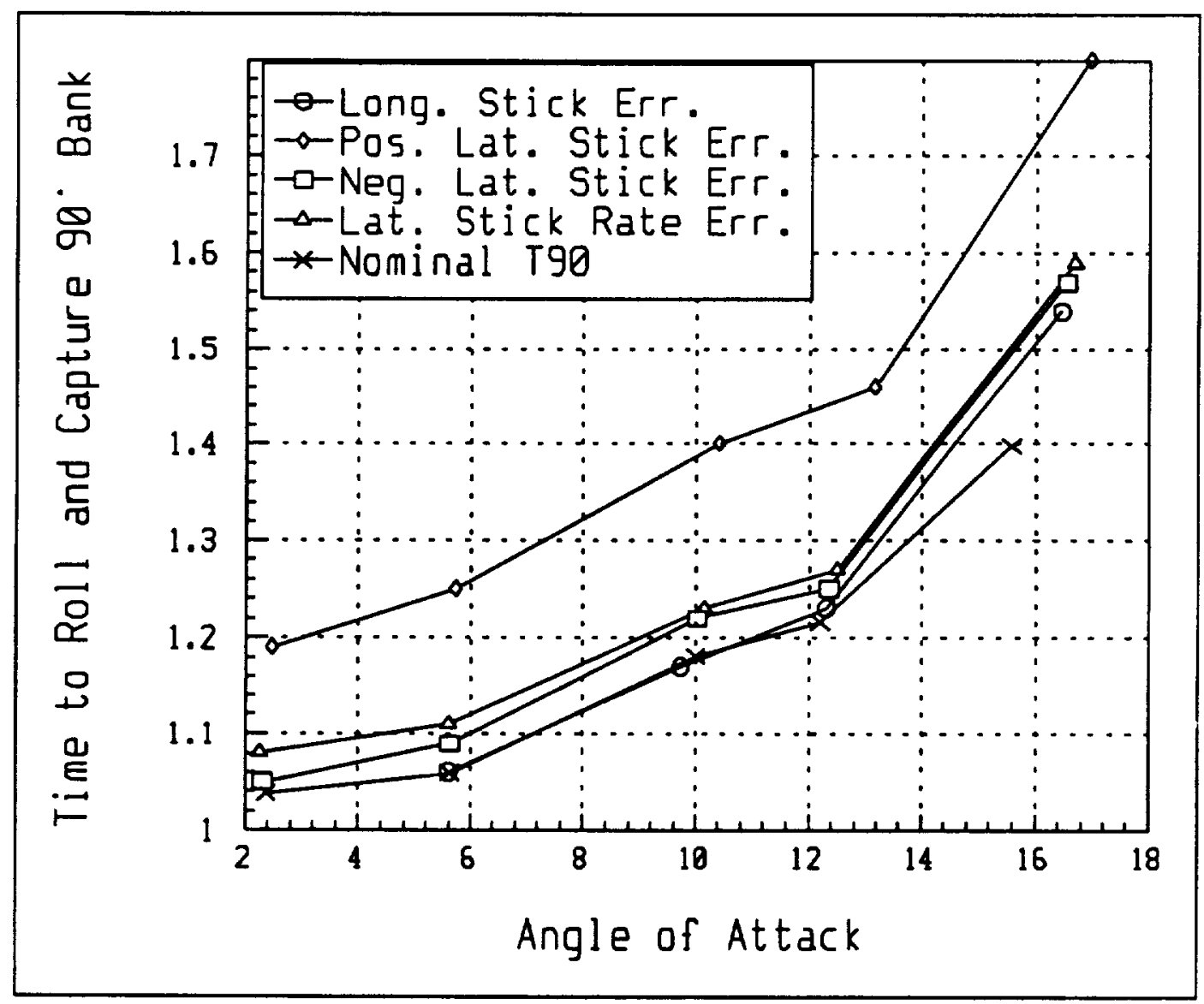

Figure 4.10: $T_{90}$ Error Sensitivity,

Mach .6, $15,000 \mathrm{ft}$

even though the final bank angle is incorrect, the maneuver generated the same maximum roll rate as in the nominal case. For rolls commanded with less than nominal lateral stick inputs that assumption is invalid. As a result, $T_{90}$ values calculated from maneuvers commanded with $20 \%$ less than nominal (full deflection) lateral stick averaged about $10 \%$ greater than $\mathrm{T}_{90}$ values from nominal maneuvers. 


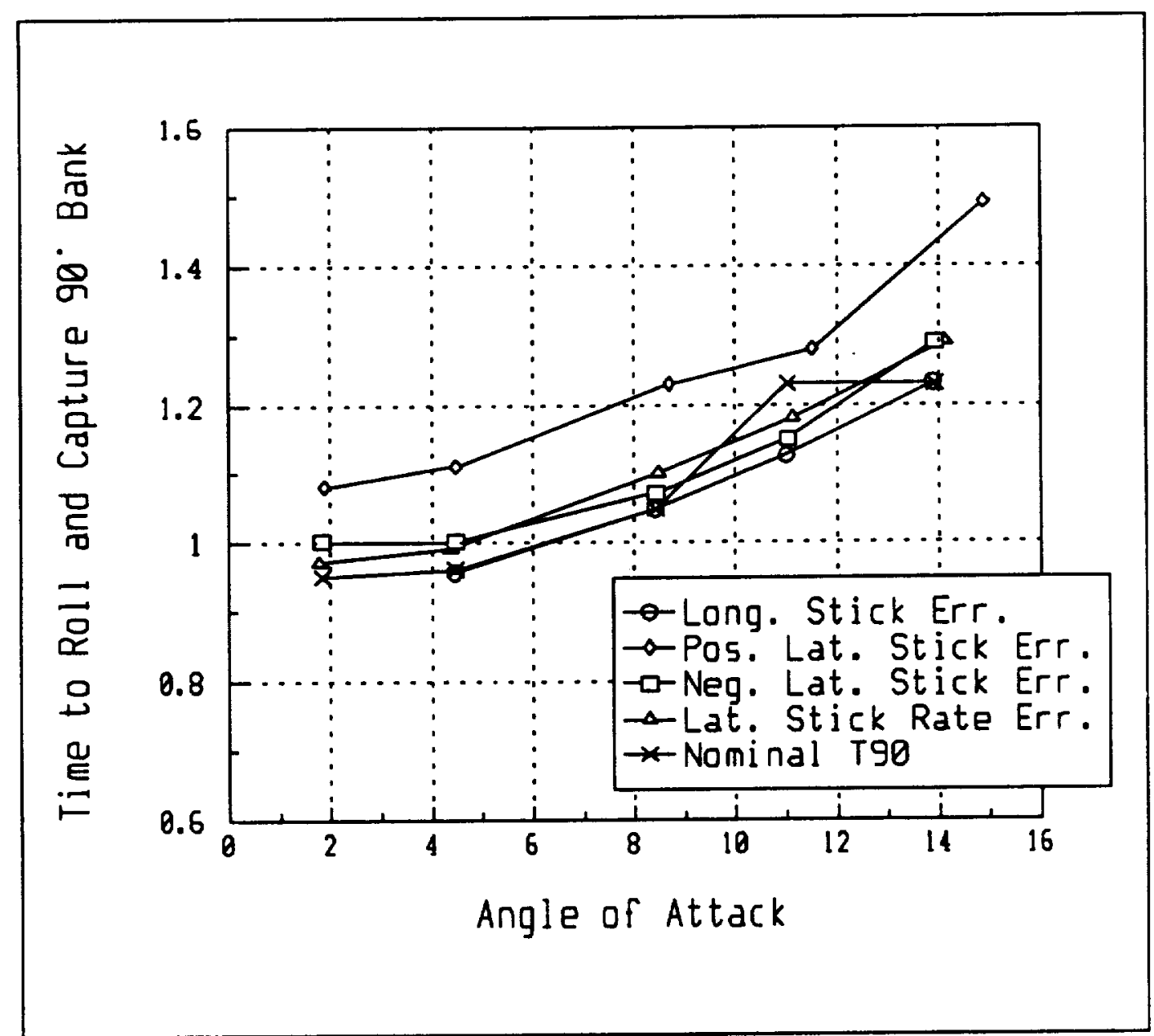

Figure 4.11: $\mathrm{T}_{90}$ Error Sensitivity,

Mach .7, 15,000 ft

As shown in Figure 3.27, the loaded roll maneuvers studied here are completed by stopping the roll rate with a brief application of full lateral stick opposite to the direction of the roll. Sensitivity to this opposite stick deflection was evaluated by reducing the peak of the opposite stick input by $20 \%$ while leaving its starting and stopping time unchanged. As expected, this resulted in 


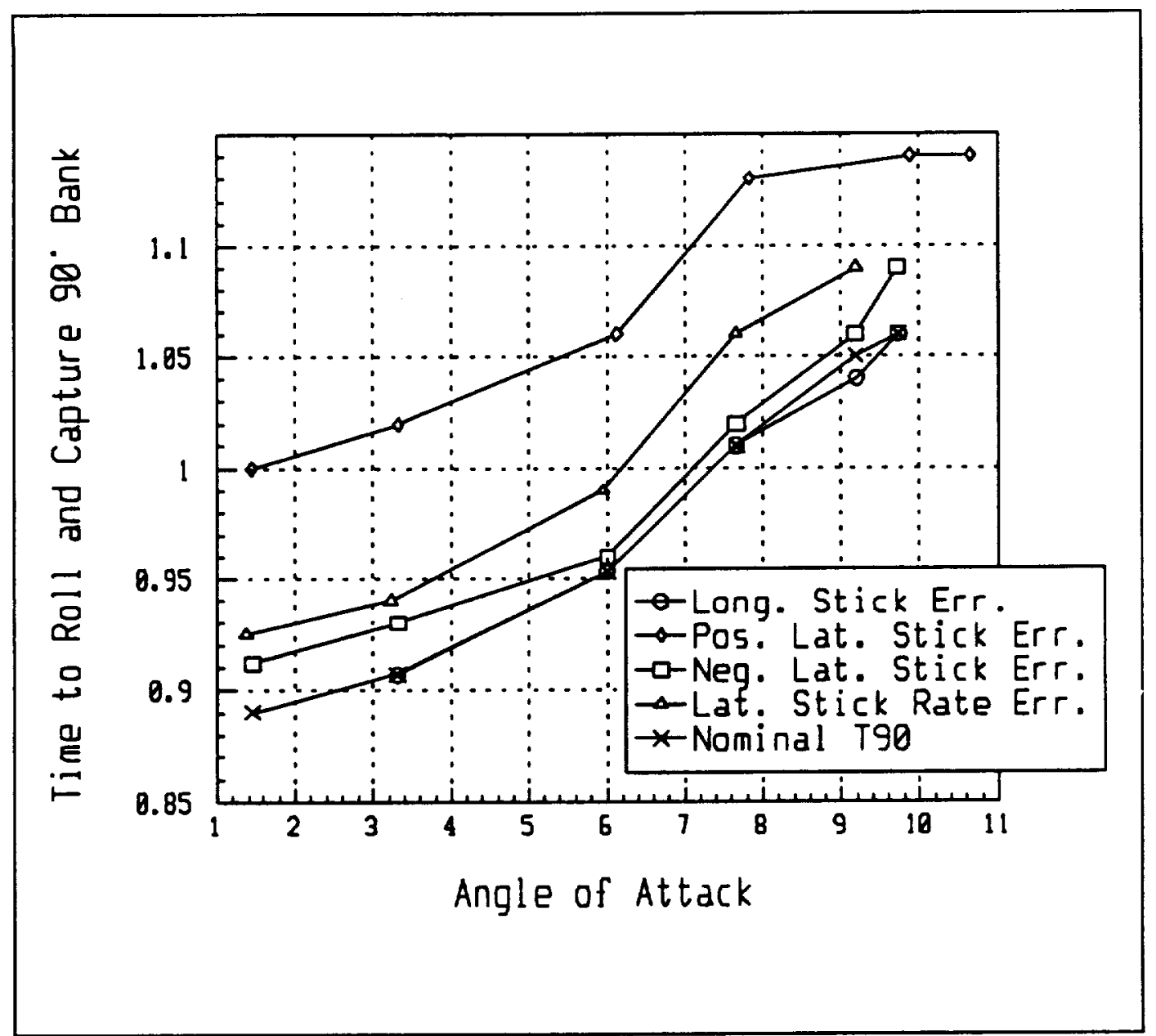

Figure 4.12: $\mathrm{T}_{90}$ Error Sensitivity,

Mach .8, 15,000 ft

a captured bank angle greater than the nominal $90^{\circ}$. Over the same test points used in the preceding paragraph, the captured bank angle exceeded $90^{\circ}$ by an average of $13^{\circ}$. This error in opposite stick deflection produced a smaller roll angle deviation than the error in positive stick deflection described in the preceding paragraph because opposite stick is applied for a briefer period of 
time than positive lateral stick. Also, because the maximum roll rates experienced here are the same as in the nominal cases (since the initial roll commands are the same), the data reduction algorithm was able to accurately correct for the error in final bank angle. The calculated $T_{90}$ values varied from those of the nominal maneuvers by less than $2 \%$ across all cases.

Finally, the rate at which the test pilot applies lateral stick movements could deviate from that directed by his steering cues even while the maximum stick deflections and times between stick movements match the cues exactly. The sensitivity of the $T_{90}$ metric to this error was investigated by reducing by half the rate at which lateral stick commands were applied during loaded roll maneuvers at 15,000 feet altitude. While this change resulted in the captured bank angle being smaller than the nominal $90^{\circ}$, the data reduction algorithm largely corrected for this difference as it did for other error types described earlier in this section. Specifically, reducing the lateral stick rate by $50 \%$ for each of the test cases at 15,000 feet changed the values of the $T_{90}$ metric by an average of only $3 . \%$.

In summary, the $T_{90}$ agility metric is not overly sensitive to inaccuracies that may be introduced as the pilot follows steering cues designed to replicate nominal loaded roll maneuvers. As long as the roll is initiated with full lateral stick deflection, the data reduction algorithm successfully normalizes the 
maneuver to a $90^{\circ}$ bank angle change and thereby compensates for error introduced as the pilot tracks the subsequent steering cues. However, when the roll is initiated with a maximum lateral stick deflection less than that directed by the steering cue, the data reduction scheme normalizes the maneuver with a lower maximum roll rate and produces $\mathrm{T}_{90}$ results significantly different then that obtained from the nominal maneuver. 


\subsection{Instrumentation for Agility Flight Testing}

The motivation for the development of new metrics is to measure facets of aircraft capability that have not previously been emphasized. Since current flight test instrumentation has been designed to support the traditional measures of merit, there has been some doubt about quantifying the new agility ideas during flight test. Much of this concern stems from early attempts to define agility as an entirely new phenomena with terms relating to the second derivatives of linear and angular velocities (Reference 2, 5, 12). However, specific agility metrics have been based (see Figure 2.1 and Appendix B) on useful, measurable capability rather than on theoretical definitions. As a result, almost all of the published metrics rely on physical quantities that are readily available from standard flight test instrumentation.

Flight testing axial agility metrics described in Section 3.1 would require measurement of Mach, altitude, net axial force, time, throttle position and fuel flow (to obtain aircraft weight). Specific excess power is then easily calculated and the power onset and power loss parameters follow immediately.

Several ways to quantify pitch agility are presented in Section 3.2. The time to maximum $\mathrm{g}$ and time to unload metrics have the advantage of being easily evaluated with standard flight test instrumentation. Mach, altitude, stick position and load factor (or normal acceleration) time histories are the only data 
required. Pitch rate and angle of attack measurements are also available from normal flight test instrumentation such as that on NASA Dryden's F-18 HARV. The time derivative of load factor is not directly measurable so load factor rate metrics would require data differencing and smoothing algorithms. In fact, the onset of buffet during flight test will likely prevent the extraction of useful load factor rate data entirely. The ability to extract load factor rate from flight test data is a future research topic.

Lateral agility, quantified with the $T_{90}$ metric, also relies only on currently available measurements. Mach, altitude, time, stick position, angle of attack and bank angle are the required quantities. 


\section{SUMMARY}

Fighter agility has been defined in this report to encompass transient capabilities within the conventional flight envelope that are not emphasized in the traditional approach to fighter performance and maneuverability. Functional metrics which consist of longer term flight segments connected by periods of linear acceleration or nearly constant rate turns do not focus on transient agility and are not analyzed here. Transient capabilities outside the conventional flight envelope are popularly called supermaneuverability and are also not studied here.

A number of researchers have proposed new metrics to quantify agility. Each proposed metric is briefly presented in the text and discussed in detail in Appendix B. Within the restricted definition of agility described above, only a few of the proposed metrics are actually found to be measures of transient agility. Others focus on longer time scale maneuvers. They are more closely related to steady state performance and reflect new ways to measure that capability rather than transient agility. These performance oriented metrics, called functional metrics in Chapter Two, are not analyzed in this report.

The remaining transient agility metrics are further classified in Chapter

Two according to the primary type of aircraft motion involved. Axial agility 
deals with the ability to quickly change specific excess power levels. Axial agility metrics, studied in Chapter 3.1, are driven by the transient performance of the engine and drag producing devices.

Pitch agility measures the ability of the aircraft to quickly initiate symmetric pitching maneuvers. Requirements for the magnitude and controllability of such maneuvers are contained in the flying qualities standard and supporting handbook. Several metrics suggested to measure this transient capability include time to maximum load factor, time rate of change of load factor and maximum pitch rate. A key contribution of several agility researchers has been the recognition that both nose up and nose down pitch agility is important. In Chapter 3.2, each of the proposed pitch agility metrics is quantified in both the nose up and nose down direction.

Lateral agility concerns the ability to perform precise rolling maneuvers at elevated angles of attack. Lateral agility metrics emphasize the need for controlled rolling maneuvers by measuring the time to roll to and capture a given bank angle change. Ninety degree bank angle changes have been proposed in the literature and are studied in Chapter 3.3.

Flight testing agility will involve the use of transient maneuvers that are not now a part of standard flight test technique. Successful test will depend on the ability of the pilot to fly the maneuvers accurately and repeatably. A 
method of relaying steering cues to the pilot has been developed at NASA and will be used to support agility flight tests. Since the pitch and lateral agility metric requires the most complex pilot inputs, the sensitivity of those metrics to errors in following the steering cues was studied in Chapter 4.

\subsection{Conclusions}

1. Agility continues to be discussed and analyzed without the benefit of a commonly accepted definition. Transient agility metrics studied in this report offer ways to assess kinds of fighter capability that are not well quantified by traditional measures of merit. Functional agility metrics deal with longer term maneuvers and offer little insight that cannot already be gained with the traditional performance measures.

2. The power onset parameter, power loss parameter, nose up pitch rate, nose down pitch rate and the $T_{90}$ parameter together form a simple set of agility metrics that encompass the kinds of fighter capability generally grouped under the term agility. 
3. Two alternatives to pitch rate for measuring pitch agility have been published and are evaluated in this report. The metric consisting of time to maximum load factor and time to unload to zero load factor is not recommended since misleading values sometimes occur due to variations in the maximum load factor achievable at different flight conditions (see Section 3.2). Maximum positive and negative load factor rates are also not recommended as useful agility metrics since their values cannot be extracted from flight test results with any confidence using current instrumentation and analysis techniques (see recommendations).

4. Each of the recommended agility metrics listed above may be evaluated via flight test with no requirement for instrumentation or sensors not now available on the F-18 HARV aircraft.

5. None of the published pitch agility metrics, time to maximum load factor, load factor rate and pitch rate, are overly sensitive to errors in following steering cues relayed through the ADI steering needles. Nose up pitch rate is the most sensitive of the metrics. A $20 \%$ deviation in aft stick command causes a 10 to 15 degree fer second reduction in that metric at lower air speeds. The 
load factor rate metric in either the nose up or nose down direction is virtually unaffected by the pilot input errors studied in this report.

6. The $T_{90}$ metric is also not excessively sensitive to errors in following steering cues relayed through the ADI steering needles. The effects of deviating from the nominal stick inputs were largely corrected by the data reduction algorithm discussed in Section 3.3. Errors in lateral stick displacement of $20 \%$ caused $\mathrm{T}_{90}$ values to change on the average by $10 \%$. Erroneous longitudinal stick motion during the $\mathrm{T}_{90}$ maneuvers and changes in the stick deflection rates produced variations in $\mathrm{T}_{90}$ of less than $5 \%$. 


\subsection{Recommendations for Further Research}

1. Agility has been quantified here for one aircraft, the F-18. A necessary next step is to apply the same metrics and test methods to study the agility of other fighter aircraft. The relative agility of various aircraft can be studied via simulation at the University of Kansas and by flight test at NASA Dryden. Methods of graphically displaying different agility levels similar to the differential $P_{S}$ plots shown in Section 2 should be explored. To confirm that agility is a useful concept, the differences in levels of agility must then be correlated with the experiences of the pilots who employ the aircraft in operational air-to-air and air-to-ground missions.

2. If agility is an important attribute for future aircraft then the links between agility and aircraft configuration design should be explored. The F-18 simulation should be expanded to generate linear models of the airframe at trimmed and transient flight conditions. Linear flight control models are also needed in transfer function or state space form. These models could then be used to quantify relationships between agility, as defined by the metrics studied in this report, to aircraft and control system design parameters, e.g. control power, wing loading, inertias, time constants, and actuator rates. 
3. The links between agility and flying qualities should be established. Thanks to decades of research, much is known about the damping ratios, time constants and frequencies that are associated with good flying qualities. Pilot rating scales similar to the Cooper-Harper system are needed to determine how much agility is desirable. If agility can be tied to pilot approval, then the relationships and conflicts between good flying qualities and good agility may be discovered.

4. Because of the proprietary restrictions placed on reports containing complete derivations and developments of Dr. Herbst's agility metrics, those metrics are not evaluated here. If Dr. Herbst's work cannot be evaluated at the University of Kansas, then it should be reviewed by Mr. Eggold at NASA Dryden.

5. Load factor rate would be a useful pitch agility metric if that data could be extracted from flight test results with sufficient reliability. Optimal estimation methods should be explored as a possible approach to getting useful load factor rate data from current flight test instruments. 


\section{REFERENCES}

1. Dorn, Matthew (USAF). The Science of Aircraft Agility: A Framework for Classification and Exploration," presented at the AIAA Aerospace Engineering Conference and Show, Feb 89.

2. Dorn, Matthew (USAF). "Aircraft Agility: The Science and the Opportunities," presented at the AIAA Aircraft, Design Systems and Ops Meeting, Aug 89.

3. Herbst, W.B. (MBB). "Dynamics of Air Combat," Journal of Aircraft, Vol. 20, No. 7, July 83, pp 594-598.

4. Herbst, W.B. (MBB). "Supermaneuverability," Presented at the Joint Automatic Control Conference, June 81.

5. Herbst, W.B. (MBB). "Future Fighter Technologies," AIAA Journal of Aircraft, Vol. 17, No.8, Aug 80, AIAA \#80-4077.

6. McAtee, T.P. (GD). "Agility - Its Nature and Needs in the 1990's," presented at the Society of Experimental Test Pilots Symposium, Sept 87.

7. McAtee, T.P. (GD). "Agility in Demand," Aerospace America, May 88.

8. Skow, A.M. and Hamilton, W.L. (Eidetics). "Advanced Fighter Agility Metrics," Eidetics Report 84-05 for AFFDL, Sept 84.

9. Skow, A.M. and others (Eidetics). "Transient Agility Enhancements for Tactical Aircraft," Eidetics TR-89-001, done for ASD contract \#F3365787-C-2045, Jan 89.

10. Tamrat, B.F. "Fighter Aircraft Agility Assessment Concepts and Their Implication on Future Agile Fighter Design," AIAA Aircraft Design, Systems and Ops Meeting, Sept 88, AIAA \#88-4400. 
11. Foltyn, R.W. and others (Eidetics). "Development of Innovative Air Combat Measures of Merit for Supermaneuverable Fighters," AFWALTR-87-3073.

12. Herbst, W.B. (MBB). "X-31A," presented at NAECON 87, SAE \#871346.

13. Herbst, W.B. (MBB). "Future Fighter Maneuverability for Air Combat," presented at the AIAA Design, Systems and Ops Meeting, Oct 83.

14. Ray, B.S. and Cord, T.J. "Supermaneuverability and Flying Qualities Issues," presented at the 1986 IEEE National Aerospace Electronics Conference (NAECON).

15. Sweetman, B. "X-31, Through the Grape Barrier," Interavia, May 87.

16. Brown P.T. and others (USAF). "T-38A/F-16B Agility Metrics Evaluation (Agile Lightning)," USAF Test Pilots School TR-87A-S04, Dec 87.

17. Scott, W.B. (Av Week). "Air Force, NASA Conduct Test to Define Fighter Aircraft Agility," 9 Jan 89.

18. Chin, J. (Grumman). "X-29A Flight Control System Performance During Flight Test," presented at the AIAA Aircraft Design, Systems and Ops Meeting, Sept 87, AIAA \#87-2878.

19. Trippensee, G.A. and Lux, D.P. (NASA). "X-29A Forward-Swept-Wing Flight Research Program Status," NAECON 87, SAE \#782418.

20. Foltyn, R.W. and others (Eidetics). "Innovative Cockpit Display and Cuing Systems for Operation in an Extended Flight Envelope," NASATR-87-215.

21. Beaufrere, Henry. "Integrated Flight Control System Design for Fighter Aircraft Agility," presented at the Aircraft Design, Systems and Ops Meeting, Sept 88, AIAA \#88-4503. 
22. Riley, Dave and Drajeske, Mark (McAir). "An Experimental Investigation of Torsional Agility in Air-to-Air Combat," presented at the AIAA Atmospheric Flight Mechanics Conference, Aug 89, AIAA \#893388.

23. Wendel,T.R. (McAir). "Flight Control Synthesis to Meet Flying Qualities Specifications: An Evaluation of Multivariable Synthesis Techniques," AIAA Aircraft Design, Systems and Ops Meeting, Sept 87, AIAA \#87-2880.

24. Kalviste, Juri (Northrop). "Spherical Mapping and Analysis of Aircraft Angles for Maneuvering Flight," AIAA Journal of Aircraft, Vol. 24, No. 8, Aug 87.

25. Kalviste, Juri (Northrop). "Roll Reversal Agility Parameter," AFFDL Aircraft Agility Workshop Summary Booklet, Aug 89.

26. Bitten, Robert (Rockwell). "Qualitative and Quantitative Comparison of Government and Industry Agility Metrics," presented at AIAA Flight Mechanics Conference, Aug 89.

27. Jane's All the World's Aircraft, Janes Publishing, 1985.

28. Nicolai, L.M. Fundamentals of Aircraft Design, University of Dayton School of Engineering, 1985.

29. Anon. USAF Test Pilot School Performance Phase Textbook, USAFTPS-CUR-86-01, April 1986.

30. Spearman, M.L. (NASA). "Some Fighter Aircraft Trends," presented at the AIAA Aircraft Design, Systems and Ops Meeting, Nov 84, AIAA \#84-2503.

31. Gilbert, W.P. "Overview of NASA High-Alpha Technology Program (HAPT)," presented at the High Alpha Technology Program Workshop, Nov 89.

32. Twisdale, T. and Franklin D. "Tracking Task Techniques for Handling Qalities Evaluations," AFFTC-TD-75-1, May 75. 
33. Cord, Tom J. (AFFDL). "A Standard Evaluation Maneuver Set for Agility and the Extended Flight Envelope - An Extension to HQDT," presented at the AIAA Atmospheric Flight Mechanics Conference, Aug 89, AIAA \#89-3357.

34. Anon. USAF Test Pilot School Flying Qualities Textbook, USAF-TPSCU-86-03, April 1986.

35. Anderson, John (USAF). "Agile Fighter Aircraft Simulation," AIAA \#89-0015.

36. Walker, H.C. (USAF). AFFTC Agility Flight Test Committee Meeting Minutes, June 1987.

37. Military Specification, Flying Qualitities of Piloted Airplanes, MIL-F8785-C, Novemever, 1980.

38. Shaw, Robert L. Fighter Combat, Tactics and Maneuvering. United States Naval Institute Press, 1985.

39. Rutowski, E.S. "Energy Approach to the General Aircraft Performance Problem," Journal of Aeronautical Science, Vol. 21, No.3, March 1954, pp. 187-195.

40. Lan, C.E. and Roskam, J. Airplane Aerodynamics and Performance, Roskam Aviation and Engineering, 1980.

41. Chin, Hubert H. (Grumman). "A Knowledge Based System for Supermaneuver Selection for Pilot Aiding," presented at the AIAA Aircraft Design, Systems and Ops Meeting, Sept 88, AIAA \#88-4442.

42. Stubben, Mark (USAF). "A Pilot's Perspective of the Advanced Fighter Technology Integration Automated Maneuvering Attack System," NAECON 87, SAE \#871349.

43. Dowden, D.J. (USAF) and Bessette, D.E. (NASA). "Advanced Fighter Technology Integration (AFTI/F-16) Automated Maneuvering $f$ ttack System Final Flight Test Results," presented at NAECON 87, SAE \#871348. 
44. Linn, D. F-18 Hornet in Detail and Scale, Tab Books, 1982.

45. Moomaw, R.F., Trame, L.W., Hess, R.K. F/A-18 flight control system Design Report. McDonnell-Douglas Report MDC A1713, June 1984.

46. Valasek, J. SIM-II F-18 Flight Simulation Program Documentation. KU-FRL-831-1, August, 1990 (projected). 


\section{Appendix A: Specific Excess Power $\left(\mathbf{P}_{\mathrm{S}}\right)$}

Over the last fifteen years energy maneuverability has been the primary tool for comparing fighter performance. The unit of measurement for this comparison is Specific Excess Power or $P_{s}$. In this appendix the equations for $P_{S}$ are derived from first principles.

The energy approach to aircraft performance was originally developed by Rutowski in the mid 1950's (Reference 39). The derivation here generally follows that presented in Reference 29. In its most basic form the following assumptions are made

1. Configuration is fixed.

2. Weight is constant.

3. Load factor is constant.

4. Thrust level is fixed.

5. Kinetic and potential energy can be exchanged instantly and with no losses. 
The total energy of an aircraft is the sum of its kinetic and potential energy and can be written as

$$
E=m g h+\frac{m V^{2}}{2}
$$

Normalizing with aircraft weight gives specific energy,

$$
\mathrm{E}_{s}=\frac{\mathrm{V}^{2}}{2 \mathrm{~g}}+\mathrm{h}
$$

An expression for the rate of change of this specific energy is found by differentiating equation A.2 with respect to time.

$$
\frac{d E_{g}}{d t}=\frac{V}{g} \frac{d V}{d t}+\frac{d h}{d t}
$$

Summing forces along the flight path of an aircraft in accelerated climbing flight (Figure A.1) gives

$$
\frac{W}{g} \frac{d V}{d t}=T \cos \left(\alpha-\phi_{T}\right)-D-W \sin \gamma
$$




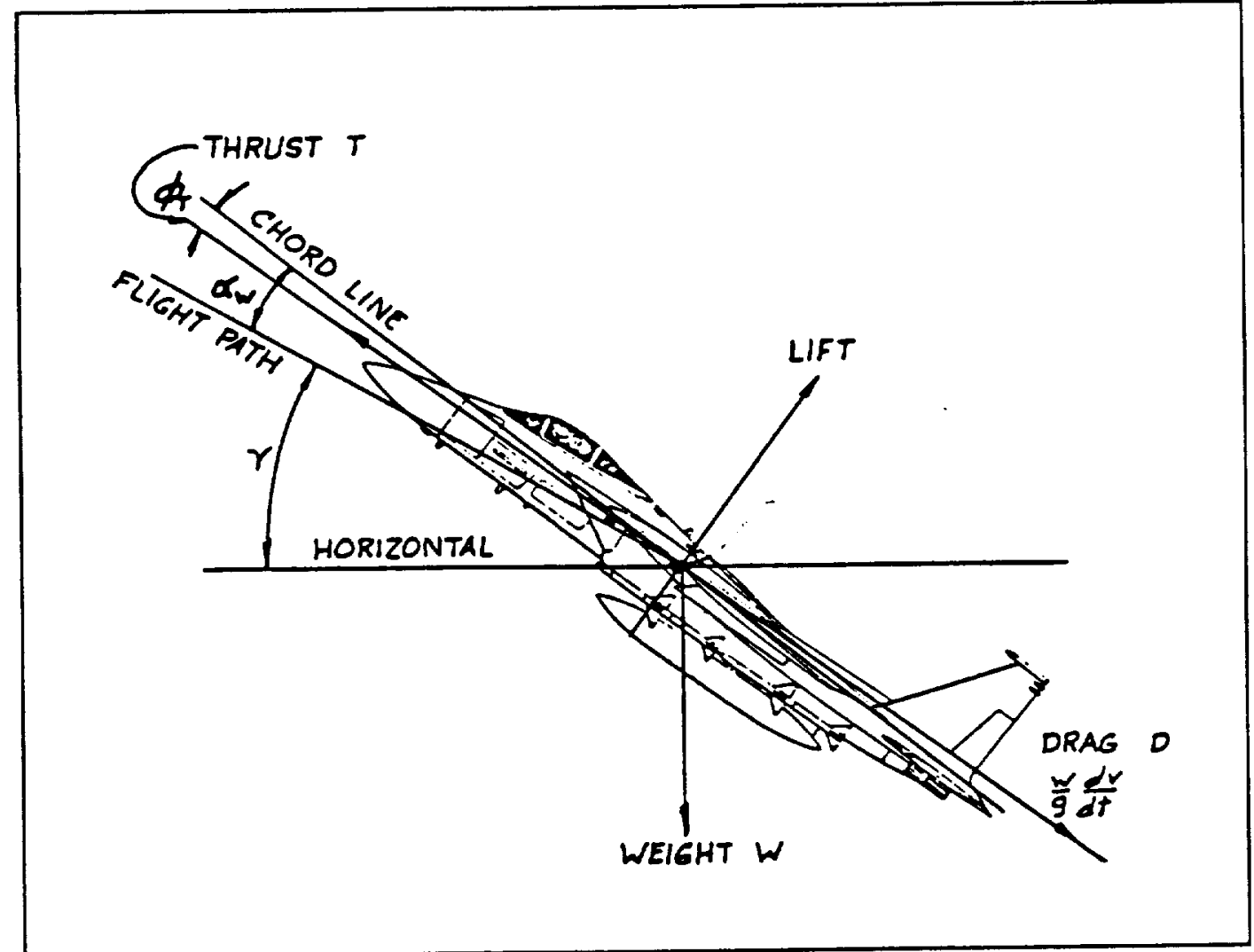

Figure A.1: Flight Path Geometry for Airplane

in Accelerated Climb (Reference 40)

Multiplying equation A.4 by $\mathrm{V}$, dividing by $\mathrm{W}$ and recognizing that

$$
\mathrm{V} \sin \gamma=\frac{\mathrm{dh}}{\mathrm{dt}}
$$

gives 


$$
\frac{V}{g} \frac{d V}{d t}+\frac{d h}{d t}=\frac{V\left(T \cos \left(\alpha-\phi_{T}\right)-D\right)}{W}
$$

Therefore,

$$
\frac{d E_{s}}{d t}=\frac{V\left(T \cos \left(\alpha-\phi_{T}\right)-D\right)}{W}
$$

Since thrust times velocity is power, $\mathrm{dE}_{\mathrm{g}} / \mathrm{dt}$ is usually called specific excess power, $\mathrm{P}_{\mathrm{s}}$ so

$$
P_{3}=\frac{d E_{s}}{d t}
$$




\section{Appendix B: Published Agility Metrics}

Though numerous papers have discussed the need for new ways of measuring fighter agility characteristics, relatively few authors have actually proposed new metrics that could be used to develop a quantitative measure of agility. The agility metrics that have been published deal with many different aspects of fighter capability. What follows is a brief definition and discussion of each of the agility metrics found in the literature.

\section{Metric Name: Pitch Agility}

Proposed by: Eidetics ("Transient Agility Enhancements for Tactical Aircraft," Eidetics TR-89-001, ASD contract F33657-87-C-2045, Reference 9.)

Definition: (Time to pitch from one $g$ to maximum $C_{L}$ or $n_{z}$ ) $+($ Time to pitch down from maximum $C_{L}$ or $n_{z}$ to zero $g$ )

Discussion: The authors of the Eidetics report observed that both nose up and nose down pitch agility are important. However, a number of questions about pitch agility remain are not addressed in the Eidetics report. 
1. If the times associated with nose up and nose down pitch maneuvers are to be summed, should the two be equally weighted?

2. Is the time to pitch up significantly different than the time to pitch down?

3. Does an aircraft with better positive pitch agility necessarily have better negative pitch agility?

Since these questions remain to be resolved by flight testers, engineers and fighter pilots, values associated with positive pitch maneuvers and those associated with nose down pitching are treated as separate metrics through out this report rather than summed into a single figure of merit.

Though the time to achieve maximum load factor and the time to unload to zero $n_{z}$ are conceptually simple, several difficulties arise when these metrics are evaluated with realistic aircraft models. While it is easy to initiate the pitch up from steady level flight conditions, the pitch down from maximum $\mathrm{n}_{\mathrm{z}}$ may start from a condition where airspeed and altitude are rapidly changing. If pitch agility is to be plotted against flight condition, the choice of flight condition may often be somewhat arbitrary. 
Also, because of flight control and aerodynamic nonlinearities, the load factor response will often not be well damped. Determining time to maximum load factor is often subjective when no steady state value is reached or the maximum value is approached asymptotically. 


\section{Metric Name: Lateral Agility, $\mathbf{T}_{90}$}

Proposed by: Eidetics ("Transient Agility Enhancements for Tactical Aircraft," Eidetics TR-89-001, ASD contract F33657-87-C-2045, Reference 9).

Definition: Time to roll $90^{\circ}$ and stop while maintaining angle of attack. This metric is a function of Mach, altitude and load factor or angle of attack.

Discussion: Many fighters possess very limited ability to roll quickly at high angles of attack. How (or should) this maneuver be compared to the more common technique of unloading first, then rolling at one or zero $\mathrm{g}$ and then pitching to reestablish the initial angle of attack? The unload-roll-load method is probably faster especially for high angle of attack conditions. Using the loaded roll method, i.e. holding angle of attack during the roll, the aircraft heading angle is changed during the rolling maneuver. However, with the unloaded roll method the aircraft orientation is changed but the heading angle is not rotated since the roll is accomplished while unloaded. The opinion of Eidetics and others is that the loaded roll is important since it measures the ability of the aircraft to maneuver at high angles of attack even though it is not as commonly used by current fighters engaged in air combat maneuvering (Reference 38). 
Several loaded roll maneuvers could be used to test for the $T_{90}$ metric. Options are to (1) start with wings level, pull to target load factor (or angle of attack) and then apply lateral stick and roll to $90^{\circ}$, or (2) first roll to $90^{\circ}$, pull to the target load factor and then roll to wings level, or (3) roll to $45^{\circ}$, pull to target load factor and then roll to opposite bank angle. The first method is easiest to simulate. The second is probably the easiest to fly since the pilot can use the horizon to judge the target roll angle. Preliminary flight test (Reference 16) used the third method and found that it was hard for the pilot to hit and hold the target load factor during the maneuver. Pilots also had to balance fast roll rate against the ability to stop at the target bank angle. Individual pilots produced greatly different results because they often did not use the aircraft's maximum roll rate capability. Manned simulation or flight test may be required to determine which method is easiest to test and most meaningful to tactical (as opposed to test) pilot.

An alternate metric is the time to roll $180^{\circ}$ instead of $90^{\circ}$ while holding angle of attack. This metric may be more representative of actual tactics than $T_{90} . T_{180}$ is also a more demanding test of the flight control system since the build up of adverse -raw will be more pronounced over the longer maneuver. 
The only related MIL SPEC concerning the roll axis is the requirement that deals with rolls through $90^{\circ}$ or $180^{\circ}$ at a load factor of one and at a single loaded condition. There is no requirement stop at a target bank angle (Reference 37). 


\section{Metric Name: Torsional Agility, $T R / T_{00}(T R=$ turn rate $)$}

Proposed by: Eidetics ("Transient Agility Enhancements for Tactical Aircraft,"

Eidetics TR-89-001, ASD contract F33657-87-C-2045, Reference 9).

Definition: Turn rate divided by the lateral agility metric, $T_{90}$, as defined for the lateral agility metric. Resulting units are degrees per $\sec ^{2}$.

Discussion: This metric would be calculated from the same flight test results used to obtain $T_{90}$ data so all the issues associated with that metric apply here also. Turn rate is not measured directly during the flight test but is calculated from test results based on airspeed and load factor as

$$
\mathrm{TR}=\frac{8 \sqrt{\left(\mathrm{n}_{z}^{2}-1\right)}}{\mathrm{V}}
$$

When these quantities change during the rolling maneuver the choice of which speed and load factor to use in calculating turn rate is unresolved.

This metric indicates that turn rate and $T_{90}$ are equally critical to agility. For example, an aircraft with twice the normal acceleration for a given angle of attack and airspeed is exactly as $t$ rsionally agile as one 
with half the $T_{90}$ at the same conditions. This one-to-one ratio is arbitrary and unsupported (in fact, it is contradicted by the Eidetics report cited above). As a result this metric seems of little practical use to a pilot or designer. 


\section{Metric Name: Axial Agility}

Proposed by: Eidetics ("Transient Agility Enhancements for Tactical Aircraft," Eidetics TR-89-001, ASD contract F33657-87-C-2045, Reference 9.)

Definition: The difference between the aircraft's $P_{S}$ in its maximum thrust, minimum drag configuration and its $P_{S}$ in the minimum thrust, maximum drag configuration, $\Delta \mathrm{P}_{\mathrm{S}}$, divided by the time required to transition between these two configuration, $\Delta t$. This time increment is affected by engine spool time, speed brake deployment time and thrust reversers, if any. Transition from minimum to maximum power is called the power onset parameter and transition from maximum to minimum power is termed the power loss parameter.

Discussion: The time increment $\Delta \mathrm{t}$ is probably driven by engine spool time since the time constants associated with speed brake deflection and thrust reversers will be smaller. The axial agility of a fighter is also affected by the engine's transient performance at elevated angles of attack and sideslip. The transient behavior of the engine during large scale maneuvers and high angle of attack flight is an important contributor to overall combat effectiveness. The pow $r$ onset and power loss parameters do not address this aspect of engine performance. 
V. Metric Name: Relative Energy State, $\left(V / V_{c}\right)$

Proposed by: B.F. Tamrat (Northrop, "Fighter Agility Assessment Concepts and Their Implications on Future Agile Fighter Design," AIAA \#88-4400, Aircraft Systems, Design and Operations Meeting, Sept 88, Reference 10.)

Definition: The ratio of the aircraft's speed to its corner speed at completion of a $180^{\circ}$ turn at maximum $\mathrm{g}$ from a given starting position (altitude and airspeed). This ratio, $\mathrm{V} / \mathrm{N}_{\mathrm{c}}$, should be as close to 1.0 as possible.

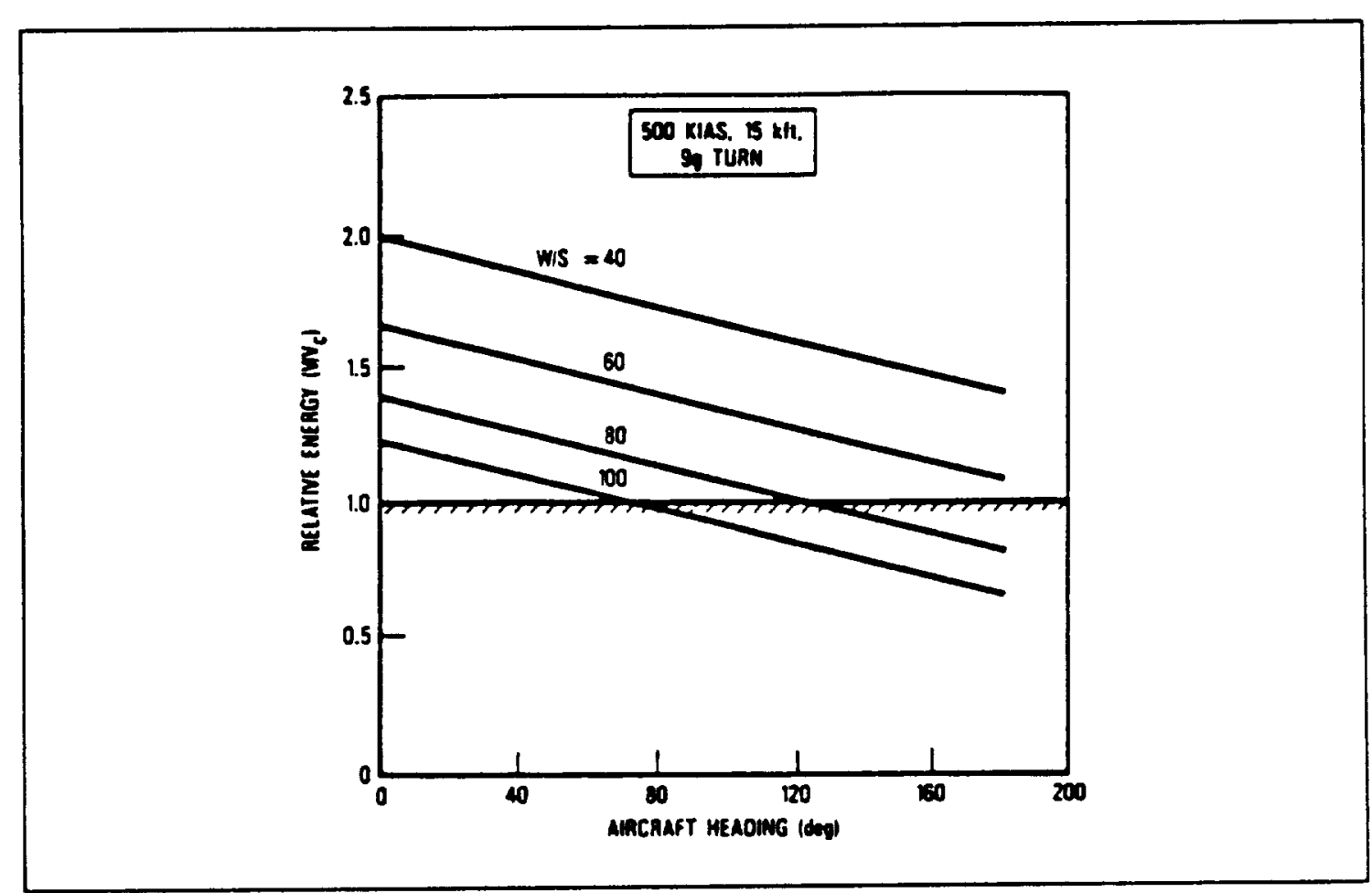

Figure B.1: Relative Energy State 
Discussion: This parameter neglects the turn rate associated with each configuration and thus the time required to complete the $180^{\circ}$ turn. Relative energy state is a performance parameter driven solely by thrust and drag characteristics and not a transient agility metric. 


\section{Metric Name: Combat Cycle Time}

Proposed by: B.F. Tamrat (Northrop, "Fighter Agility Assessment Concepts and Their Implications on Future Agile Fighter Design," AIAA \#88-4400, Aircraft Systems, Design and Operations Meeting, Sept 88, Reference 10.)

Definition: $t_{1}+t_{21}+t_{22}+t_{3}+t_{4} \quad$ where:

$t_{1}=$ time to pitch from one $g$ to the limit load factor

$t_{21}+t_{22}=$ time to turn to a specified new heading angle at maximum load factor

$t_{3}=$ time to unload the aircraft to a load factor of one (or zero) $t_{4}=$ time to accelerate to the original energy level

Discussion: This metric would be calculated for a given set of starting conditions and some specified heading angle change. It is not clear from Tamrat's paper whether he intends for the aircraft to be at the same Mach and altitude at the end of the combat cycle or only to have the same total energy. 
Times $t_{1}$ and $t_{3}$ are probably negligible relative to the others so this parameter is dominated by turn rate and $\mathrm{P}_{\mathrm{s}}$. As a result, it also a performance rather than agility metric.

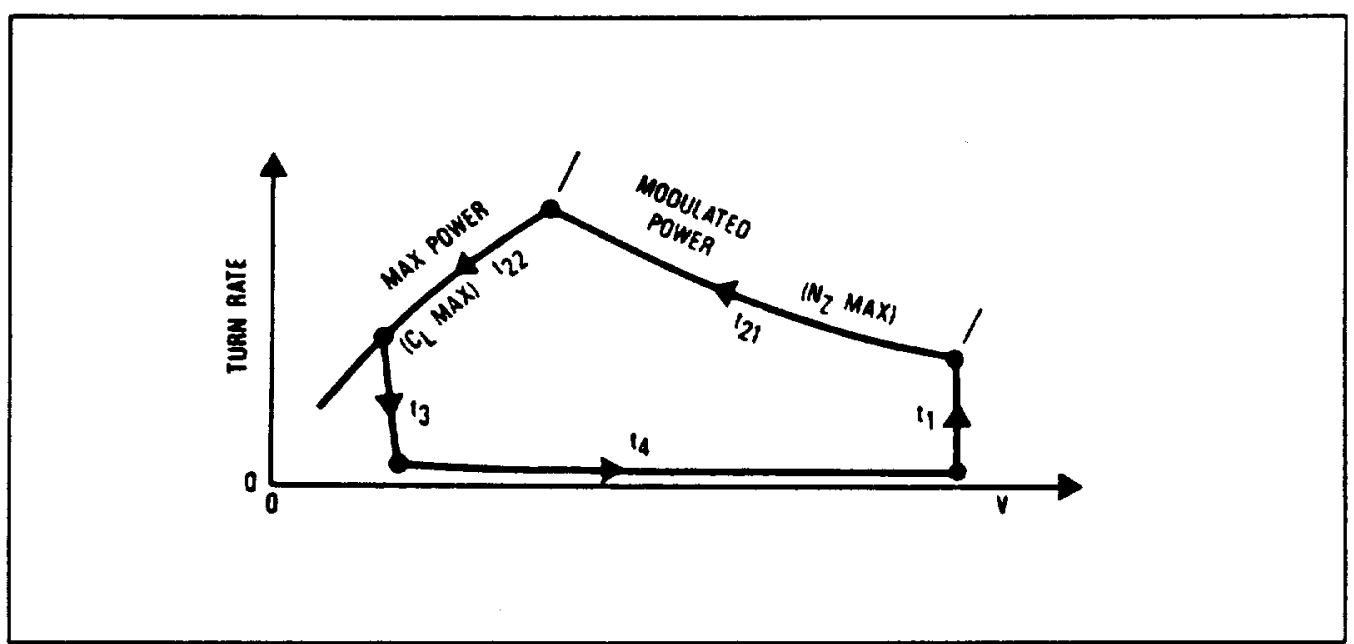

Figure B.2: Concept of Combat Cycle Time 


\section{Metric Name: Pointing Margin}

Proposed by: B.F. Tamrat (Northrop, "Fighter Agility Assessment Concepts and Their Implications on Future Agile Fighter Design," AIAA \#88-4400, Aircraft Systems, Design and Operations Meeting, Sept 88, Reference 10.)

Definition: The angle between the nose of the adversary and the line of sight at the instant the friendly fighter is aligned with the line of sight.

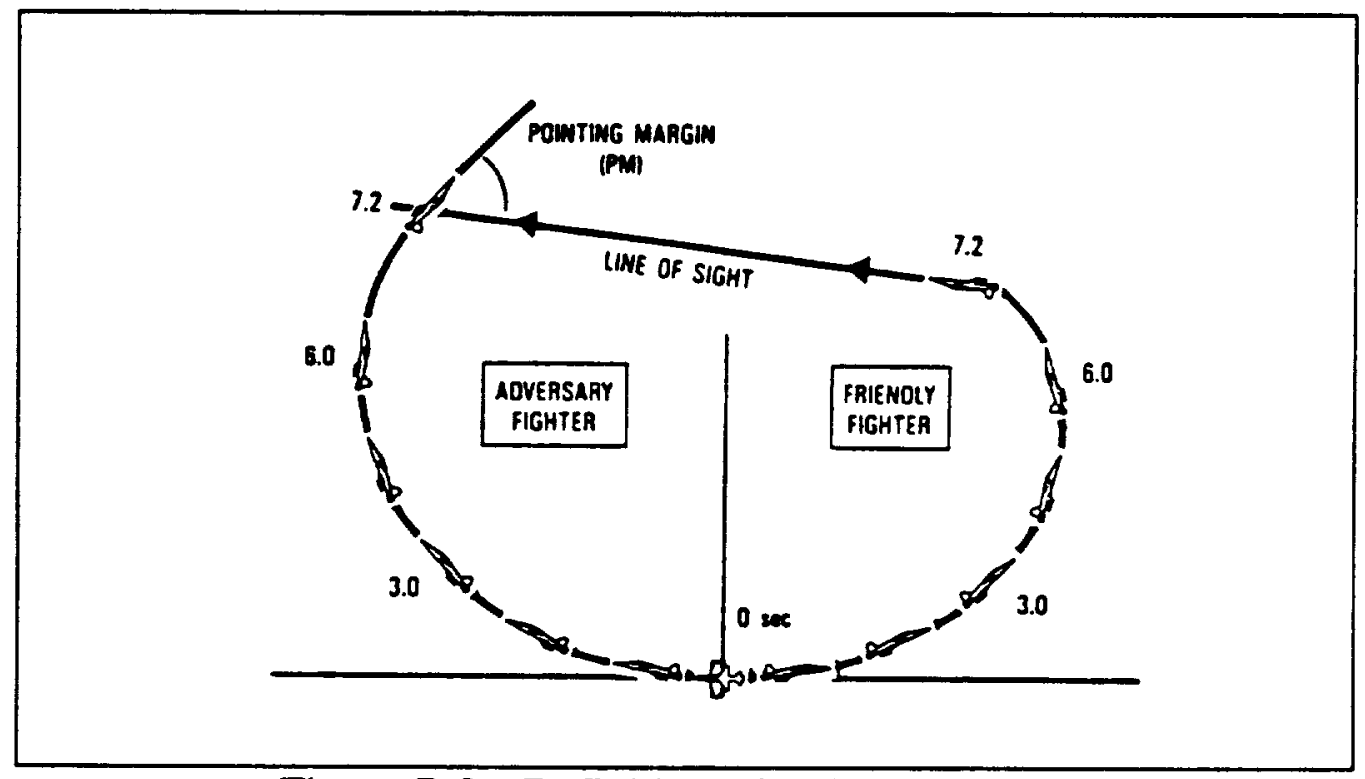

Figure B.3: Definition of Pointing Margin 
Discussion: This metric requires the definition of some standard adversary turn performance (load factor, speed loss, altitude change, etc). Tamrat's paper implies that both aircraft are to be constrained to a single maneuver plane. This metric incorporates the effects of pitch rate, thrust and drag transient characteristics but long term performance (7 - 10 seconds) will have a greater impact than transient agility. The same aircraft capabilities could be assessed by measuring the time to reverse heading by $180^{\circ}$. 


\section{Metric Name: Dynamic Speed Turns}

Proposed by: T.P. McAtee, (General Dynamics, "Agility - Its Nature and Need in the 1990's," Society of Experimental Test Pilots Symposium, Sept 87 and "Agility in Demand," Aerospace America, May 88, Reference 6, 7.)

Definition: The Dynamic Speed Turn is not actually a new metric but a plot of $P_{S}$ against maximum tum rate at a given starting airspeed. The objective is to clearly show bleed rate for maximum acceleration turns and the straight and level acceleration capability at various airspeeds.
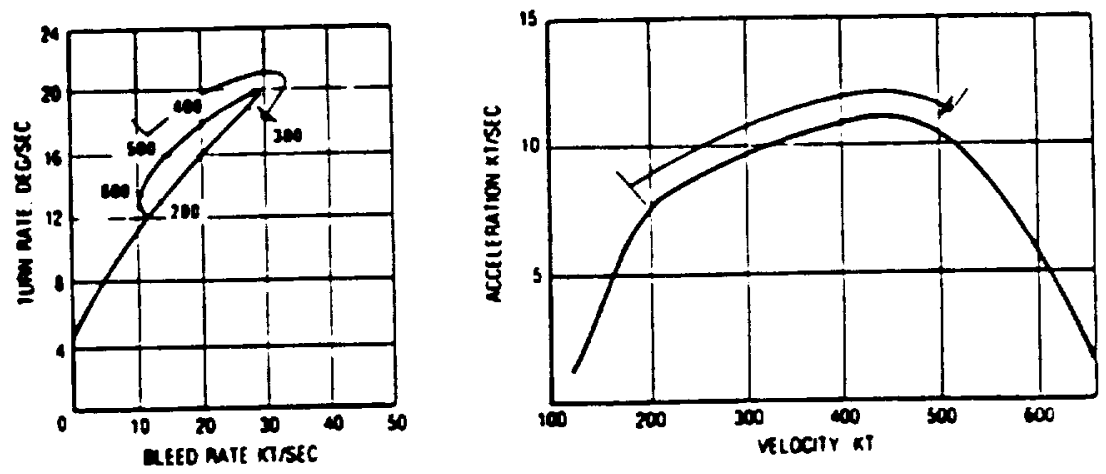

Figure B.4: Dynamic Speed Turn Plots 


\section{Metric Name: Agility Potential and Maneuvering Potential}

Proposed by: Spearman (NASA Langley, "Some Fighter Aircraft Trends," AIAA \#84-2503, Aircraft systems, Design and Operations Meeting, Oct 84, Reference 30.)

Definition: Agility potential is the aircraft's maximum thrust to weight ratio divided by its wing loading. The maneuvering potential is not explicitly defined in the referenced paper but is referred to only as a function of the thrust to weight ratio, the lift to drag ratio, the maximum lift coefficient and wing loading.

Discussion: These two parameters relate aircraft size and configuration to agility using traditional measures of merit, wing loading and thrust to weight ratio. They do not address the flight control characteristics, high angle of attack capability or body rate controllability. They are not intended to address transient aircraft agility. 
X. Metric Name: Pitch Agility Criteria or Maximum Initial Pitch Acceleration Parameter

Proposed by: Eidetics ("Transient Agility Enhancements for Tactical Aircraft," Eidetics TR-89-001, ASD contract F33657-87-C-2045, Reference 30.)

Definition: This metric is defined as

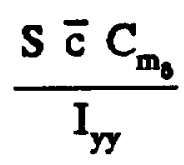

where $\mathrm{C}_{\mathrm{m}_{\delta}}$ is the nondimensional pitching moment produced by maximum deflection the aircraft's pitch control surfaces. Here, $S, \bar{c}$ and $\mathrm{I}_{\mathrm{yy}}$ are standard notation for reference wing area, mean aerodynamic chord and pitch axis moment of inertia.

Discussion: This parameter is extracted from the expression for the dimensional pitching moment derivative 


$$
\mathbf{M}_{\mathbf{z}}=\frac{\overline{\mathrm{q}} \mathbf{S} \overline{\mathrm{c}} \mathrm{C}_{\mathrm{m}_{\mathrm{g}}}}{\mathrm{I}_{\mathrm{yy}}}
$$

and is a measure of the airframe's potential to generate pitch acceleration. It can be calculated directly from aerodynamic coefficients and configuration data but does not reflect any flight control system limits. Though the authors of the Eidetics report address only the Pitch Agility Criteria, their ideas could be easily extended to a Roll Agility Criteria.

$$
L_{\mathbf{z}}=\frac{\bar{q} S \text { b C } \mathrm{I}_{\mathrm{g}}}{\mathrm{I}_{\mathrm{xx}}}
$$

where $\mathrm{C}_{\mathrm{l}_{\delta}}$ is the nondimensional rolling moment produced by maximum deflection of the aircraft's roll control surfaces and $b$ is a reference 
length. Then, the Roll Agility Criteria would be

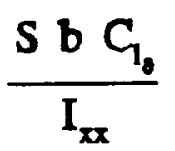

both of these parameters then have units of feet per slug. 


\section{Metric Name: Roll Reversal Agility Parameter}

Proposed by: Juri Kalviste (Northrop, presented at the Flight Dynamics Laboratory's Aircraft Agility Workshop, Aug 1989.)

Definition:

\section{Roll Reversal Parameter $=(\mathrm{T})(\mathrm{Y})$}

Where $\mathrm{T}$ is the time to reverse a turn of some given acceleration to the opposite direction and $\mathrm{Y}$ is the cross range displacement that occurs from when the reversal is initiated to when the acceleration in the opposite direction is achieved. Smaller values for this parameter reflect a more agile aircraft.

Discussion: The parameter would be based on reversing a level turn of a given load factor or on reversing from $+90^{\circ}$ to $-90^{\circ}$ of bank also at some given normal acceleration level. The metric implies that the pilot would hold the aircraft at the given load factor while reversing the turn. If he is allowed to unload first and then change bank angle before reloading to the entry load factor, the cross range distance, $\mathrm{Y}$, becomes nearly zero and the roll reversal parameter becomes very small. 
Cross range distance, $\mathrm{Y}$, is a function of the aircraft's normal acceleration during the roll.Since turn radius is inversely proportional to load factor,

$$
R=\frac{V^{2}}{g \sqrt{n_{2}^{2}-1}}
$$

and turn rate is directly proportional to load factor,

$$
\operatorname{TR}=\frac{g \sqrt{n_{z}^{2}-1}}{V}
$$

the Roll Reversal Parameter is very similar to the Torsional Agility Parameter proposed by Eidetics and defined as turn rate divided by $T_{90}$. 


\section{Appendix C: F-18 Simulation (SIM 2)}

Appendix C describes the F-18 HARV simulation used to conduct the simulation studies described in this report. A brief discussion of the aircraft models and simulation capabilities is followed by a detailed description of the program organization. A cross reference of subroutines and Fortran files is provided along with a detailed flow diagram and tabular listing of the most common variable names. User instructions are also provided. The math models, equations of motion and data structures for the simulation are documented in Reference 46 which also contains a complete listing of the Fortran source code. Simulation results were compared to a set of check cases provided by NASA Dryden. Time histories from that exercise are also presented in this appendix.

\section{C.1 Introduction}

SIM 2 is a non-real time, high fidelity, six degree-of-freedom, non-linear aircraft simulation. It is widely used by NASA and the aerospace industry to model vehicles such as HiN AT, YF-16, F-18 and B-2. SIM 2 was created at the NASA Flight Research Center in 1977 by Lee Duke and Albert Myers. 
Their goal was to initiate a standard approach to simulating digital flight control systems. The internal structure of SIM 2 is highly modular and has proven to be a very successful design tool. In addition, the modular construction has permitted SIM 2 to become the basis for real time man-in-the-loop simulations.

In May 1989, NASA Dryden provided the University of Kansas with a version of SIM 2 that included F-18 aerodynamic, engine and flight control models that ran interactively in real time on their ELXSI computer system. Mr. John Valasek and Mr. Dave Eggold rewrote major portions of the input and output routines and replaced functions that relied on the peculiar capabilities of the NASA hardware. The program now resides on an Apollo workstation and runs a non-interactive, non-real time fashion. 


\section{C.2 Capabilities and Models}

\section{C.2.1 Aerodynamics}

The F-18 aerodynamic data base is a full set of steady, non-linear aerodynamic data which is derived primarily from wind tunnel results with flight test corrections. Of the four aerodynamic data bases available for the F18 (clean, high angle of attack, power approach and take-off), only the clean and high angle of attack sets reside in the Kansas University version of the simulation. The high angle of attack data includes complete aerodynamics for flight up to $70^{\circ}$ angle of attack. The simulation transitions automatically to this data set whenever the aircraft exceeds $40^{\circ}$ angle of attack.

The modular structure of SIM 2 will accommodate aerodynamic models of various levels of fidelity. All of the aerodynamic executive and interpolation routines for a given aircraft model are in the file ARODAT.FTN. Subroutine CCALC contains the aerodynamic buildup for all of the parameters in body axes. Each term in the build up is evaluated individually and then summed to create a parameter. A dictionary of the terms is provided in comment lines at the top of subroutine CCALC.

The aerodynamic data bookkeeping is handled in a series of subroutines

YYY_INDEX where YYY is the name of the data base. Interpolation within 
the data base is performed in the YYY_TLU subroutines (TLU stands for Table Look Up).

\section{C.2.2 Flight Control System}

The flight control system was coded by NASA from McDonnellDouglas's Control System Design Book MDC A7813 (Ref. 45) for prom set 8.3.3. The digital characteristics of the F-18 flight control system including multiple update rates (see Section C.2.6) are carefully reproduced. The flight control model includes several autopilot modes which are described below in Section C.2.7. None of the control system modifications for the thrust vector control paddles are included in the simulation at the University.

\section{C.2.3 Actuators}

The file ACTUAT.FTN contains the actuator models used in SIM 2. The current actuator models are second order, rate and hinge moment limited. The actuator for each control surface is modelled separately with its own frequency, damping ratio and limits. Mr. Valasek extensively rewrote the actuator code to make the frequencies and damping ratios clearly visible (Ref. 46). A number of test cases were run to ensure that this rewrite did not change the actuator characteristics. 


\section{C.2.4 Equations of Motion}

The equations of motion are executed in a subroutine named DERIVC which uses the six degree of freedom equations with expressions for angle of attack rate and angle of sideslip rate. DERIVC also accounts for center of gravity shifts.

\section{C.2.5 Integration Method}

The equations of motion are integrated with a modified second order Runge-Kutta algorithm. This algorithm, presumably chosen to allow real time execution at NASA, has not been modified at the University.

\section{C.2.6 Multi-rate Calculations}

All of the calculations in SIM 2 are accomplished in one of three time frames. Flight control functions run at 20 and 40 Herz depending on the path involved. The engine model is updated at $40 \mathrm{Herz}$. All other vehicle and simulation tasks are performed at 80 Herz.

Subroutine MULTRT in EXEC.FTN performs the multi-rate clocking function. It sets and clears flags which indicate when the various calculations are to be made. 


\section{C.2.7 Autopilot Modes}

Two autopilot modes currently function in SIM 2. The first is an altitude hold autopilot which permits the user to select an altitude to be maintained. The required inputs are commanded altitude and the discrete time at which the autopilot is to be engaged and disengaged. The second mode is bank angle hold. The user specifies the commanded bank angle and the engage and disengage times in the same manner as for the altitude hold mode. Autopilot inputs are made with the user input file (see section C.4).

\section{C.3 Program Organization}

The general flow of the simulation portrayed in Figure C.1. A detailed wiring diagram reflecting interaction of each subroutine is presented later as Figure C.2. 


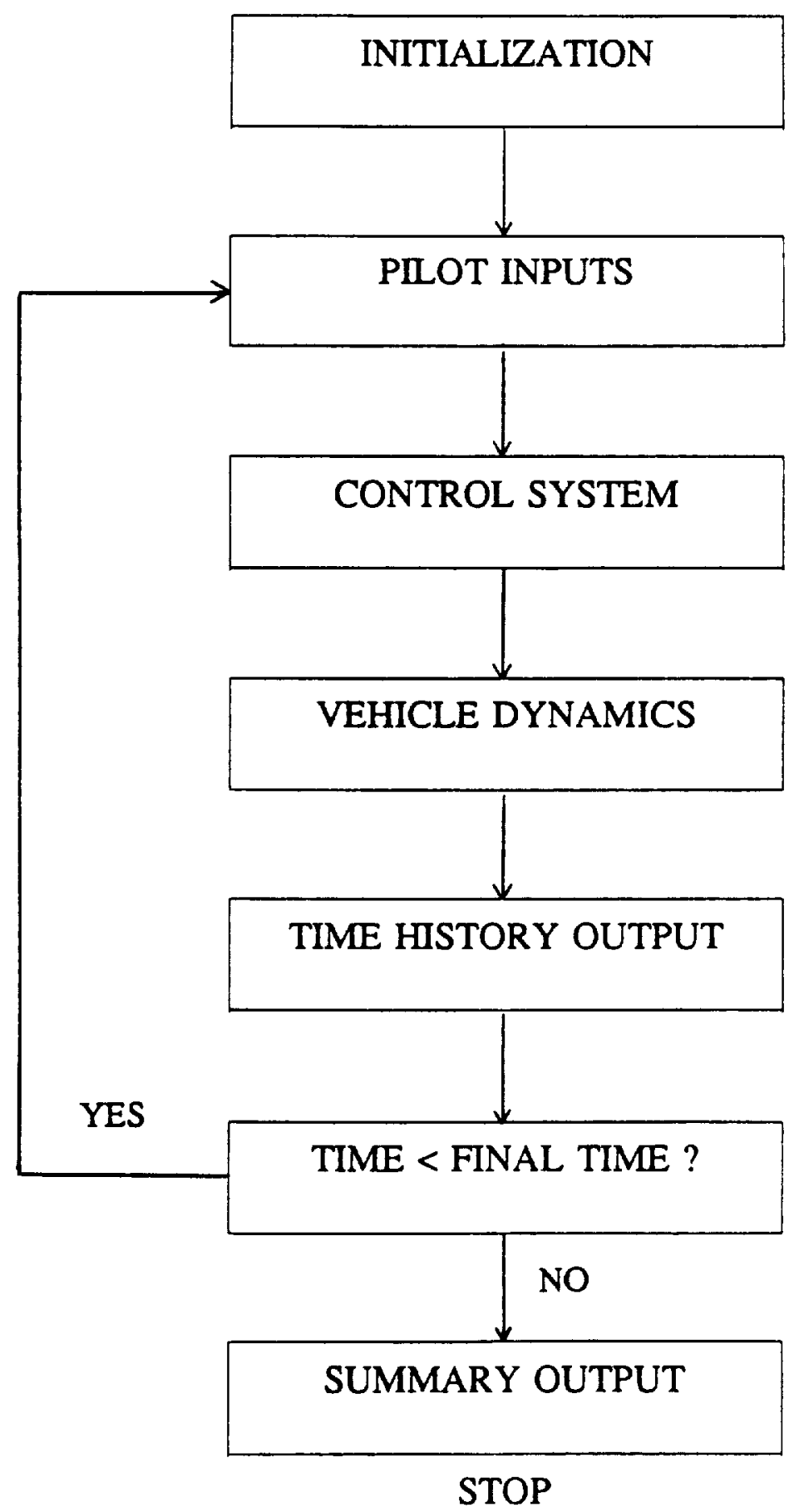

Figure C.1: Generalized Simulation Flow Diagram 
The source code for SIM 2 is contained in nine files, ACTUAT.FTN, ARODAT.FTN, CLEAN.FTN, HIGH.FTN, CONSYS.FTN, CSINIT.FTN, ENGINE.FTN, EXEC.FTN and OUTPUT.FTN which must be individually compiled and linked into a single executable file before running (a sample command sequence is given in Section C.4). Subroutines and functions, the files they reside in and a brief description of each are listed below.

Subroutine File Description

ACTDEF CSINIT Initialization routine done once for each actuator. Calculates first 8 values of actuator arrays.

ACTDYN

ACTUAT Initializes coefficients for actuator filters. Calls subroutines to get hinge moments and surface positions.

ACTMOD ACTUAT Second order actuator model with position and rate limits and hysteresis. 
ACTSET

ADATIN

AGILE

ALTFN

AOASEL

APCOMP

ATOPLT
CSINIT Calls ACTDEF for each actuator.

CSINIT Reads in aero data from F18FDAT.

EXEC Computes several terms needed for agility testing.

EXEC Computes quantities that are functions of altitude.

CONSYS Computes ALPHAT and ALPHAS based on angle of attack from the equations of motion.

CONSYS Autopilot gain calculations.

CONSYS Autopilot system. 
CCALC

ARODAT Executive for determining the total aerodynamic coefficients in the body axis frame of reference.

CD_FULL_SCALE Entry in CLEAN_INDEX.

CDAT

CSINIT Reads input data from INPUT

CDATI3

ENGINE Computes airplane weight and inertias.

CHUTE

EXEC

Calculates drag of the spin chute.

CLEAN_INDEX

CLEAN

Computes indices and interpolation ratios for the clean configuration aerodynamics table lookup procedure.

CLEAN_TLU CLEAN Calls functions to evaluate the clean configuration aerodynamic coefficients. 
CLOSEU CSINIT Closes files and devices.

CONINT CSINIT Initializes control system values.

CONSYS CONSYS Executive for control system and actuator models.

DERIVC

EXEC

Computes airplane accelerations using the equations of motion.

EINDEX

ENGINE Calculates indices and interpolation ratios for engine thrust and fuel flow table lookup.

ENGDIN

ENGINE Reads engine data from G4ECRD and initializes values for the engine model.

ENGIN18

ENGINE Computes engine thrust and fuel flow. 
ENGMDL

ENGTLU2

FCSENS

FLAPCMD

GLIMIT

HEADER 1

HEADER2

HIFLEX
ENGINE Executive for the engine model.

ENGINE Calls functions to evaluate thrust and fuel flow from tabular data.

CONSYS Models $\alpha$ probe and on-board accelerometers.

CONSYS Automatic flap command system.

CONSYS FCS G-limiter.

OUTPUT Writes output file headers.

OUTPUT Writes output file headers.

HIGH Computes indices and interpolation ratios for the high $\alpha$ flexibility effects table lookup procedt re. Evaluates the flexibility coefficients. 
HIGH_INDEX HIGH Computes indices and interpolation ratios for the high alpha aerodynamics table lookup procedure $(\alpha>39.99$ deg).

HIGH_TLU

HIGH

Calls the functions to evaluate the high $\alpha$ aerodynamic coefficients.

HINGE

ACTUAT Sets no load actuator rate limits, maximum hinge moment capability and computes rate limits based on hinge moments.

HINGEIN

CSINIT Reads hinge moment data from HNGDAT.

ACTUAT Computes indices and interpolation ratios for the hinge moment table lookup procedure. 
ACTUAT Calls functions to evaluate hinge moments from the tabular data.

ICSET

EXEC

Sets the airplane states to initial values.

INTG

EXEC

Modified second order Runge-Kutta numerical integration.

MODINT

EXEC

Entry in MODSET for initialization.

MODSET

EXEC

Sets and clears simulation and FCS mode flags.

MULTRT

EXEC

Called at every time step $(80 \mathrm{~Hz})$ and controls the calling of the $40 \mathrm{~Hz}$ and $20 \mathrm{~Hz}$ loops.

CSINIT Opens files and devices. 
OUTPUT

PITCAS

PKCOMP

RKCOMP

ROLCAS

SETMOD

SIM2

SPINLOG
OUTPUT User customized routine for displaying and recording of results.

CONSYS FCS pitch axis control augmentation system (CAS).

CONSYS Pitch axis gain calculations.

CONSYS Roll axis gain calculations.

CONSYS FCS roll axis CAS.

CONSYS Determines if the system is in degraded or auto mode.

EXEC Main program. Simulation initialization and computation loop.

CONSYS FCS spin logic. 
EXEC Calculates commands for each time step from the data in the input file.

TFRS

CONSYS Performs the transient-free, constant rate switch function.

TFS

CONSYS Performs the transient-free-switch function.

WINDIN

CSINIT Sets wind to zero.

WINDS

EXEC

Calculates winds aloft (zero in this case).

YAWCAS

CONSYS FCS yaw axis CAS.

YKCOMP

CONSYS Yaw axis gain calculations. 
Function

CLN1AA

CLN2CA to CLN2CS

CLN3EA to CLN3EY

FLIMIT

HI_1AA

HI_2CA to HI_2CI

HI_3EA to HI_3EO

HI_4GA

HNG2CA to HNG2CG

HNG3EA to HNG3EI

HNG4GA to HNG4GH

RLIMIT
File

CLEAN Interpolation functions

for calculating clean

aerodynamic coefficients

CONSYS Limits inputs to

maximum and minimum values.

HIGH Interpoloation functions

for calculating high

alpha aerodynamic

coefficients

ACTUAT Interpolation hinge

moment calculations

CONSYS Limits maximum change

from the provious value

(rate limit. 
A detailed flow diagram, Figure C.2, portrays the overall structure of the program. The initialization sequence performed by the simulation at the start of each run is shown in Table C.1. Table C.2 lists the sequence of calls accomplished during each 80 Herz time frame. 


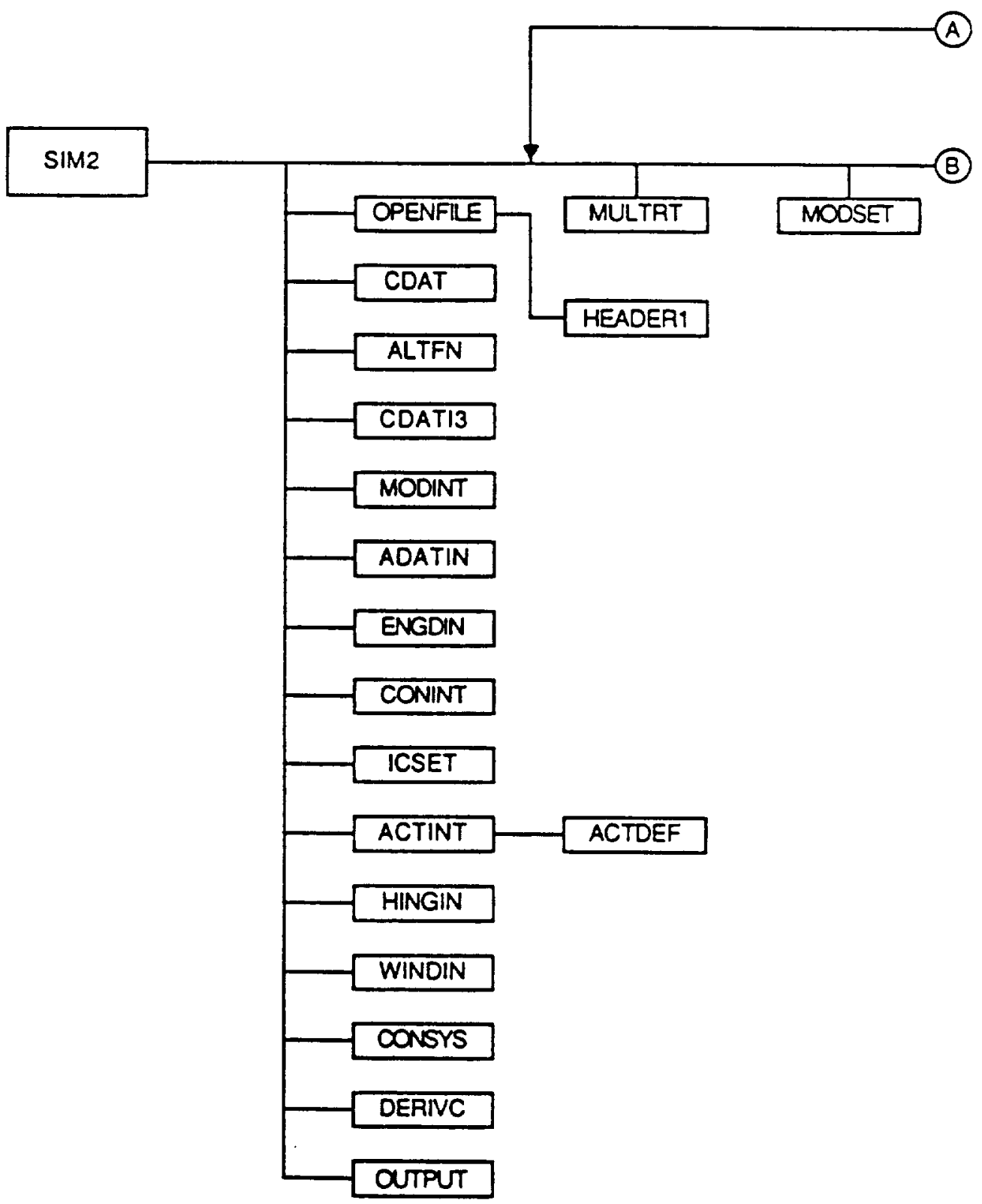

Figure C.2: Detailed Simulation Wiring Diagram 
(A)

(B)

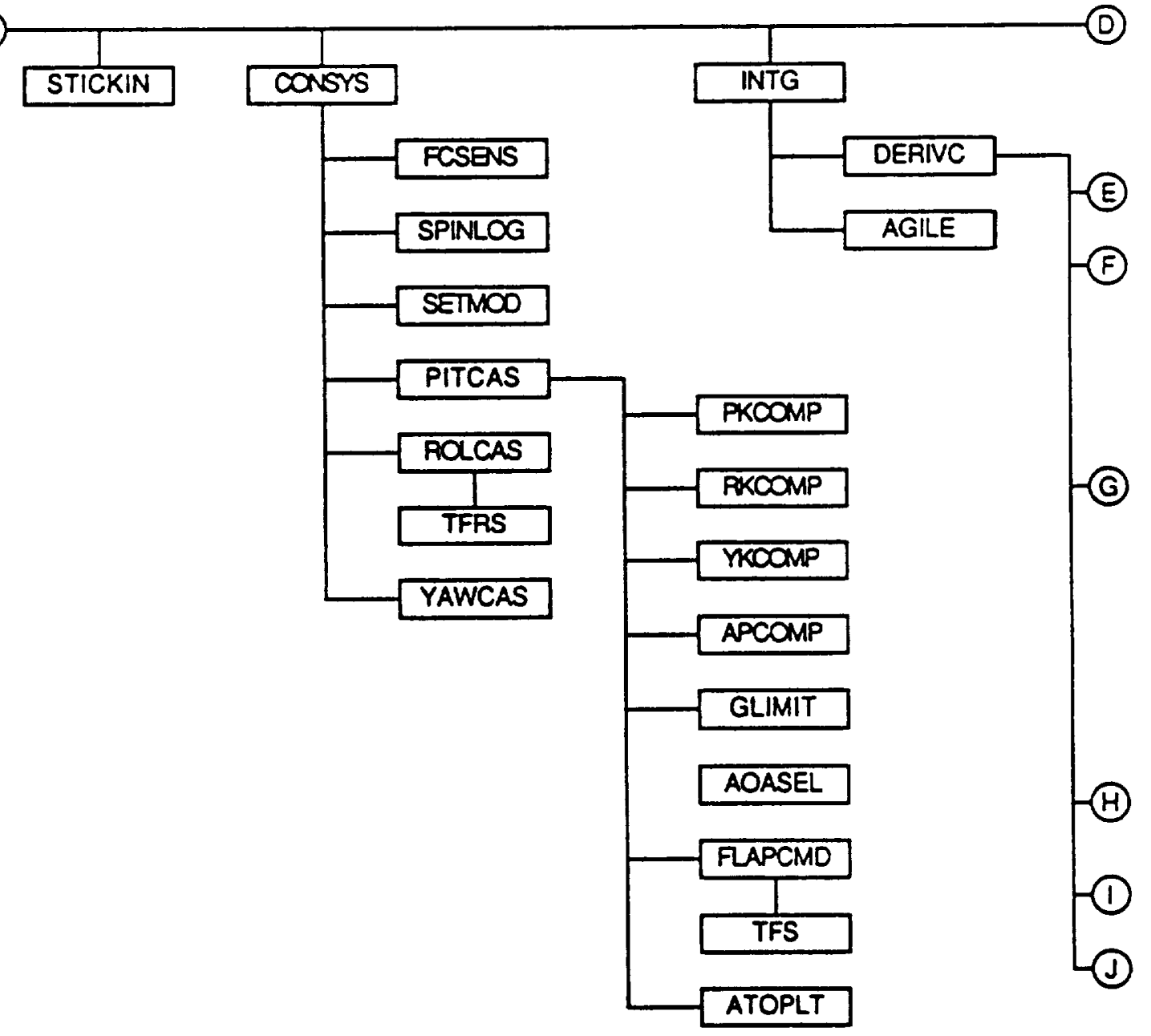

Figure C.2 (continued) 


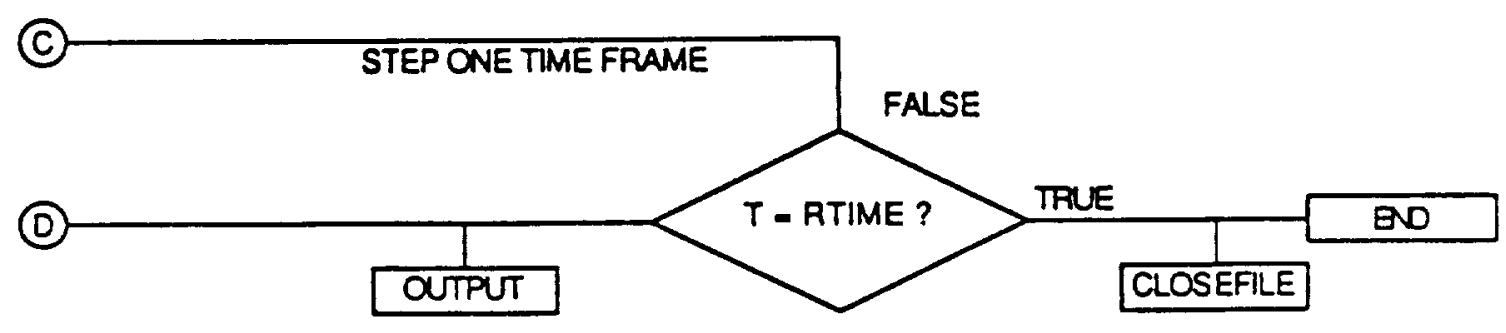

(E) ALTFN

(F) ENGMD ENGIN18

ENGTLU2

ENDEX

(G) ACTDYN

HNG_INDX

HNG_RU

FINGE

ACTMOOO

(H) CCALC

(1) CHUTE

(J) WINDS

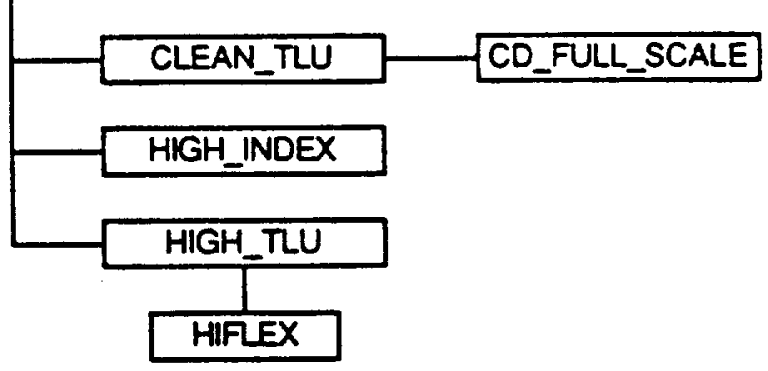

Figure C.2 (concluded) 


\begin{tabular}{||l|l|l||}
\hline \multicolumn{2}{|c|}{ Table C.1: Initialization Sequence } \\
\hline 1 & Read & User input data \\
\hline 2 & Initialize & Atmospheric properties \\
\hline 3 & Initialize & Simulation pun parameters \\
\hline 4 & Initialize & Vehicle system modes \\
\hline 5 & Read & Aerodynamic data \\
\hline 6 & Read & Engine data \\
\hline 7 & Initialize & Flight control constants and past values \\
\hline 8 & Initialize & Actuator constants and past values \\
\hline 9 & Read & Hinge moment data \\
\hline 10 & Initialize & Pilot commands \\
\hline 11 & Initialize & Flight control system \\
\hline 13 & Initialize & Equations of motion \\
\hline
\end{tabular}


Table C.2: Dynamic Loop Sequence for One Frame

Multi-rate computation

Vehicle system modes

Pilot inputs

Air data

Flight control gains

Flight control system

First integration

Atmospheric properties

Gust model

Actuator model

Aero coefficient buildup

Equations of motion

Second integration

Output 
A list of the more frequently used simulation variables is given in Table C.3.

\begin{tabular}{|c|c|c|c|}
\hline \multicolumn{4}{|c|}{ Table C.3: Common Simulation Variables } \\
\hline Array & Variable & Physical Quantity & Units \\
\hline $\mathrm{F}(1)$ & $\mathrm{T}$ & Time & Seconds \\
\hline $\mathrm{F}(2)$ & $\mathbf{P}$ & Body Axis Roll Rate & $\mathrm{Rad} / \mathrm{sec}$ \\
\hline$F(3)$ & $Q$ & Body Axis Pitch Rate & $\mathrm{Rad} / \mathrm{sec}$ \\
\hline $\mathrm{F}(4)$ & $\mathbf{R}$ & Body Axis Yaw Rate & $\mathrm{Rad} / \mathrm{sec}$ \\
\hline$F(5)$ & V & Total Velocity & $\mathrm{Ft} / \mathrm{sec}$ \\
\hline$F(6)$ & ALP & Angle of Attack & $\operatorname{Rad}$ \\
\hline$F(7)$ & BTA & Sideslip Angle & $\operatorname{Rad}$ \\
\hline$F(8)$ & THA & Euler Pitch Angle & $\operatorname{Rad}$ \\
\hline$F(9)$ & PSI & Euler Heading Angle & $\operatorname{Rad}$ \\
\hline$F(10)$ & PHI & Euler Roll Angle & $\operatorname{Rad}$ \\
\hline$F(11)$ & $\mathrm{H}$ & Altitude & Feet \\
\hline$F(12)$ & $\mathrm{X}$ & Downrange Position & Feet \\
\hline
\end{tabular}




\begin{tabular}{|c|c|c|c|}
\hline \multicolumn{4}{|c|}{ Table C.3: Common Simulation Variables } \\
\hline Array & Variable & Physical Quantity & Units \\
\hline$F(13)$ & Y & Crossrange Position & Feet \\
\hline $\mathrm{DF}(2)$ & PDOT & Roll Acceleration & $\mathrm{Rad} / \mathrm{sec}^{2}$ \\
\hline $\mathrm{DF}(3)$ & QDOT & Pitch Acceleration & $\operatorname{Rad} / \mathrm{sec}^{2}$ \\
\hline $\mathrm{DF}(4)$ & RDOT & Yaw Acceleration & $\operatorname{Rad} / \sec ^{2}$ \\
\hline $\mathrm{DF}(5)$ & VDOT & Total Acceleration & $\mathrm{Ft} / \mathrm{sec}^{2}$ \\
\hline $\mathrm{DF}(6)$ & ALPDOT & Angle of Attack Rate & $\mathrm{Rad} / \mathrm{sec}$ \\
\hline $\mathrm{DF}(7)$ & BTADOT & Sideslip Angle Rate & $\mathrm{Rad} / \mathrm{sec}$ \\
\hline $\mathrm{DF}(8)$ & THADOT & Euler Pitch Rate & $\mathrm{Rad} / \mathrm{sec}$ \\
\hline $\mathrm{DF}(9)$ & PSIDOT & Euler Heading Rate & $\mathrm{Rad} / \mathrm{sec}$ \\
\hline $\mathrm{DF}(10)$ & PHIDOT & Euler Roll Rate & $\mathrm{Rad} / \mathrm{sec}$ \\
\hline $\mathrm{DF}(11)$ & HDOT & Altitude Rate & $\mathrm{Ft} / \mathrm{sec}$ \\
\hline $\mathrm{DF}(12)$ & XDOT & Downrange Velocity & $\mathrm{Ft} / \mathrm{sec}$ \\
\hline
\end{tabular}




\begin{tabular}{|c|c|c|c|}
\hline \multicolumn{4}{|c|}{ Table C.3: Common Simulation Variables } \\
\hline Array & Variable & Physical Quantity & Units \\
\hline \multirow[t]{2}{*}{$\mathrm{DF}(13)$} & YDOT & Crossrange Velocity & $\mathrm{Ft} / \mathrm{sec}$ \\
\hline & ANG & Load Factor & G's \\
\hline \multirow[t]{10}{*}{$\mathrm{UX}(33)$} & & Wind Axis Roll Rate & $\mathrm{Rad} / \mathrm{sec}$ \\
\hline & PSUBS1 & Specific Excess Power & $\mathrm{Ft} / \mathrm{sec}$ \\
\hline & PLAL & Throttle Position (Left) & $\%$ of $\max$ \\
\hline & PLAR & Throttle Position (Right) & $\%$ of $\max$ \\
\hline & AMCH & Mach Number & \\
\hline & DAP & Lateral Stick Position & Inches \\
\hline & DEP & Long. Stick Position & Inches \\
\hline & DRP & Rudder Pedal Input & Pounds \\
\hline & CLFT & Lift Coefficient & \\
\hline & $\mathrm{CD}$ & Drag Coefficient & \\
\hline
\end{tabular}




\begin{tabular}{|c|c|c|c|}
\hline \multicolumn{4}{|c|}{ Table C.3: Common Simulation Variables } \\
\hline Array & Variable & Physical Quantity & Units \\
\hline & THRST & Total Engine Thrust & Pounds \\
\hline & TRATED & Turn Rate & $\mathrm{Deg} / \mathrm{sec}$ \\
\hline & TRATER & Turn Rate & $\mathrm{Rad} / \mathrm{sec}$ \\
\hline & TEMP & Ambient Temperature & ${ }^{\circ} \mathbf{R}$ \\
\hline & PA & Ambient Pressure & PSF \\
\hline & RHO & Ambient Density & Slug $/ \mathrm{ft}^{3}$ \\
\hline & QBAR & Dynamic Pressure & PSF \\
\hline & KIAS & Indicated Airspeed & Knots \\
\hline & VTAS & True Airspeed & $\mathrm{Ft} / \mathrm{sec}$ \\
\hline & QC & $\begin{array}{l}\text { Compressible Dynamic } \\
\text { Pressure }\end{array}$ & PSF \\
\hline & WEIGHT & Aircraft Weight & Pounds \\
\hline & VEAS & Equivalent Airspeed & $\mathrm{Ft} / \mathrm{sec}$ \\
\hline
\end{tabular}




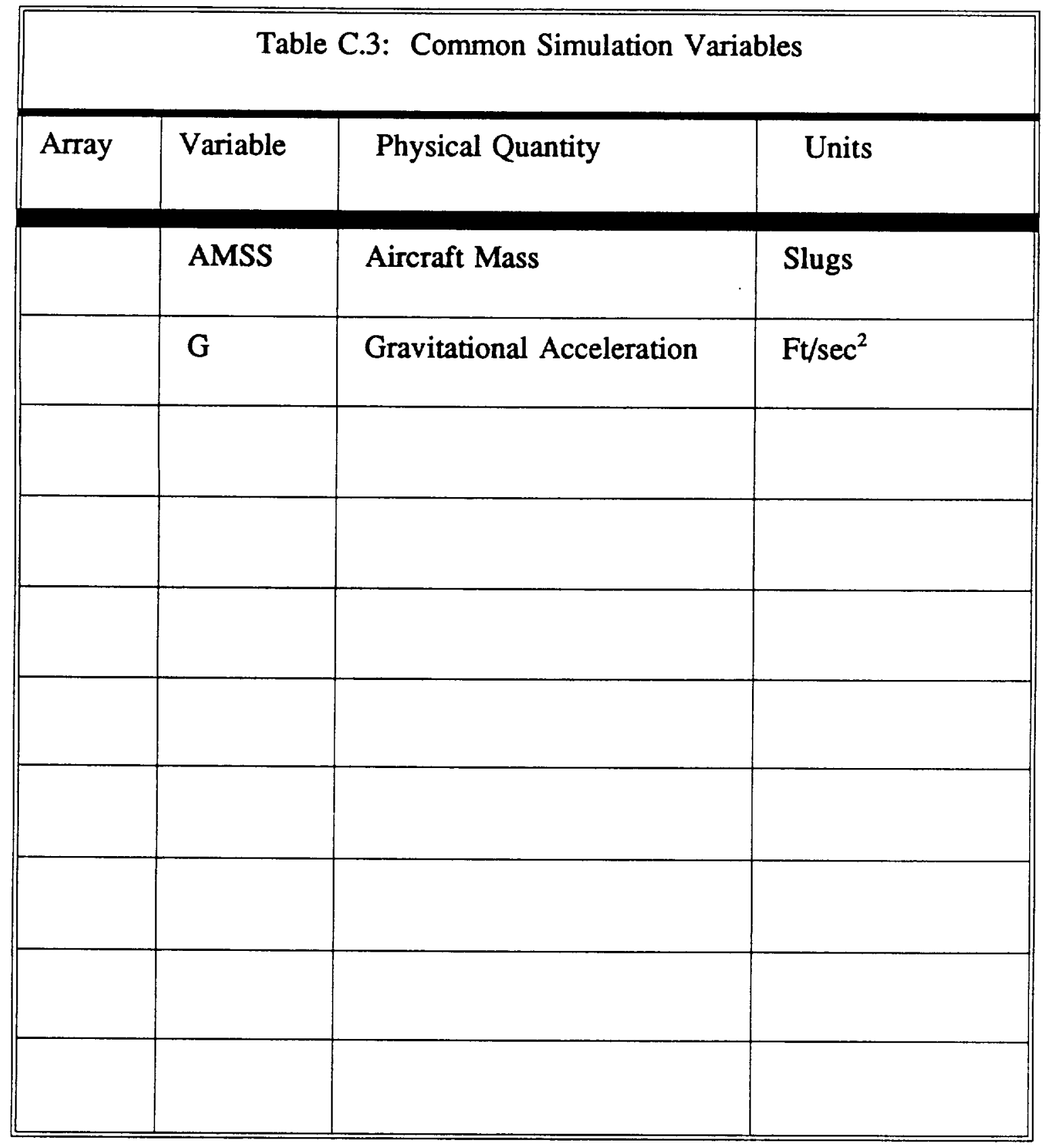




\section{C.4 User Instructions}

Because there is no automatic trim logic on the University's version of SIM 2, input files have been generated to trim the aircraft at a large number of subsonic flight conditions. A test case is begun by allowing the aircraft to settle at the trim condition for five seconds with no control inputs. Stick, rudder pedal and throttle commands can then be applied in any combination. A sample input file is shown in Figure C.3. Though the number of input values cannot be changed without modifying the source code, the spacing of the values is not critical since the data is read as unformatted. After each of the nine files containing the Fortran source code have been compiled, the binary code is linked into a single, executable file with the command SIM2.LINK. Program execution is begun with the command SIM2.EX. The program then prompts the user for the name of the input file to be used. Output is displayed on the screen and saved in two other files, SIM2.PLOT.DAT and SIM2.OUT1.DAT. The .PLOT.DAT file contains columns of data with no text so the file is suitable for use by a plotting program. The .OUT1.DAT file presents the output in a more readable format along with a summary of the initial conditions and pilot commands. 


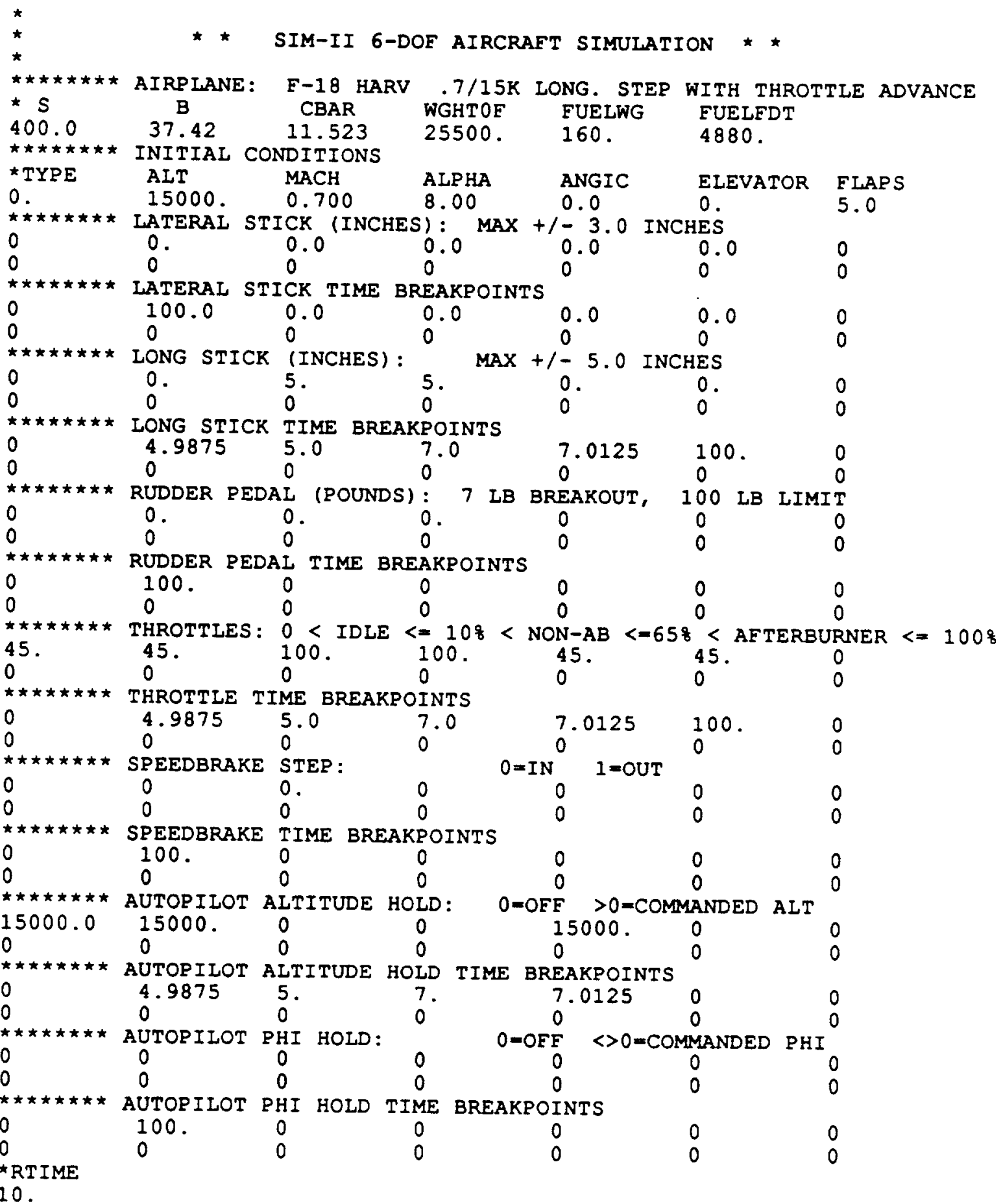

Figure C.3: Sample Input File fo-SIM 2 


\section{C.5 Check Case Comparisons}

Throughout the process of rehosting the F-18 from the interactive NASA version to the University of Kansas hardware, no changes were made to the program logic, dynamic models or data tables. However, numerous other changes were required due to the considerable hardware differences between the two computer systems. In order to build confidence in the University's version of the F-18 simulation, a series of test cases were run to match against cases provided by NASA Dryden. These cases are not results from NASA's SIM 2 but are output from McDonnell-Douglas's F-18 simulation and were used originally by NASA to check their SIM 2 . Because of this, an exact match with the McDonnell cases is not expected.

Longitudinal and lateral check cases were flown at four subsonic flight conditions and compared to the McDonnell-Douglas runs. Results are presented on the following pages. The solid time history traces are the Kansas University SIM 2 output while the dashed lines indicate the McDonnell-Douglas data. Where no dashed lines appear the simulation and check case results are essentially identical. While some differences are apparent, they are small and do not grow significantly during the test maneuvers. 

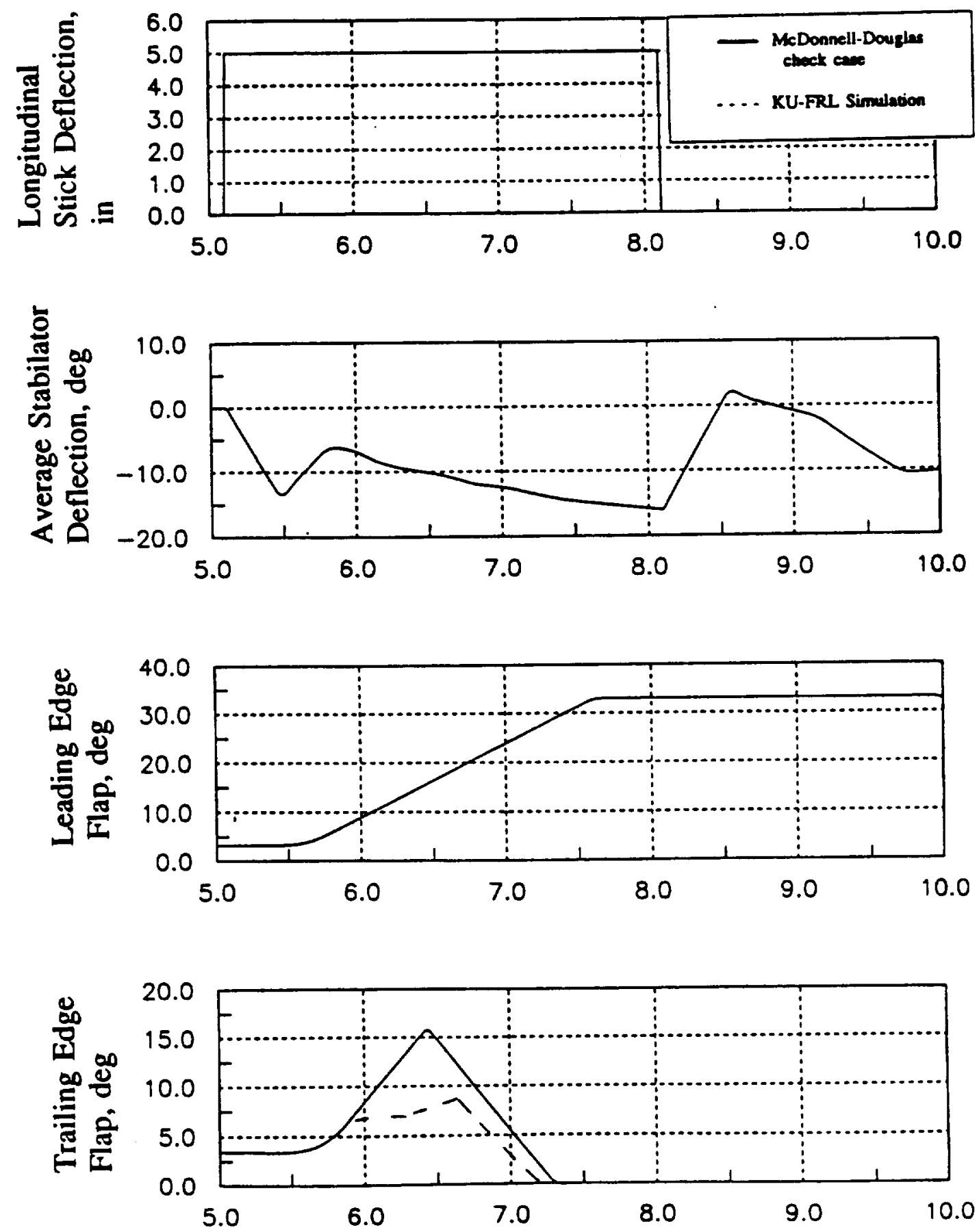

Figure C.4: Longitudinal Check Case, Mach .6, 10,000 ft. 

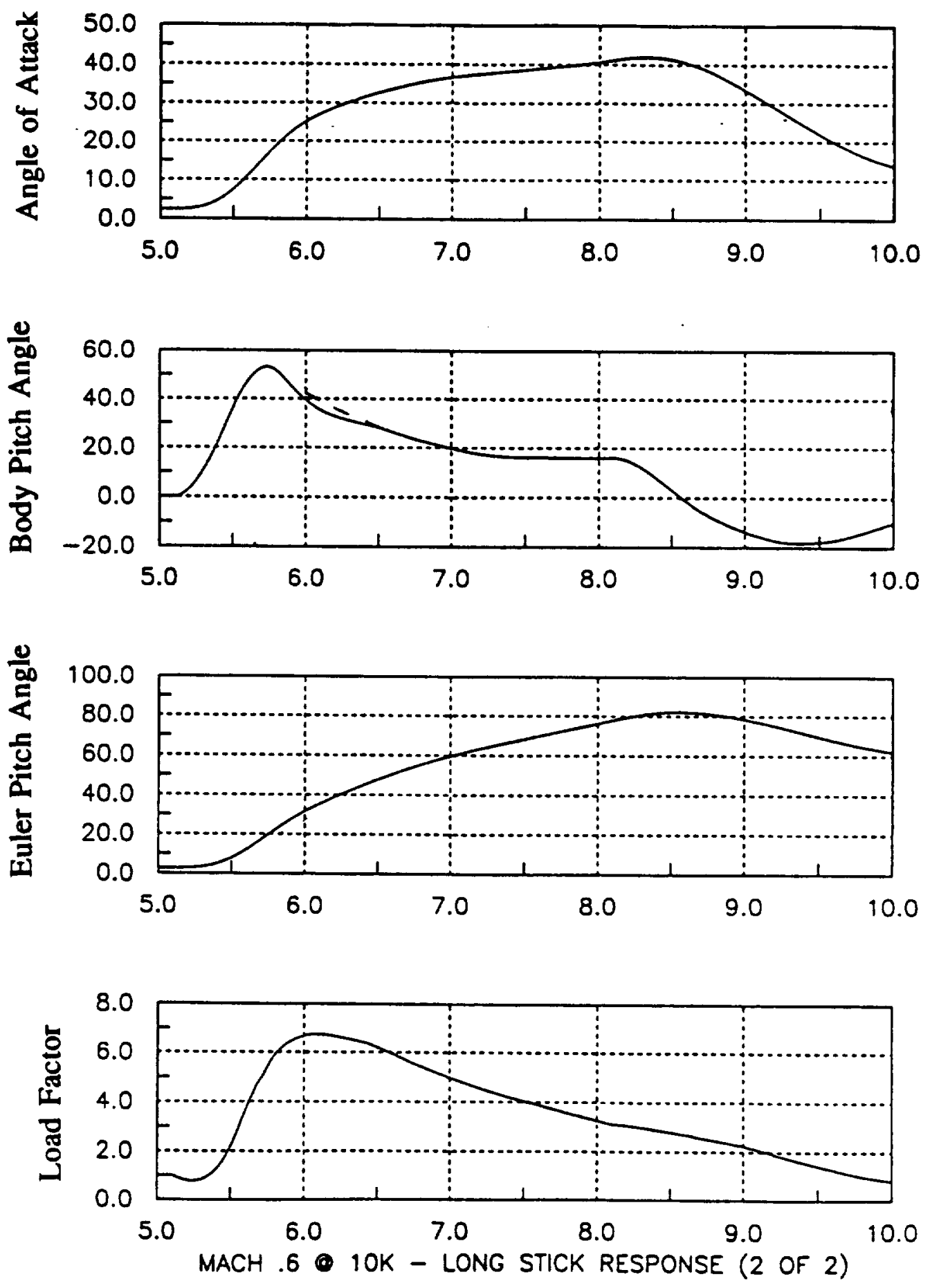

Figure C.4 (continued) 

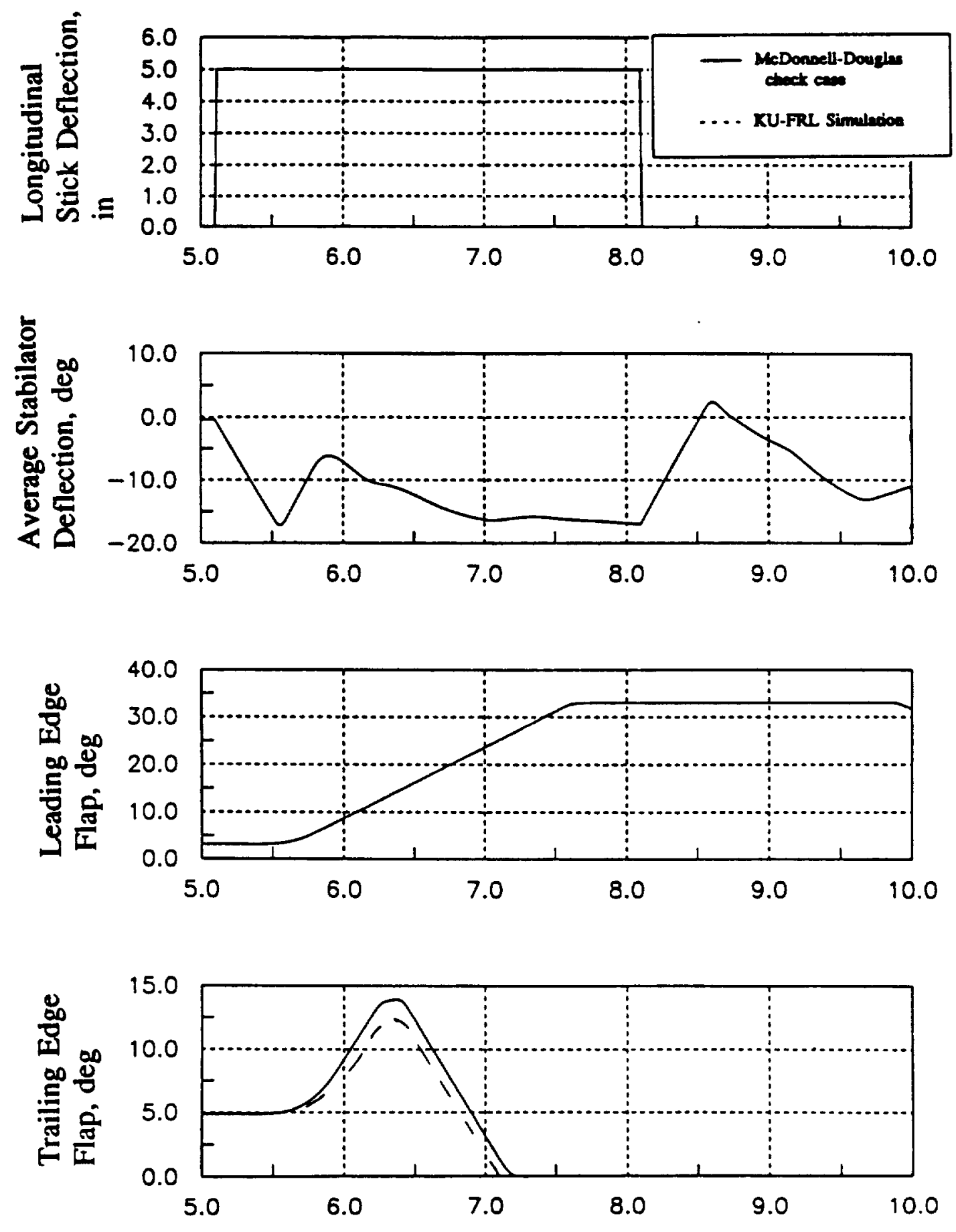

Figure C.5: Longitudinal Check Case, Mach $.8,35,000 \mathrm{ft}$ 

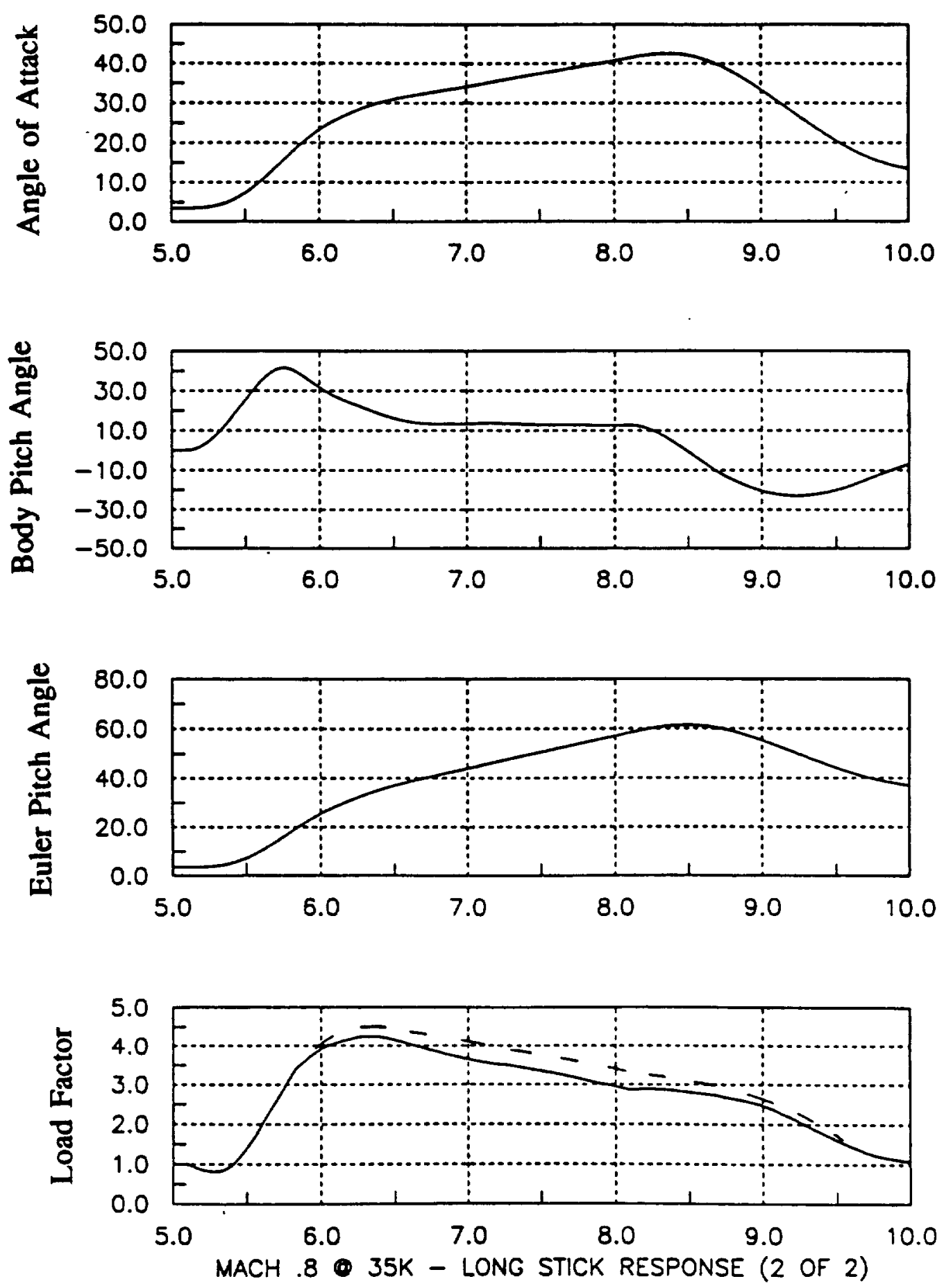

Figure C.5 (continued) 

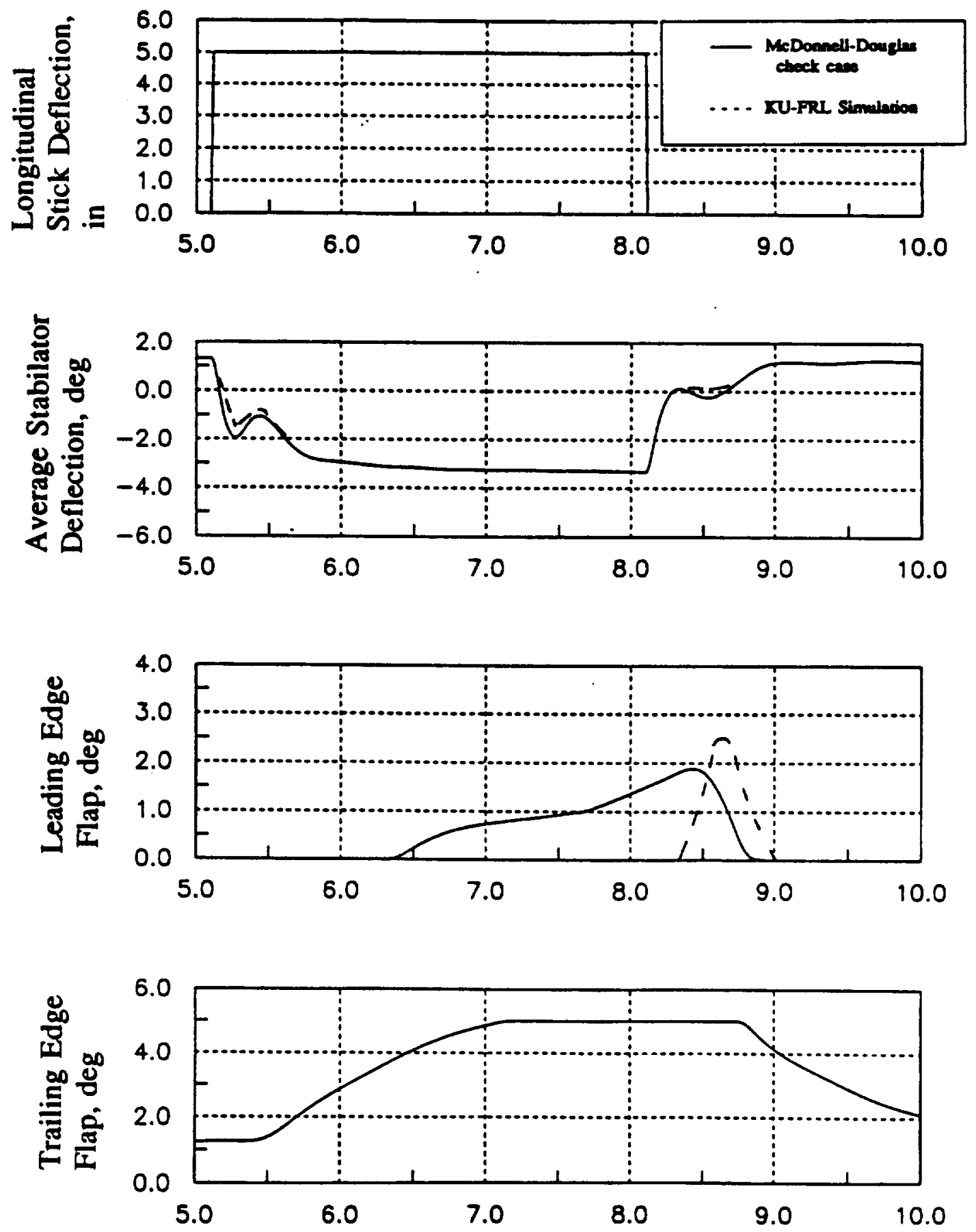

Figure C.6: Longitudinal Check Case, Mach .9, Sea Level 

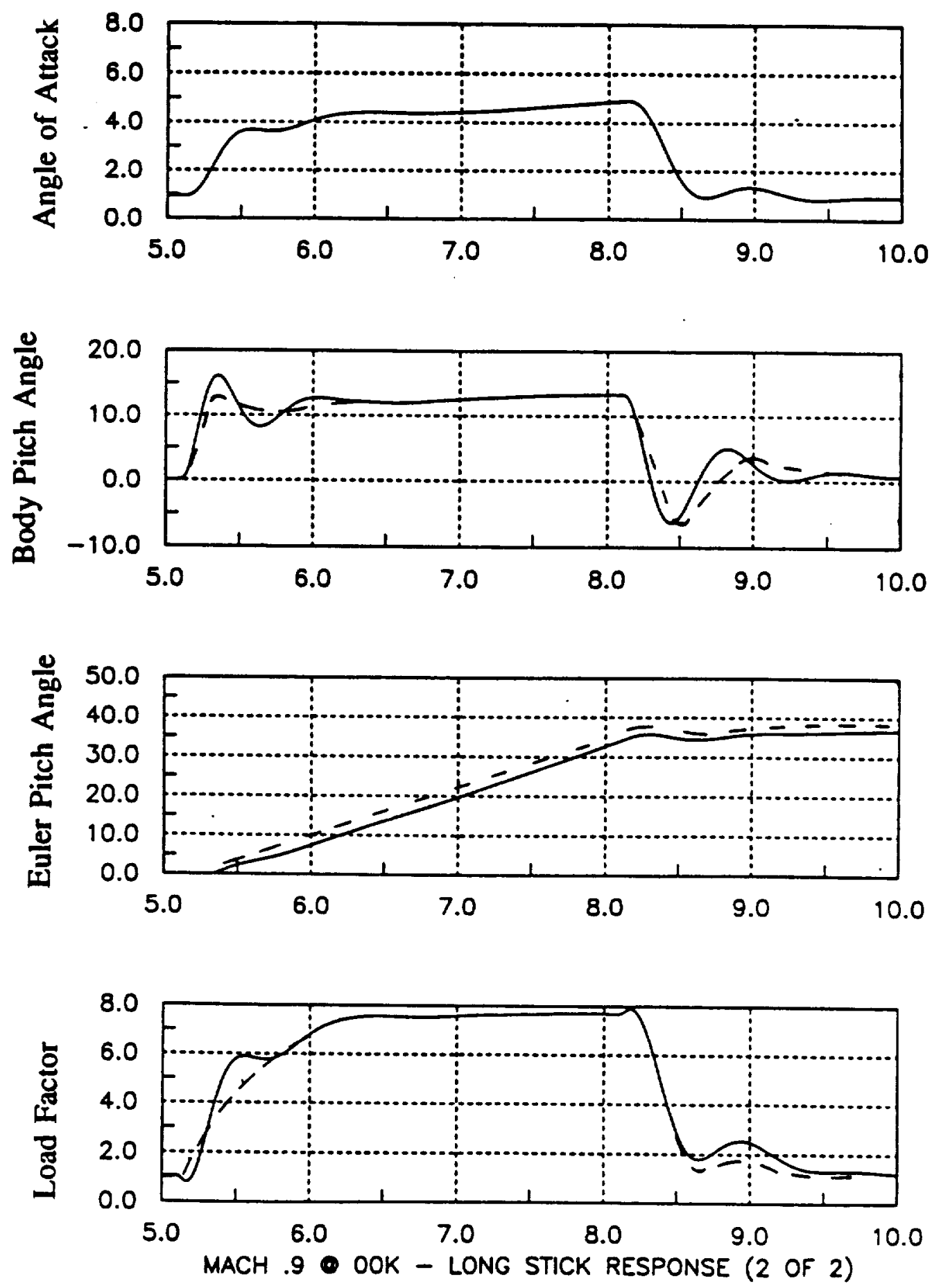

Figure C.6 (continued) 

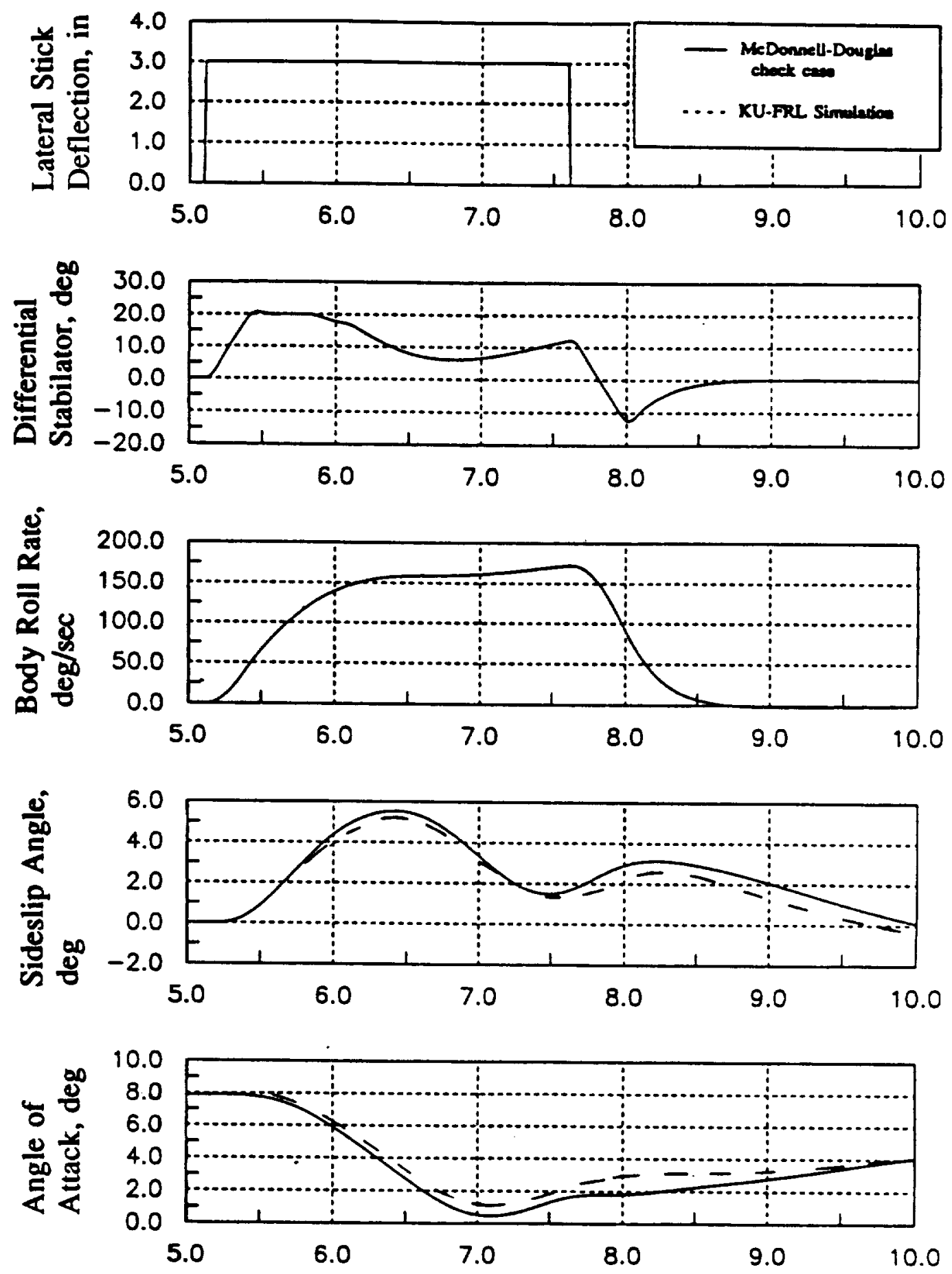

Figure C.7: Lateral Check Case, Mach .4, 20,000 ft. 

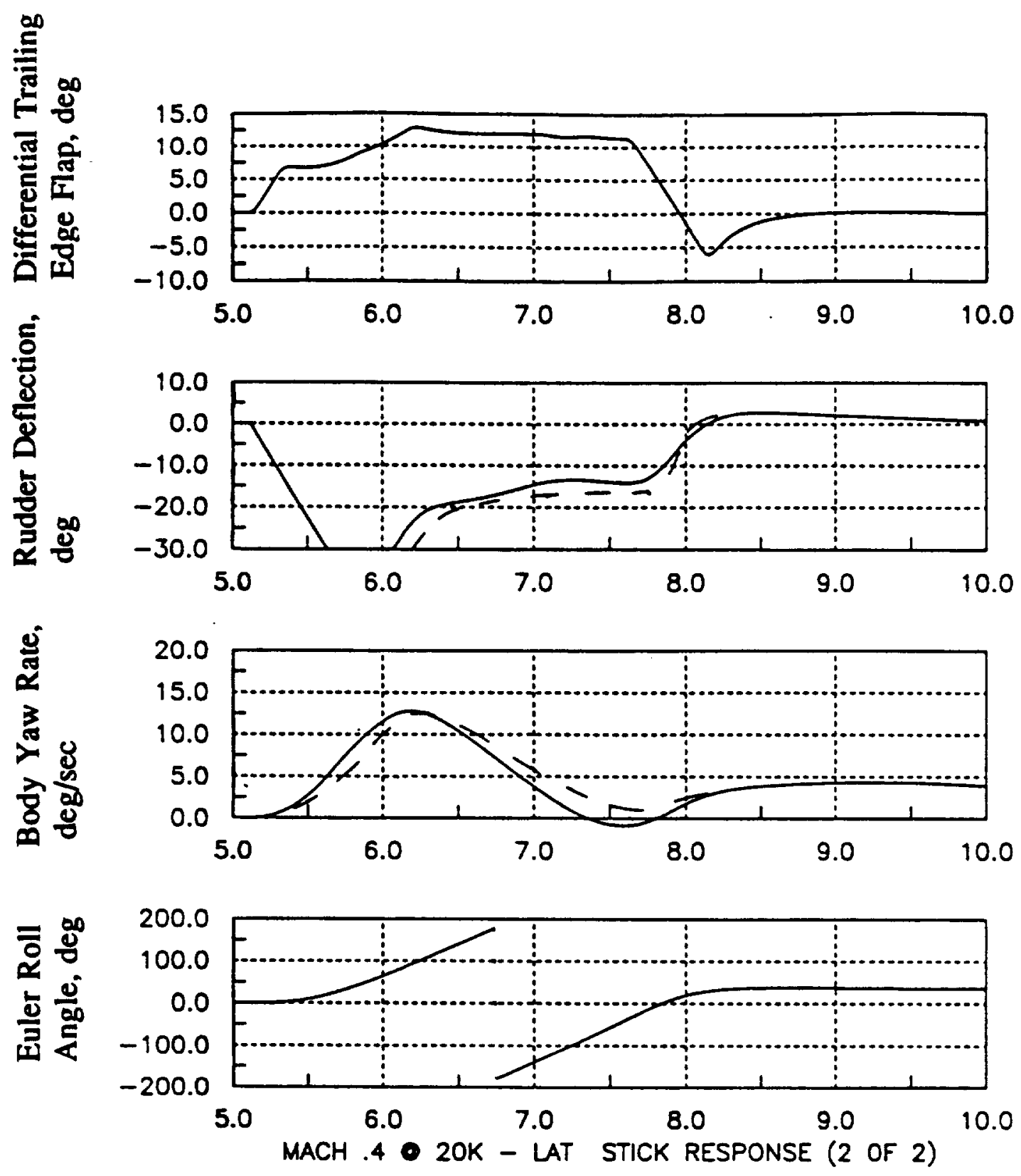

Figure C.7 (continued) 

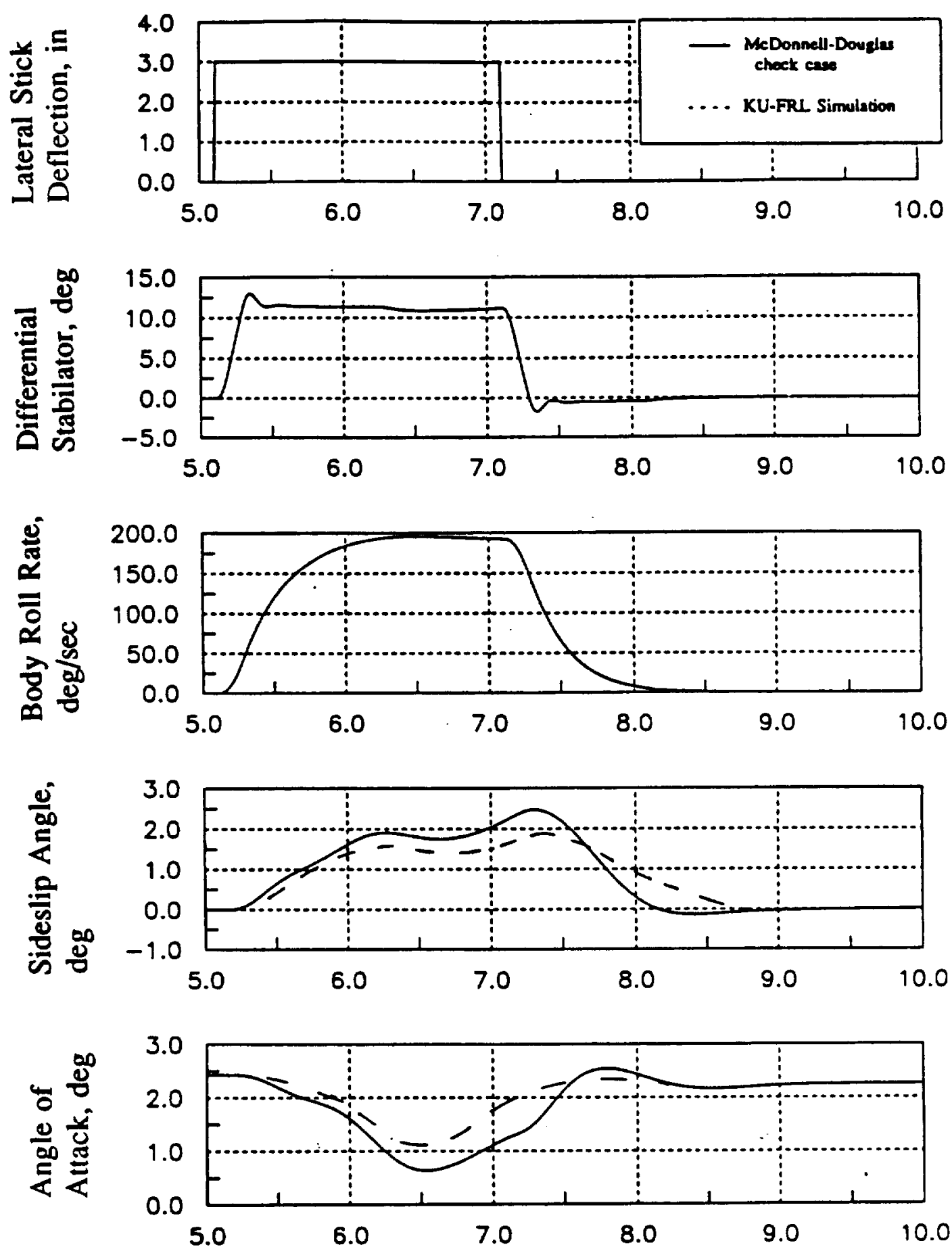

Figure C.8: Lateral Check Case, Mach .6, 10,000 ft. 

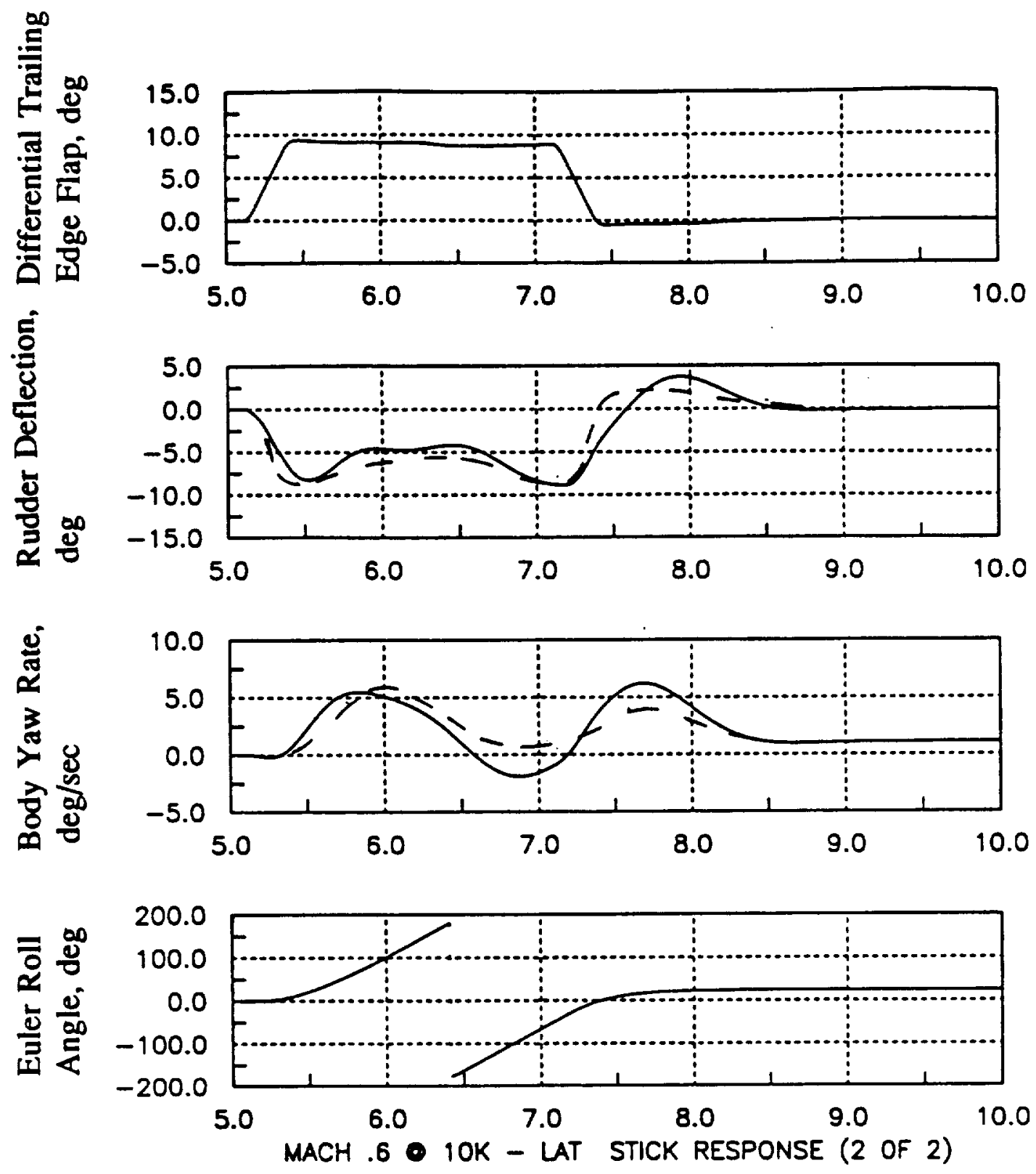

Figure C.8 (continued) 

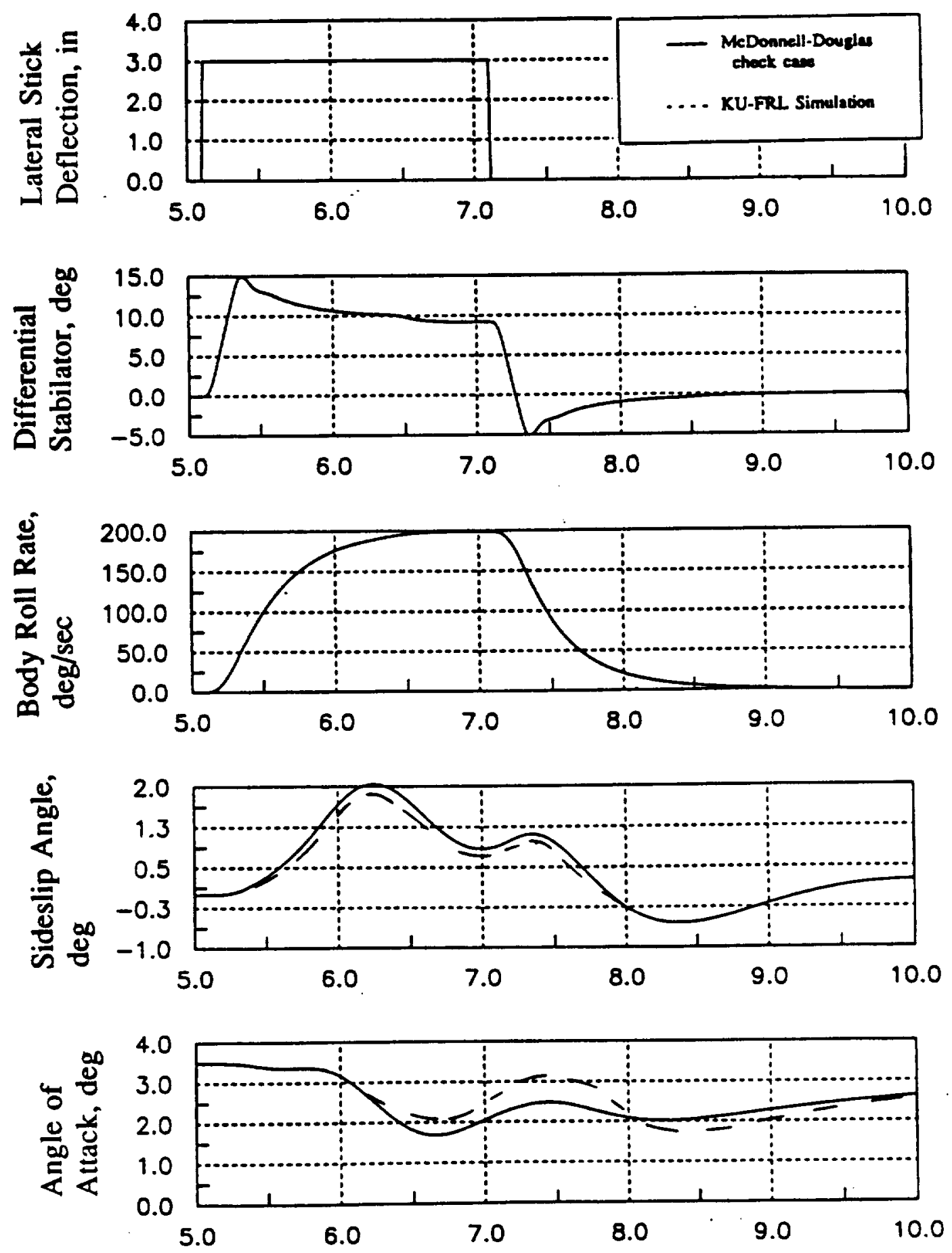

Figure C.9: Lateral Check Case, Mach .8, 35,000 ft. 

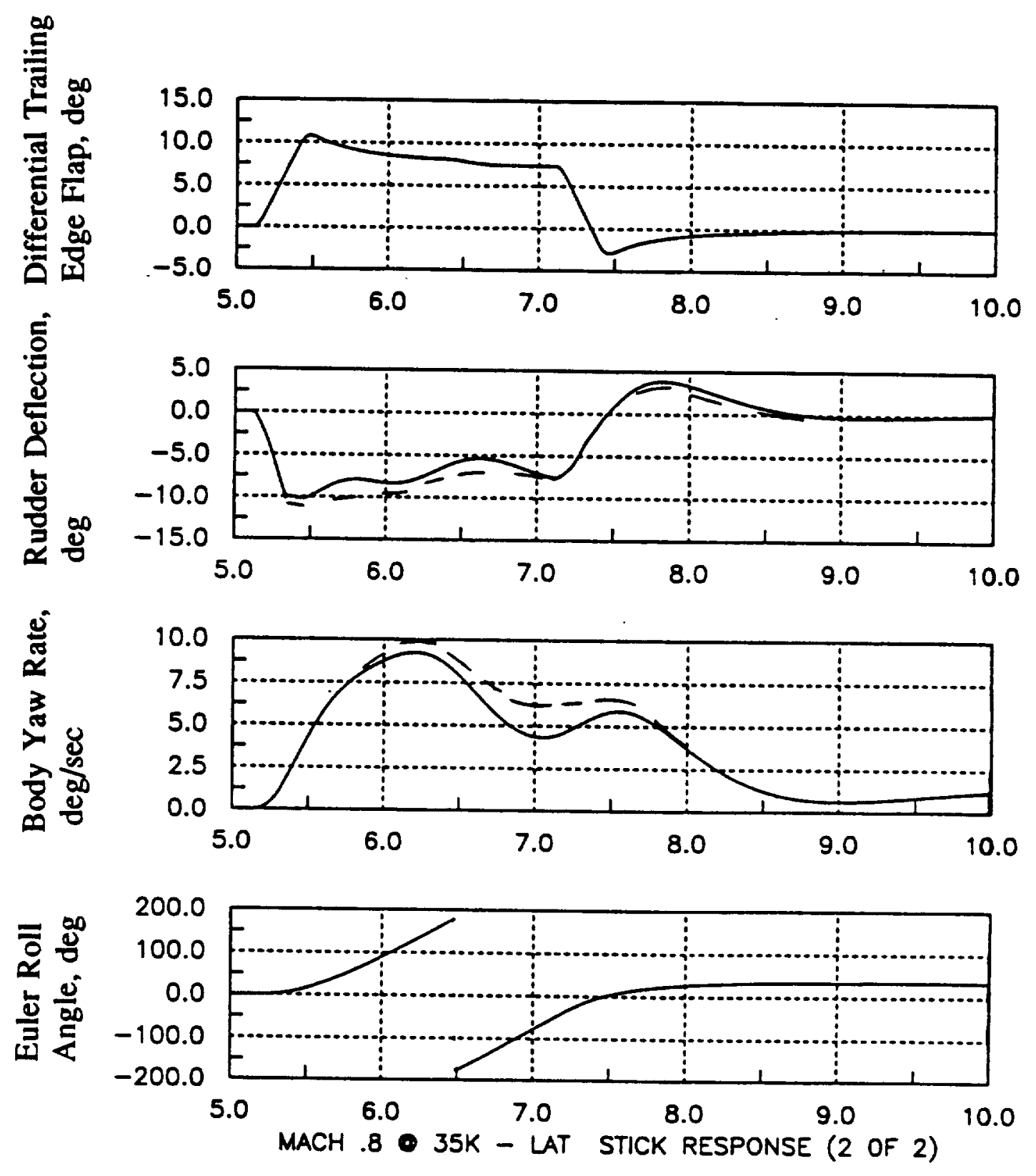

Figure C.9 (continued) 

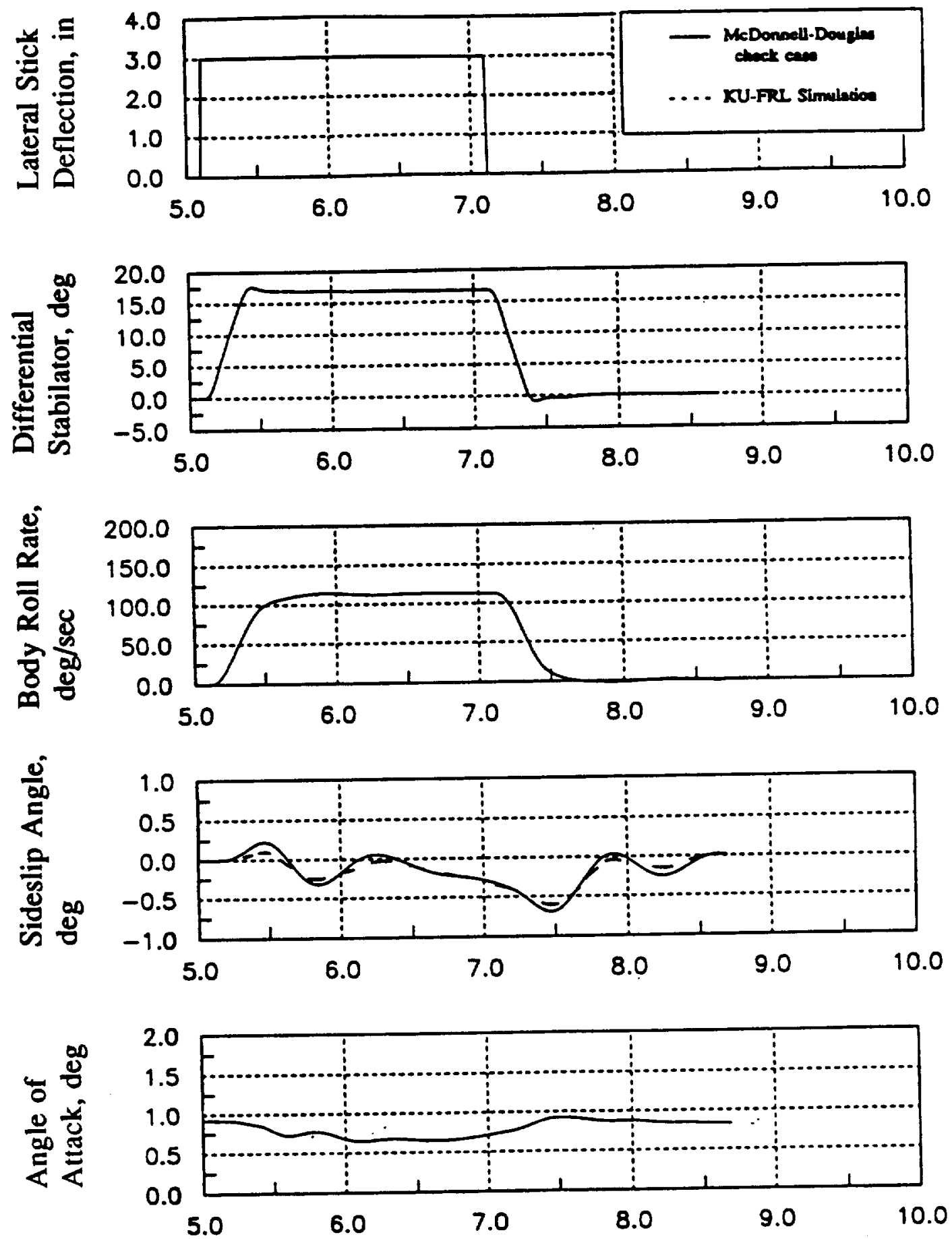

Figure C.10: Lateral Check Case, Mach .9, Sea Level 

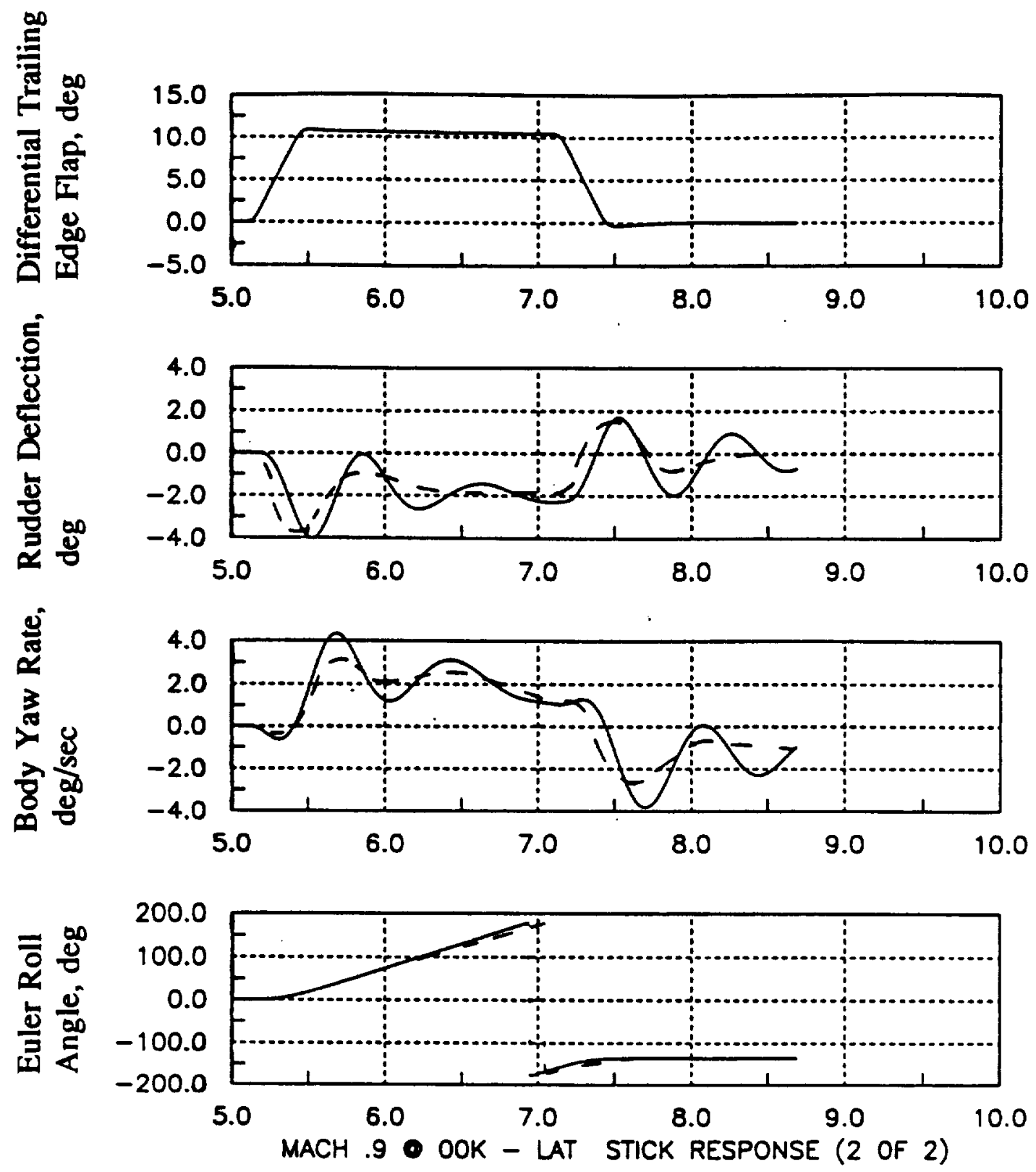

Figure C.10 (continued) 
